\title{
Análise comparativa do grau de rotação de parafusos para sistema UCLA em estruturas fundidas em monobloco provenientes de abutments calcináveis e com cinta de Cobalto-Cromo.
}

\section{LUÍS EDUARDO BUTIGNON}

Dissertação apresentada à Faculdade de Odontologia de Bauru, da Universidade de São Paulo, como parte dos requisitos para a obtenção do título de Mestre em Odontologia, na área de Reabilitação Oral.

Orientador: Prof. Dr. Wellington Cardoso Bonachela 


\section{Butignon, Luís Eduardo}

975a Análise comparativa do grau de rotação de parafusos para sistema UCLA em estruturas fundidas em monobloco provenientes de abutments calcináveis e com cinta de Cobalto-Cromo. Luís Eduardo Butignon - Bauru, 2007. 124p.: il.; $30 \mathrm{~cm}$

Dissertação (Mestrado) -- Faculdade de Odontologia de Bauru. USP

Orientador: Prof. Dr. Wellington Cardoso Bonachela

Autorizo, exclusivamente para fins acadêmicos e científicos, a reprodução total ou parcial desta dissertação/tese, por processos fotocopiadores e outros meios eletrônicos.

Assinatura do autor:

Data: 


\title{
DADOS CURRICULARES
}

\author{
LUÍS EDUARDO BUTIGNONｌuibut@hotmail.com \\ Nascimento \\ 26 de Setembro de 1979 \\ São Carlos - SP
}

Filiação

José Butignon

Vanda Helena Orlandi Butignon

$1998-2002$

Curso de Graduação em Odontologia Universidade do Sagrado Coração - USC

- Bauru - SP

$2002-2003$

Curso de Aperfeiçoamento em Periodontia - Instituto de Ensino Odontológico - IEO / Bauru - SP

$2002-2004$

Estagiário do Departamento de Prótese da Faculdade de Odontologia de Bauru FOB / USP

$2005-2007$

Curso de Pós-Graduação em Reabilitação Oral em nível de Mestrado, na Faculdade de Odontologia de Bauru - FOB / USP.

Associações: APCD - Associação Paulista de Cirurgiões-Dentistas.

SBPqO - Sociedade Brasileira de Pesquisa Odontológica. 


\section{DEDICATÓRIA}

Aos meus pais, José e Vanda; pelo amor, carinho, educação e pelo apoio incondicional em todos os momentos da minha vida. Devo tudo a vocês.

Obrigado pai, obrigado mãe!

A minha irmã Liz; pelo seu amor e exemplo de dedicação, disciplina, ética, profissionalismo e competência.

Por isso e por muitas outras coisas você é mais que especial!

Ao meu irmão Luciano, meu grande amigo; pela nossa amizade e cumplicidade.

A minha tia Sergia; simplesmente por existir. Sem você tia querida, tenho certeza que nada seria igual.

Obrigado por tudo!

A minha avó Angelina; por sempre querer o meu bem!

A Keila; principalmente pela sua sábia paciência diante das minhas ausências e minhas preocupações.

Vencemos juntos este difícil período. Outros virão e vamos vencer também.

Obrigado! 


\section{AGRADECIMENTOS}

A Deus; por estar sempre ao meu lado, já que quando precisei, orei e senti sua presença.

Ao meu orientador, Wellington Cardoso Bonachela; pela sua orientação segura, pelos ensinamentos compartilhados, pelas oportunidades oferecidas, pelos conselhos e principalmente pela confiança no meu trabalho.

Muito Obrigado!

Ao meu cunhado Sergio; pela sua amizade, confiança, respeito e pelas muitas idéias compartilhadas. Considero você meu irmão!

Ao Professor Accácio Lins do Valle; pela oportunidade de estar aqui, pelos seus ensinamentos, pela sua amizade e companheirismo. A você professor, minha eterna gratidão!

A SIN (Sistema de Implantes Nacional); pela gentileza de ceder grande parte dos materiais utilizados neste estudo e apoio nas leituras de Microscopia Eletrônica de Varredura. Sem esta parceria, a realização deste trabalho se tornaria inviável.

Ao Engenheiro Fernando Margarido; pela sua disponibilidade, persistência e sabedoria para nos ajudar no desenvolvimento do dispositivo leitor de graus, utilizado neste estudo.

Ao Júnior, técnico de laboratório de prótese, responsável pela fundição dos corpos de prova deste estudo. 
Ao Professor Marco António Húngaro Duarte; pelo auxílio durante as análises estatísticas deste estudo.

Ao CCDM (Centro de Caracterização de Materiais), da Universidade Federal de São Carlos, pela realização das análises em microscopia eletrônica de varredura.

Aos meus grandes amigos; Romão, Thiago, Jefferson, João Paulo e Guilherme; pelos anos de convivência, de moradia e de amizade. Independente do tempo, considero todos meus irmãos.

Aos meus colegas de turma; Ana Paula, Adriana, Flora, Gabriela, Luciana, Paola, Valéria, Daniel, Fernando e Rafael: Embora de maneiras diferentes, vocês todos de alguma forma, foram muito importantes para meu aprendizado e crescimento. Obrigado!

Aos colegas contemporâneos do curso de Reabilitação Oral da Faculdade de Odontologia de Bauru: Ana Lúcia, Andréia, Eduardo Ayub, Érico, Estevam, Jefferson, Jonas, Kátia, Leila, Lívia, Lucas, Luiz Gustavo, Marcio, Marinele, Marly, Mikaela, Osvaldo, Patrícia, Paulo Fukashi, Paulo Rossetti, Rafael, Renato, Rodrigo, Tânia, Tatiany e Valdey.

Aos ex-estagiários do Departamento de Prótese e hoje mestrandos que ajudaram muito nas clínicas da pós-graduação: Aline, Daniel, Fabio, Gustavo e Marcelo.

Ao colega Marcos Blatt, ex-estagiário do Departamento de Prótese; pela sua parceria durante a realização de alguns trabalhos.

Aos colegas contemporâneos dos outros programas da pós-graduação que de alguma forma, também foram importantes, em especial a Janine, a Marcela Calábria e ao Caio. 
Ao Professor Luiz Fernando Pegoraro; pelo convívio, pelos seus ensinamentos e principalmente pelas "dicas, truques e macetes" relacionadas à prótese dentária.

Ao Professor Paulo Martins Ferreira; por compartilhar seus conhecimentos de forma irrestrita e pelas suas considerações sempre pertinentes.

Ao Professor Ricardo Marins de Carvalho; pela sua amizade, seus ensinamentos e pelo exemplo de docência a ser seguido.

Aos demais professores do Departamento de Prótese da Faculdade de Odontologia de Bauru; que de alguma forma fizeram a diferença e foram importantes para minha formação acadêmica, pessoal e profissional: Carlos Araújo, Gerson Bonfante, José Henrique Rubo, Lucimar Falavinha, Milton Salvador, Paulo Conti, Pedro de Oliveira e Vinícius Carvalho Porto.

Aos Funcionários do Departamento de Prótese; pela assistência prestada durante nosso período de convivência, em especial a Claudia, Déborah, Valquíria, Marcelo

e Reivanildo.

A Cleusa e Hebe; funcionárias da clínica da pós-graduação e ao Eduardo; exfuncionário, por estarem sempre de prontidão para ajudar. Muito obrigado!

As secretárias do Prof. Wellington, Jussara e Simone, por terem sido sempre tão prestativas e atenciosas.

Aos pacientes que aqui eu tive, pela confiança e oportunidade do aprendizado!

A todas as pessoas que de forma direta ou indireta participaram e contribuíram tanto pra minha formação pessoal quanto profissional. Muito Obrigado! 


\section{SUMÁRIO}

LISTA DE FIGURAS viii

LISTA DE GRÁFICOS xiv

LISTA DE TABELAS xvi

LISTA DE ABREVIATURAS E SÍMBOLOS Xix

RESUMO XXi

1 INTRODUÇÃO

2 REVISÃO DA LITERATURA

2.1 - Complicações em Próteses Sobre Implantes 9

2.2 - A estabilidade da união parafusada: Uma análise biomecânica e 14 comportamental dos parafusos.

2.3 - O abutment UCLA 41

2.4 - Podem os parafusos permanecer sempre apertados? Como evitar o 44 afrouxamento dos parafusos. Interpretação dos autores.

3 PROPOSIÇÃO

4 MATERIAL E MÉTODOS 51

4.1 - Dispositivo de avaliação dos graus de rotação dos parafusos 53

4.2 - Implantes e componentes protéticos 56

4.3 - Confecção dos corpos de prova $\quad 57$

4.3.1 - Inclusão, fundição, desinclusão e acabamento dos corpos de prova 60

4.4 - Análise por meio de Microscopia Eletrônica de Varredura (MEV) 63

4.4.1 - Teste EDS (Espectrometria de Energia Dispersiva de Raios-X) ) 64

4.5 - Teste laboratorial $\quad 64$

$\begin{array}{ll}4.5 .1 \text { - Funcionamento do dispositivo } & 67\end{array}$

$\begin{array}{ll}4.6 \text { - Análise estatística } & 70\end{array}$ 
5 RESULTADOS

5.1 - Momento de Torque $\quad 79$

5.2 - Momento de Re-torque 80

5.3 - Destorque 82

5.4 - Comparação entre ensaios - Momento de Torque 84

5.5 - Comparação entre ensaios - Momento de Re-torque 86

5.6 - Comparação entre ensaios - Destorque 88

6 DISCUSSÃO

$\begin{array}{ll}7 \text { CONCLUSÕES } & 105\end{array}$

$\begin{array}{ll}\text { ANEXOS } & 109\end{array}$

$\begin{array}{ll}\text { REFERÊNCIAS } & 113\end{array}$

$\begin{array}{ll}\text { ABSTRACT } & 121\end{array}$ 


\section{LISTA DE FIGURAS}

Figura 1 Exemplo de um parafuso de abutment e os diferentes segmentos que o compõem.

Figura 2 Desenho esquemático representando a teoria de 20 acomodação das superfícies, embedment relaxation, que ocorre na região da união parafusada. Após o $1^{\circ}$ torque, picos estruturais em contato se aplainam devido à força de apreensão entre os componentes, oriunda da pré-carga gerada no interior do parafuso, sendo necessário um $2^{\circ}$ torque a fim de aproximar mais uma vez os componentes.

Figura 3 Desenho esquemático do dispositivo de avaliação dos graus de rotação dos parafusos, antes de sua confecção: Projeto em AutoCAD - Vista superior.

Figura 4 Dispositivo de avaliação dos graus de rotação dos parafusos, após sua confecção, com mouse e cabo PS2 já conectados para conexão com computador. Vista superior.

Figura 5 Desenho esquemático do dispositivo de avaliação dos graus de rotação dos parafusos, antes de sua confecção: Projeto AutoCAD - Vista lateral.

Figura 6 Dispositivo de avaliação dos graus de rotação dos parafusos, após sua confecção. Vista lateral. 
Figura 7 Implante e componentes utilizados durante 0 experimento, (SIN - Sistema de Implante). A Implante Revolution; B - Abutment UCLA com base usinada em Co-Cr; C - Abutment UCLA de plástico; D - parafuso de titânio com encaixe para chave quadrada.

Figura 8 Uso de fresadora (A) para padronização do tamanho dos abutments (B) e micro motor acoplado (C).

Figura 9 Abutments parafusados sobre os implantes (A) para 59 enceramento dos padrões para fundição e obtenção dos corpos de prova. Parafusos de trabalho para orientar inserção e remoção da matriz de silicona (B).

Figura 10 Introdução da matriz de silicona para orientar fixação 59 da barra.

Figura 11 Fixação da barra (seta) aos abutments por meio de 59 resina acrílica.

Figura 12 Vista frontal do padrão para fundição finalizado no dispositivo. Notar marcação no abutment esquerdo em sua face "vestibular".

Figura 13 Vista oclusal do padrão para fundição preparado no dispositivo.

Figura 14 Dois padrões para fundição unidos à base formadora de cadinho antes da inclusão em revestimento para o procedimento de fundição propriamente dito. 
Figura 15 Após presa, os blocos de revestimento são removidos do anel e estão prontos para serem levados ao forno.

Figura 16 Visão da liga liquefeita incandesceste, no interior do cadinho, no momento da sua centrifugação.

Figura 17 Início da desinclusão dos corpos de prova, ainda cobertos em parte pelo revestimento.

Figura 18 Corpos de prova após a desinclusão e limpeza por 61 jateamento, antes dos cortes dos condutos de alimentação.

Figura 19 Grupo Acrílico Calcinável.

Figura 20 Grupo Co-Cr.

Figura 21 Corpos de prova fixados em dispositivo para realização da MEV.

Figura 22 Microscópio Eletrônico de Varredura, CCDM - UFSCAR.

Figura 23 Diferenciação dos parafusos com caneta de tinta permanente (setas) preta (esquerdo) e vermelha (direito) e os mesmos localizados no interior dos abutments.

Figura 24 Aperto bidigital dos parafusos no interior dos abutments, até encontrar a primeira resistência. 
Figura 25 Torquímetro com chave bidigital adaptada em sua extremidade inferior (seta).

Figura 26 Vista superior do torquímetro. Agulha cega mostrando a quantidade de Newtons obtida.

Figura 27 Chave bidigital (seta) adaptada ao torquímetro (A), realizando aperto do parafuso do abutment durante realização dos testes.

Figura 28 Conjunto de polias de acionamento do sistema leitor 68 óptico infravermelho, os cálculos matemáticos e os resultados.

Nota: as dimensões das polias estão em milésimos de milímetros.

Figura 29 Contato (seta) entre porção cilíndrica do torquímetro 69 (A) e polia intermediaria da caixa acessória (B). Quando o torquímetro é ativado, durante o torque, a polia intermediária se movimenta, registrando a quantidade de graus necessária para o aperto do parafuso.

Figura 30 Interface com o software GRAUS antes (30a) e durante (30b) a leitura da quantidade de graus que identifique o aperto dos parafusos de fixação, na condição de Newtons recomendados pelo fabricante.

Figura 31

Base de assentamento de um abutment UCLA do grupo Co-Cr (sobrefundido). Notar regularidade superficial. Aumento 65x. 
Figura 32 Base de assentamento de um abutment UCLA do grupo Acrílico Calcinável, (totalmente calcinável). Notar grande quantidade de irregularidades superficiais e "ovalamento" do orifício para o parafuso. Aumento 65x.

Figura 33 Rugosidade superficial da base de assentamento das infra-estruturas as quais se apóiam as plataformas dos implantes, antes da realização dos testes - a: grupo CoCr; b: grupo Acrílico Calcinável. Aumento 500x.

Figura 34 Rugosidade superficial da base de assentamento das infra-estruturas após realização dos testes - a: grupo CoCr; b: grupo Acrílico Calcinável. Notar incorporação de partículas de titânio aderidas às rugosidades superficiais (setas), segundo dados do EDS (ANEXOS). Aumento $500 x$.

Figura 35 Superfície dos parafusos de titânio, antes da realização dos testes - a: região entre cabeça e pescoço; b: região central das roscas; c: região apical e primeira rosca. Observar na textura de superfície as marcas do processo de usinagem. Aumento 150x.

Figura 36 Observar danos ocorridos na $1^{\mathrm{a}}$ rosca do parafuso durante os testes, na forma de ranhuras (seta azul) e dobramentos (seta vermelha). Aumento 150x.

Figura 37 Observar o mesmo dobramento na $1^{\text {a }}$ rosca do parafuso (seta vermelha) da imagem anterior durante os testes, agora em maior aumento (1500x).

Figura 38 Observar mais ranhuras ocorridas na $1^{\text {a }}$ rosca do parafuso durante os testes, na forma de ranhuras (setas). Aumento 150x. 
Figura 39 Observar a mesma ranhura da imagem anterior (seta), agora em 101 maior aumento (1500x).

Figura 40 Observar amassamento na região da base de assentamento da 101 cabeça do parafuso sobre o pilar protético após os testes. Aumento 150x.

Figura 41 Observar em mais um parafuso o amassamento na região da base de 101 assentamento da sua cabeça sobre o pilar protético após os testes. Aumento 150x.

Figura 42 Observar ranhura na porção externa da cabeça do parafuso (seta), 102 provavelmente oriunda de um contato indevido entre esta e a porção interna do pilar sobre o pilar protético durante os testes. Aumento $150 x$.

Figura 43 Observar a mesma e outras ranhuras (setas) na porção externa da 102 cabeça do parafuso da imagem anterior, agora em maior aumento (1000x). 


\section{LISTA DE GRÁFICOS}

Gráfico 1 Comparação dos valores médios de rotação dos parafusos, em graus, no Momento de Torque entre os dois grupos.

Gráfico 2 Comparação dos valores médios de rotação dos parafusos no momento de re-torque entre os dois grupos.

Gráfico 3 Comparação dos valores médios de Destorque entre os grupos.

Gráfico 4 Representação dos valores médios de rotação dos parafusos, durante o momento de torque, nos diferentes ensaios realizados para o grupo Acrílico calcinável.

Gráfico 5 Representação dos valores médios de rotação dos parafusos, durante o momento de torque, nos diferentes ensaios realizados para o grupo Co-Cr.

Gráfico 6 Representação dos valores médios de rotação dos parafusos, durante o momento de re-torque, nos diferentes ensaios realizados para o grupo Acrílico Calcinável.

Gráfico 7 Representação dos valores médios de rotação dos parafusos, durante o momento de re-torque, nos diferentes ensaios realizados para o grupo Co-Cr. 
Gráfico 8 Representação dos valores médios de destorque dos parafusos, durante o afrouxamento dos mesmos, nos diferentes ensaios realizados para o grupo Acrílico calcinável.

Gráfico 9 Representação dos valores médios de destorque dos parafusos, durante o afrouxamento dos mesmos, nos diferentes ensaios realizados para o grupo Co-Cr. 


\section{LISTA DE TABELAS}

Tabela 1 Resultados para o grupo Acrílico Calcinável. Os

corpos de prova seguidos de linha (N') referem-se aos parafusos do abutment esquerdo, conforme citado anteriormente no capítulo Material e Métodos.

Tabela 2 Resultados para o grupo Cobalto - Cromo (Co-Cr). Assim como na tabela anterior, os corpos de prova seguidos de linha (N') referem-se aos parafusos do abutment esquerdo, conforme citado anteriormente no capítulo Material e Métodos.

Tabela 3 Valores convertidos em graus no grupo Acrílico Calcinável, para obtenção das médias da quantidade de graus necessários para o aperto dos parafusos durante os momentos de torque e re-torque.

Tabela 4 Valores convertidos em graus no grupo Cobalto Cromo (Co-Cr), para obtenção das médias da quantidade de graus necessários para o aperto dos parafusos durante os momentos de torque e retorque.

Tabela 5 Comparação dos momentos de Torque entre grupos no ensaio 1.

Tabela 6 Comparação dos momentos de Torque entre grupos no ensaio 2. 
Tabela 7 Comparação dos momentos de Torque entre grupos no ensaio 3.

Tabela 8 Comparação dos momentos de Re-torque entre grupos no ensaio 1.

Tabela 9 Comparação dos momentos de Re-torque entre grupos no ensaio 2.

Tabela 10 Comparação dos momentos de Re-torque entre 81 grupos no ensaio 3.

Tabela 11 Comparação dos valores de Destorque entre grupos 82 no ensaio 1.

Tabela 12 Comparação dos valores de Destorque entre grupos 82 no ensaio 2.

Tabela 13 Comparação dos valores de Destorque entre grupos no ensaio 3.

Tabela 14 Comparação do momento de Torque entre ensaios no grupo Acrílico Calcinável.

Tabela 15 Comparação do momento de Torque entre ensaios no grupo Co-Cr.

Tabela 16 Comparação do momento de Re-torque entre 86 ensaios no grupo Acrílico Calcinável. 
Tabela 17 Comparação do momento de Re-torque entre ensaios no grupo Co-Cr.

Tabela 18 Comparação dos valores de Destorque entre ensaios no grupo Acrílico Calcinável.

Tabela 19 Comparação dos valores de Destorque entre 89 ensaios no grupo Co-Cr. 


\section{LISTA DE ABREVIATURAS E SÍMBOLOS}

\begin{tabular}{|c|c|}
\hline UCLA & Universal Casting Long Abutment \\
\hline $\mathrm{Ncm}$ & Newtons / centímetro \\
\hline mm & milímetros \\
\hline $\mathbf{N}$ & Newtons \\
\hline MEV & Microscopia Eletrônica de Varredura \\
\hline 3I & Implant Innovation Inc \\
\hline GPa & Giga Pascal \\
\hline$\circ$ & graus \\
\hline \pm & mais ou menos \\
\hline DLC & Diamond Like Carbon \\
\hline$\mu \mathrm{m}$ & micrometro \\
\hline $\mathrm{Ni}-\mathrm{Cr}$ & Níquel - Cromo \\
\hline $\mathrm{Co}-\mathrm{Cr}$ & Cobalto - Cromo \\
\hline SENAI & Serviço Nacional de Aprendizagem Industrial \\
\hline $\mathbf{c m}$ & centímetro \\
\hline SIN & Sistema de Implante Nacional \\
\hline DIN & Deutsches Institut für Normung \\
\hline ASTM & American Society for Testing Materials \\
\hline${ }^{\circ} \mathrm{C}$ & Graus Celsius \\
\hline Psi & libra por polegada quadrada \\
\hline $\mathrm{cm}^{3}$ & centímetro cúbico \\
\hline CCDM & Centro de Caracterização de Materiais \\
\hline UFSCar & Universidade Federal de São Carlos - SP \\
\hline \multirow[t]{2}{*}{ EDS ou EDX } & (Energy Dispersive x-Ray Detector) - Espectrometria de \\
\hline & Energia Dispersiva de Raios-X \\
\hline $\boldsymbol{P}$ & Nível de significância \\
\hline$<$ & Menor \\
\hline C & Carbono \\
\hline
\end{tabular}




$\begin{array}{ll}\mathbf{N a} & \text { Sódio } \\ \mathbf{A l} & \text { Alumínio } \\ \mathrm{Si} & \text { Silício } \\ \mathbf{M o} & \text { Molibdênio } \\ \mathbf{F e} & \text { Ferro } \\ \mathbf{C r} & \text { Cromo } \\ \mathbf{N i} & \text { Níquel } \\ \mathbf{W} & \text { Tungstênio } \\ \mathrm{Ti} & \text { Titânio } \\ \mathbf{S} & \text { Enxofre } \\ \mathbf{C o} & \text { Cobalto }\end{array}$


RESUMO 
Problemática: De ocorrência clínica bastante comum, o afrouxamento dos parafusos que compõe uma prótese sobre implante é uma complicação que traz transtornos tanto para o profissional quanto para o paciente.

Proposição: O objetivo deste estudo foi comparar o grau de rotação de parafusos de titânio (grau 5), durante testes de torque, re-torque e os valores de destorque $(\mathrm{Ncm})$, sobre infra-estruturas fundidas em monobloco, a partir de abutments tipo UCLA totalmente calcináveis e com cinta usinada em Co-Cr.

Material e métodos: Um dispositivo leitor da quantidade de graus foi especialmente desenvolvido para este estudo, juntamente com um software . Dois implantes Revolution - SIN de 3,75 mm de diâmetro e $13 \mathrm{~mm}$ de comprimento e hexágono externo foram montados na base de um dispositivo e diretamente sobre eles foram obtidos os padrões para fundição dos corpos de prova. Cada corpo de prova foi formado por dois abutments tipo UCLA, totalmente calcináveis ou com cinta em Co-Cr, interligados por uma barra acrílica. Foram obtidos 10 corpos de prova para cada grupo e 40 parafusos de titânio (Grau 5) foram usados para os testes. Obteve-se então a medição do ângulo criado durante o aperto e re-aperto dos parafusos, sendo o re-aperto realizado após 10 minutos do aperto inicial, ambos sob torque de $30 \mathrm{Ncm}$. Após o procedimento de re-aperto, o valor de destoque era imediatamente aferido e anotado em $\mathrm{Ncm}$, possibilitando avaliar a quantidade de torque retido pelo parafuso após o procedimento, sendo esta seqüência realizada 3 vezes para cada corpo de prova. Análises em MEV foram realizadas nas bases de assentamento dos abutments antes e após a realização dos testes, assim como na superfície dos parafusos, a fim de se encontrar eventuais danos na microestrutura dos mesmos. O teste " $t$ " de student foi aplicado para uma avaliação entre os grupos e o teste ANOVA a um critério foi utilizado para análise intra-grupo.

Resultados: Os resultados revelaram que durante os procedimentos de torque (aperto), os parafusos empregados em infra-estruturas obtidas a partir de abutments totalmente calcináveis apresentaram um maior grau de rotação (ensaio 
1: $61,664^{\circ}$; ensaio 2: $47,718^{\circ}$; ensaio 3: $47,374^{\circ}$ ), quando comparados aos parafusos empregados em infra-estruturas obtidas de abutments com cinta

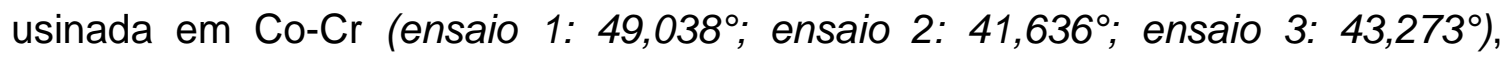
sendo a diferença entre os grupos estatisticamente significante em todos os ensaios realizados; $P<0,05$. Além disso, em ambos os grupos, a maior rotação dos parafusos ocorreu no primeiro aperto dos mesmos tanto durante o procedimento de torque quanto no procedimento de re-torque. Durante o re-torque, o ângulo formado na cabeça dos parafusos também foi sempre maior para o grupo Acrílico

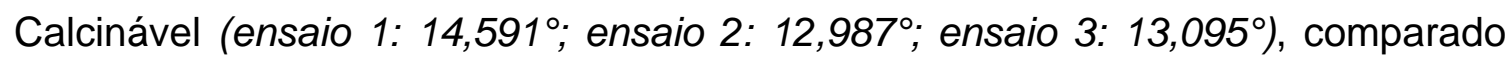
ao grupo Co-Cr (ensaio 1: $11,481^{\circ}$; ensaio 2: 10,117 ; ensaio 3: $12,213^{\circ}$ ), sendo que diferença estatisticamente significante foi encontrada entre os ensaio 1 e 2; $P<0,05$. Os valores médios de destorque (quantidade de torque retido durante 0 aperto dos parafusos) também foram sempre maiores para o grupo Acrílico Calcinável (ensaio 1: 27,325 Ncm; ensaio 2: 27,050 Ncm; ensaio 3: 26,975 $\mathrm{Ncm}$ ), quando comparado ao grupo Co-Cr (ensaio 1: 26,250 Ncm; ensaio 2: 26,975 Ncm; ensaio 3: $26,400 \mathrm{Ncm}$ ), porém sem diferença estatisticamente significante. As Imagens obtidas das análises em MEV demonstraram que as superfícies das bases de assentamentos do abutments obtidos a partir de abutments totalmente calcináveis apresentaram grandes irregularidades superficiais, comparadas às obtidas a partir de bases usinadas em Co-Cr, as quais apresentaram um padrão mais liso e uniforme. Quanto à análise dos parafusos, foi encontrado que as maiores deformações dos mesmos ocorrem na base de assentamento de sua cabeça no interior do abutments assim como na região da sua primeira rosca (apical).

Conclusões: Tanto para o momento de torque quanto para o momento de re-torque, infra-estruturas do grupo Acrílico Calcinável permitiram maior rotação dos parafusos dos abutments, quando comparados com o grupo Co-Cr. Na análise dos valores de destorque, estatisticamente os grupos foram considerados semelhantes. Imagens em MEV, antes da realização dos testes de torque, retorque e destorque revelaram que a base de assentamento do grupo Acrílico Calcinável apresentou aspecto mais irregular da fundição quando comparado ao 
grupo Co-Cr. Em ambos os grupos, partículas de titânio foram encontradas incrustadas nestas bases de assentamento após a realização desses testes, segundo dados do EDS. As imagem em MEV revelaram ainda que os parafusos se deformam principalmente na base de sua cabeça que se assenta no interior dos abutments, assim como na região da sua primeira rosca(apical).

Palavras chave: Implantes osseointegrados, Afrouxamento de parafusos, Biomecânica sobre implantes, Próteses parafusadas. 


\section{INTRODUÇÃO}

A implantodontia passou a ser realmente conhecida em meados da década de 80 , quando surgiram os primeiros trabalhos de divulgação dos protocolos de instalação denominados implantes osseointegrados (BRANEMARK; ZARB; ALBREKTSSON ${ }^{12}$, 1985). O sucesso dessa nova modalidade de tratamento baseou-se em alguns aspectos relatados na literatura, tais como longevidade do tratamento (ALBREKTSSON², 1988; ADELL et al. ${ }^{1}$, 1990), possibilidade de repetição do processo quando ocorrer insucessos (BRANEMARK; ZARB; ALBREKTSSON ${ }^{12}$, 1985) e simplicidade da técnica quando respeitados os protocolos cirúrgicos, protéticos clínicos e protéticos laboratoriais (BRANEMARK; ZARB; ALBREKTSSON ${ }^{12}, 1985$; ALBREKTSSON; JANSSON; LEKHOLM³ ${ }^{3}, 1986$; ALBREKTSSON², 1988).

Os primeiros protocolos de tratamento com implantes osseointegrados baseavam-se na reabilitação de mandíbulas totalmente edêntulas, em pacientes considerados por Branemark como "inválidos orais", obtendo-se altos índices de sucesso (ALBREKTSSON², 1988; ADELL et al. ${ }^{1}$, 1990). Com o passar dos anos, e devido a essa alta previsibilidade dos tratamentos, as indicações para o uso de implantes osseointegrados foram expandindo-se e, logo, pacientes parcialmente desdentados, assim como aqueles que necessitavam repor apenas um único dente perdido passaram a ter mais uma opção para substituição de seus dentes ausentes, baseadas em estudos que previam taxas de sucesso semelhantes às de reabilitações de mandíbulas totalmente edêntulas (JEMT; LINDEN; LEKHOLM ${ }^{36}$, 1992; EKFELDT; CARLSSON; BORJESSON $\left.{ }^{23}, 1994\right)$.

Embora havendo altas taxas de sucesso nas restaurações protéticas sobre implantes, e maior aceitabilidade por parte dos pacientes, diante dessa modalidade de tratamento, essas não estão livres de complicações, podendo estas ser de ordem funcional (JEMT; LINDEN; LEKHOLM ${ }^{36}$, 1992; CARLSON; CARLSSON $^{17}$, 1994), estéticas (JEMT; LINDEN; LEKHOLM ${ }^{36}$, 1992; CARLSON; CARLSSON ${ }^{17}$, 1994) e biomecânicas (COX; ZARB ${ }^{21}, 1987$; NAERT et al. ${ }^{49}$, 1992; GOODACRE et al. ${ }^{27}$, 2003). Apesar de a literatura vastamente relatar diversos tipos de complicações, neste trabalho 
procuraremos manter o foco sobre as complicações biomecânicas, principalmente aquelas que interferem na estabilidade da união parafusada, região esta da interface entre o implante osseointegrado e os componentes que compõem a prótese sobre implante.

Após o implante de titânio, material extremamente biocompatível, estar devidamente integrado ao tecido ósseo, o mesmo se torna apto a receber cargas funcionais advindas das restaurações protéticas provisórias e/ou definitivas. A restauração protética pode ser conectada ao implante de duas maneiras distintas: diretamente à cabeça do implante, sendo a prótese confeccionada sobre a estrutura de um pilar e este conectado à cabeça do implante por meio de um parafuso; ou através de um componente intermediário, o qual após estar conectado à cabeça do implante, também por meio de um parafuso, poderá receber a prótese construída sobre uma infraestrutura que se adapta agora sobre este intermediário, através de um segundo parafuso ou mesmo por um agente cimentante. É importante salientar que uma prótese sobre implante, cimentada, deixa de lado uma das principais vantagens das conexões parafusadas, que é a reversibilidade, ou seja, a possibilidade de a prótese poder ser removida sob determinadas circunstâncias para possíveis constatações de danos e reparos. Contudo, atualmente, há técnicas, como a descrita por APARICIO ${ }^{4}, 1995$, que associa vantagens da prótese cimentada com a da parafusada: passividade de adaptação e reversibilidade, respectivamente.

Seguramente, a principal complicação biomecânica, denominada dessa forma devido à intimidade com os tecidos vivos dos pacientes, refere-se ao afrouxamento e/ou fratura dos parafusos que compõem todo esse sistema das próteses sobre implantes. A reversibilidade, característica dada às próteses parafusadas, sem dúvida alguma é a grande vantagem da utilização desse mecanismo de fixação das próteses. Além de possibilitar avaliação individual dos implantes, quando necessário, torna possível a inspeção dos tecidos moles abaixo da prótese, remoção de eventuais cálculos e até mesmo necessidades de modificar as próteses já instaladas. Reparos podem ser feitos mais facilmente e com menor custo, tais como reparos nos materiais de revestimento estético (porcelana ou resinas), mudança na forma das restaurações e até posterior criação de meios que venham a facilitar os 
procedimentos de higienização por parte dos pacientes, caso estes apresentem dificuldades em realizar tal procedimento. Assim, para que essas restaurações desempenhem seu completo papel, da maneira como foram idealizadas, é necessário que elas permaneçam devidamente apertadas pelos seus parafusos evitando assim complicações.

Baseados em estudos de CARR; BRUNSKI; HURLEY ${ }^{18}, 1996$; KANO et al. ${ }^{39}, 2006$ e BYRNE et al. ${ }^{15}, 2006$, onde o papel dos componentes usinados ou fundidos foi discutido inter-relacionando-os na execução de próteses parafusadas, muitos relatos sobre a maior efetividade deste ou daquele tipo de componente vem se mostrando presente até os dias atuais na literatura pertinente. Visto isso, nos pomos a pensar sobre qual seria o papel exercido pelos parafusos de fixação de abutments ou pilares tipo UCLA (Universal Casting Long Abutment), em razão do seu grau de acomodação e resistência. Com a grande variedade de produtos que adentram o mercado da implantodontia e suas variações estruturais geométricas e/ou físico-químicas, reside em nossa visão uma grande curiosidade em relação ao tipo de dano que venham a sofrer esses parafusos e componentes protéticos no momento de seu aperto e desaperto (torque e destorque, respectivamente), principalmente quando os mesmos são empregados em pilares usinados de fábrica ou fundidos em laboratórios comerciais de prótese dentária, de maneira rotineira para próteses tradicionais.

Diante de muitos métodos de avaliação, podemos citar análises por elemento finito (SAKAGUCHI; BORGERSEN ${ }^{57}$, 1995), análises microscópicas (KANO et al. $^{39}$, 2006; JAARDA; RAZZOOG; GRATTON ${ }^{34}$, 1995) e análises de comportamento sob condições estáticas e dinâmicas (BINON ${ }^{8}, 1996$; BINON $^{9}$, 1998). Entretanto, a avaliação de rotação dos parafusos em graus parece também contribuir para um melhor entendimento do comportamento mecânico desse elemento tão importante na prótese sobre implante (MARTIN et al. ${ }^{46}$, 2001). Assim, diante dessas diferentes formas de análises e interpretações, surgem novas constatações que, por mera curiosidade inicialmente, acabam se transformando em ciência aplicada para avaliar os possíveis fenômenos que ocorrem no âmbito das próteses sobre implante.

Toda avaliação laboratorial, de características exclusivamente mecânicas, melhoram sobremaneira o entendimento do desempenho das 
próteses sobre implantes, já que, ainda, muitos cirurgiões-dentistas não estão familiarizados com essa modalidade de tratamento, carecendo de informações que os levem mais perto das interpretações macro e microscópicas dos componentes nelas utilizados, extremamente familiares à engenharia, principalmente mecânica, e muitas vezes distantes da odontologia. 
2 - REVISÃO DE LITERATURA 


\section{REVISÃO DE LITERATURA}

\subsection{Complicações em Próteses Sobre Implantes}

Nos dias de hoje é notável o impacto benéfico que os procedimentos cirúrgico-protéticos, baseados na instalação de implantes dentais como suporte de dentes artificiais, têm causado na vida de muitas pessoas. A possibilidade do reestabelecimeto de parte do sistema estomatognático para esses pacientes não só melhora sua qualidade de vida mas também enriquece a auto-estima dos mesmos, já que novamente eles podem não só mastigar com eficiência, como também voltar a sorrir.

Embora a substituição de dentes perdidos com implantes osseointegráveis e suas respectivas próteses, estejam sendo consideradas nos últimos anos como "o estado da arte", é justamente por esse motivo que esses tipos de procedimentos não estão livres de limitações e eventuais complicações, principalmente quando os planejamentos adotados não seguem princípios biomecânicos consagrados de certa forma por protocolos de tratamento, ou mesmo não respeitam os aspectos funcionais e estéticos do paciente. A literatura é vasta em artigos que descrevem os potenciais problemas para este tipo de procedimento e uma revisão será apresentada para tomarmos conhecimento de quais são eles e qual seu impacto sobre os tratamentos.

SKALAK ${ }^{61}, 1983$ publicou um estudo no qual fez considerações biomecânicas a respeito das próteses sobre implantes, ressaltando os aspectos importantes para evitar complicações. Segundo ele, um aspecto clínico que pode afetar a longevidade dos implantes é a maneira como os estresses mecânicos são distribuídos do implante para o tecido ósseo subjacente, sendo essencial que nenhuma das estruturas sejam estressadas além de sua capacidade de fadiga a longo prazo. O autor sugere que sempre sejam usados implantes em forma de parafuso, por permitirem aposição óssea entre suas roscas, proporcionando um comportamento biomecânico mais favorável quando comparado a implantes de superfície lisa que necessitam de uma verdadeira adesão óssea a sua superfície para atuarem de forma 
semelhante. Da mesma maneira, enfatizou sua preferência por implantes com superfície rugosa que, embora não seja um fator de macro retenção, em nível celular contribui sobremaneira para o embricamento do tecido ósseo. Já a distribuição das cargas verticais e/ou laterais da prótese para os implantes depende do número, disposição e rigidez das estruturas utilizadas (implantes e componentes protéticos). Além disso, como tais estruturas passam a formar um corpo único, é necessário que haja um alinhamento entre elas, para que não ocorram pontos de sobrecarga nem nos componentes nem no tecido ósseo subjacente, o que poderia levar todo esse sistema a falhas precoces devido a forças externas. Justamente por isso, estruturas em balanço, denominadas de cantilever, quando utilizadas devem ser planejadas com critérios, visto que o implante da extremidade sempre será sobrecarregado. Quanto à rigidez do conjunto, idealmente deve-se optar por estruturas rígidas, que não transmitam movimentos aos implantes, os quais poderiam causar perda da osseointegração. Entretanto o uso de materiais de cobertura para essas estruturas, com certo grau de resiliência, como as resinas acrílicas e dentes artificiais, podem ser uma boa opção para minimizar cargas excessivas da mastigação, as quais seriam diretamente transmitidas para os implantes caso materiais de coberturas rígidos como porcelana fossem usados. Segundo o autor, esse arranjo permite dureza e resistência da subestrutura associado a uma adequada proteção dos outros componentes.

COX; ZARB ${ }^{21}, 1987$ apresentaram um estudo longitudinal de 3 anos seguindo o protocolo de 2 tempos cirúrgicos proposto por Branemark com o objetivo de verificar a eficácia do tratamento com implantes. 26 pacientes receberam próteses totais fixas mandibulares, ancoradas sobre 4 a 6 implantes entre os forames mentonianos e foram avaliados no período de 1 a 3 anos das próteses em função. Avaliaram-se a quantidade de gengiva inserida, índice de placa, profundidade de sondagem, presença de inflamação gengival e presença de mobilidade. A taxa individual de sucesso dos implantes apresentada pelos autores foi de $87,5 \%$ e, para as próteses, de 96\%. Dentre as complicações registradas, destacou-se o alto número de fratura das infraestruturas, onde 12 das 26 fraturaram na região de cantilever. A mudança da liga utilizada de prata paládio tipo III para tipo IV associada ao aumento da secção transversal da barra foi a solução encontrada pelos autores para 
solucionar esse problema. Apenas 2 parafusos de retenção da prótese fraturaram, sendo a causa relacionada à ausência de adaptação passiva da prótese que foi posteriormente refeita e o problema eliminado. Os autores comentam que a falta de adaptação da prótese pode colocar os componentes do implante sob tensão, podendo levá-la à fratura ou à microfratura do tecido ósseo ao redor do implante, com conseqüente perda óssea.

RANGERT; JEMT; JÖRNEUS ${ }^{53}, 1989$ apresentaram algumas regras para confecção de próteses sobre implantes. Segundo eles, o desenho da prótese tem influência muito grande na distribuição das cargas sobre os implantes, sendo necessário conhecer os aspectos mecânicos do sistema para minimizar as falhas. Baseados em considerações teóricas e na experiência clínica com implantes tipo Branemark, os autores descreveram as forças atuantes no sistema como forças internas e externas. A pré-carga, uma força interna gerada no momento do aperto do parafuso e que mantem os componentes unidos, deve ser suficiente para suportar as forças externas ao sistema. Essas forças podem provocar a separação de suas partes e, como conseqüência, o afrouxamento dos parafusos. Assim foram sugeridas duas condições básicas para o sucesso do sistema: obtenção de adequada précarga e adaptação precisa das próteses. Segundo os autores, a causa primária de afrouxamento dos parafusos é a falta de adaptação das próteses. Numa condição de boa qualidade óssea, a parte frágil do sistema será sempre os parafusos de retenção, considerado como um mecanismo de segurança.

JEMT; LINDEN; LEKHOLM ${ }^{36}$, 1992 realizaram um estudo retrospectivo avaliando as principais complicações que acometeram 127 próteses parciais fixas em uma rechamada dos pacientes 1 ano pós tratamento. As 127 próteses eram compostas de 354 implantes que foram instalados tanto na mandíbula quanto na maxila. O desenho e o material utilizado para a construção dessas próteses foi o mesmo comumente adotado para as próteses totais fixas, utilizando infra-estrutura de ouro tipo III e dentes de resina acrílica. Parafusos de ouro para retenção das próteses foram usados e apertados manualmente entre 15 e 20 Ncm. Os resultados, após a avaliação de 1 ano das próteses maxilares, mostraram que o problema mais freqüentemente encontrado foi a mobilidade das prótese devido ao afrouxamento do parafuso de ouro $(13,9 \%)$, problemas estéticos $(11,4 \%)$ e 
conforto relacionado ao desenho da prótese $(9,1 \%)$. Na mandíbula as complicações mais freqüentemente encontradas foram as de ordem estética $(5,2 \%)$, fratura da resina $(5,2 \%)$ e problemas oclusais $(5,2 \%)$. Reações nos tecidos moles tais como fístulas, hiperplasias e inflamações corresponderam a 2,1\% das complicações. Os autores consideraram os resultados satisfatórios, comparando-os com os resultados de tratamento de pacientes que receberam próteses totais fixas sobre implantes, sendo as complicações aqui encontradas com menor grau de complexidade de resolução.

NAERT et al. ${ }^{49}, 1992$ publicaram a segunda parte de um estudo clínico avaliando as complicações protéticas referentes à instalação de 564 implantes sobre os quais foram confeccionadas 103 próteses totais fixas implantossuportadas. Durante o período de observação (15 anos), os pacientes eram chamados para avaliações a cada 6 meses e, numa avaliação das falhas mecânicas que acometeram as próteses, foram encontradas as seguintes ocorrências: 3 fraturas de implantes, 5 fraturas de abutments e 7 fraturas do parafuso de ouro de retenção das próteses. Duas fraturas de implantes ocorreram após afrouxamento do parafuso de ouro, provavelmente devido à atuação de forças elevadas sobre os parafusos remanescentes apertados. A outra fixação fraturada e 4 dos abutments assim encontrados foi diagnosticado em um paciente que danificou sua prótese. Já as fraturas nos parafusos de ouro foram primariamente relacionadas ao seu afrouxamento. Já as causas de afrouxamento dos parafusos dos abutments foram difíceis de estabelecer. Contudo, a taxa de sucesso das próteses foi de 96\% na maxila e 100\% na mandíbula. O autor sugere que para evitar falhas mecânicas dos componentes deve-se ter ótima passividade de adaptação da infra-estrutura sobre os implantes com um adequado arranjo oclusal; os parafusos de ouro devem ser apertados até atingir uma máxima pré-carga $(10 \mathrm{Ncm})$ não somente durante a instalação da prótese, mas também em intervalos regulares e quando os implantes forem instalados em linha reta, como freqüentemente acontece na mandíbula em razão da sua anatomia; o uso de cantilevers é permitido, desde que curtos (menores que10mm).

CARLSON; CARLSSON ${ }^{17}, 1994$ realizaram, juntamente com outros clínicos na Suécia, uma avaliação de seus pacientes por meio de um questionário, procurando identificar quais complicações protéticas estavam 
acometendo os pacientes que visitaram suas clínicas num período de 2 meses. Como critério de inclusão, apenas os pacientes de retornos periódicos nesse período, ou em caráter emergencial, foram incorporados na amostra, enquanto que os que estavam sob tratamento protético não foram incluídos. 600 próteses sobre implantes foram avaliadas, sendo que 47\% eram maxilares e $53 \%$ mandibulares. Dessas, 86\% eram próteses fixas, 8\% elementos isolados e 6\% próteses removíveis. 83\% dos pacientes avaliados estavam satisfeitos com sua condição protética, enquanto outros $17 \%$ estavam descontentes. Os descontentamentos mais freqüentes relacionavam-se a problemas estéticos (29\%) e funcionais [mastigação (11\%) e fonação (9\%)] A outra metade estava geralmente relacionada àresina acrílica integrante da prótese (fraturas e desgastes), alterações relacionadas aos tecidos moles, afrouxamento da supra-estrutura, dificuldades de higienização, sinais e sintomas de disfunção temporomandibular, diminuição da dimensão vertical de oclusão e aumento da salivação. As complicações foram mais freqüentes nas próteses removíveis, assim como também nas próteses maxilares, sendo que o problema mais freqüentemente encontrado foi associado à resina acrílica, como desgaste, fratura e/ou defeitos estéticos. Mobilidade da supra-estrutura representou 8\% das complicações, sendo relacionada a implantes não osseointegrados, afrouxamento do parafuso do abutment e/ou do parafuso de ouro. Ocorreu fratura do parafuso do abutment em 2 casos, correspondendo a $1 \%$ da amostra. Esses e outros achados, como o tempo gasto para a correção dessas complicações, que em média variou de aproximadamente 34 minutos para elementos unitários a 67 minutos para prótese removíveis, levaram os autores a concluir que a manutenção de próteses sobre implantes é necessária e que a eficácia do tratamento a longo prazo não é precisa. Segundo eles, os clínicos devem incorporar as manutenções em seus planos de tratamento.

GOODACRE et al. ${ }^{27}, 2003$ publicaram uma revisão realizada entre 1981 e 2001, procurando identificar os principais tipos de complicações relatadas no tratamento com implantes e próteses sobre implantes. Além de identificar os tipos mais comuns de complicações, a incidência das complicações associadas aos implantes foi comparada à incidência das complicações observadas em próteses convencionais. Entre as complicações protéticas mais freqüentes, com incidência superior a $15 \%$, foram relatados o 
afrouxamento dos mecanismos de retenção em próteses tipo overdenture (33\%), fratura da resina em próteses parciais fixas (22\%), perda de implantes em tratamentos com overdentures (21\%), necessidade de reembasamentos de overdentures (19\%) e fratura do clipe da overdenture (16\%). O afrouxamento do parafuso do intermediário foi observado em 6\% das próteses (365 dos 6256 parafusos), sendo a incidência maior em próteses unitárias (45\%). Já a fratura dos parafusos protéticos foi encontrada quase igualmente em próteses parciais fixas e próteses totais fixas, variando de zero a 19\%.

\subsection{A estabilidade da união parafusada: uma análise biomecânica e comportamental dos parafusos.}

A estabilidade da união parafusada e o conseqüente afrouxamento dos parafusos nas próteses sobre implantes são considerados um problema comum não só nas próteses exclusivamente retidas por eles, mas também nas próteses cimentadas que apresentam um parafuso em seu interior realizando a união entre o implante e o abutment (ZARB; SCHMITT $\left.{ }^{68}, 1990\right)$.

Embora o afrouxamento dos parafusos não seja uma complicação muito séria, por si só, é um tanto inconveniente tanto para o paciente quanto para o profissional (TAYLOR $\left.{ }^{65}, 1998 ; \mathrm{MISCH}^{48}, 2006\right)$. Como conseqüências desse afrouxamento podem-se citar a interposição de tecido mole entre 0 abutment e o implante, acúmulo de placa bacteriana nessa região, com conseqüente inflamação, além de uma maior pré-disposição à fratura do parafuso, visto que as cargas se incidirão com ele já frouxo (GOODACRE; KAN; RUNGCHARASSAENG ${ }^{28}$, 1999; KALLUS; BESSING ${ }^{38}$, 1994). Segundo PATTERSON; JOHNS ${ }^{51}$, 1992, numa análise teórica do tempo de fadiga dos parafusos usados em implantes dentários, a concentração de estresses nos parafusos ocorrem em 2 regiões basicamente: uma é a região onde se altera sua secção transversal, entre o "pescoço" do parafuso e sua "cabeça"; porém a maior concentração mesmo ocorre na região da primeira rosca do parafuso, a rosca mais apical (Figura 1). JEMT et al. ${ }^{35}, 1991$ notou que 10\% dos pacientes apresentam fístulas durante o primeiro ano após a instalação das próteses, o que, para eles, pode estar associado ao afrouxamento dos parafusos, decorrente de uma pobre qualidade na higiene oral. 


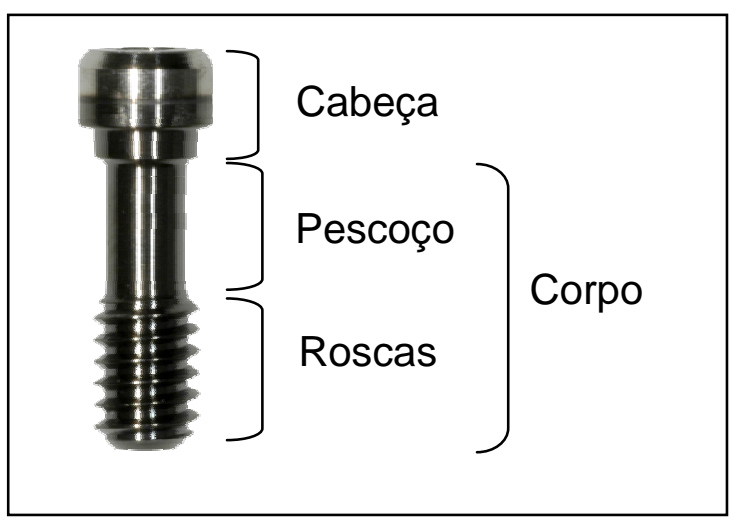

Figura 1 - Exemplo de um parafuso de abutment e os diferentes segmentos que $o$ compõem.

Geralmente, o problema se resolve com um simples reaperto do parafuso em questão, ou mesmo com a substituição do mesmo, seja ele o parafuso do abutment protético, ou o parafuso de ouro de retenção (SAKAGUCHI; BORGERSEN ${ }^{57}$, 1995)

Embora a literatura seja vasta em explicar a dinâmica de como ocorre esse processo de afrouxamento dos parafusos que compõem uma prótese sobre implante, a prevalência com que acontece é muito variada, inconsistente e difícil de ser estabelecida (TAYLOR $\left.{ }^{65}, 1998\right)$, tanto em próteses parciais fixas quanto nas próteses unitárias, estas geralmente mais susceptíveis a forças não favoráveis para a sua estabilidade.

ZARB; SCHMITT ${ }^{68}, 1990$, examinando 274 implantes, notaram que 9 parafusos de abutment e 53 parafusos de retenção de ouro haviam fraturado num período de 4 a 9 anos de observação.

NAERT et al. ${ }^{49}, 1992$, relataram que $5 \%$ de todos os parafusos de ouro estavam frouxos em um grupo de 564 implantes de 91 pacientes. Num estudo retrospectivo de 6 anos dos aspectos protéticos, de 509 implantes instalados para suprir o edentulismo parcial dos pacientes, NAERT et al. ${ }^{50}$, 1992 relatou taxas de 6\% de afrouxamento dos parafusos de ouro.

Em mais uma avaliação retrospectiva referente à substituição de coroas unitárias na região de molares, BECKER; BECKER ${ }^{6}, 1995$, usando abutments com configuração anti-rotacional de sua base e seguros com parafusos de abutment de ouro, encontraram uma taxa de afrouxamento em torno de 38\% em 21 coroas restauradas. Embora a estabilidade da união parafusada estivesse presente em $61,9 \%$ dos casos, $14,2 \%$ dos parafusos de 
ouro afrouxaram uma vez, 9,5\% duas vezes e 14,3\% três vezes num período de 24 meses.

Em estudo baseado na substituição de coroas unitárias realizado em sete multicentros por JEMT et al. ${ }^{35}$, 1991, os autores avaliaram a taxa de sobrevivência de implantes do tipo Branemark e suas respectivas próteses (coroas unitárias) após um período de um ano de instalação das mesmas. Com uma taxa de sobrevivência dos implantes da ordem de 97,2\%, a complicação protética mais freqüente foi o afrouxamento dos parafusos dos abutments o qual ficou em torno de 26\%. Uma maior incidência de afrouxamento foi relatada para a região de pré-molares, comparada com a região dos dentes anteriores, sendo essa ocorrência, segundo o autor, atribuida aos efeitos de acomodação dos componentes, fenômeno esse conhecido na literatura como embedment relaxation, que será descrito mais adiante.

Numa continuidade desse mesmo estudo multicêntrico, agora após um período de acompanhamento de 3 anos, LANEY et al. ${ }^{42}, 1994$ não encontraram mudanças na taxa de sobrevivência dos implantes e relataram que a taxa de afrouxamento dos parafusos de abutments continuaram acontecendo, embora a porcentagem de ocorrência fosse significativamente reduzida, o que, segundo eles, pode ser creditada à substituição de parafusos de titânio por parafusos de ouro.

Após 5 anos de acompanhamento, os resultados encontrados por HENRY et al. ${ }^{30}, 1996$ não foram diferentes mais uma vez. Embora com perda óssea de aproximadamente $1 \mathrm{~mm}$ em média entre os implantes, a taxa de sucesso continuou a mesma e o comportamentos dos parafusos também. Essa perda óssea, considerada normal pelos autores, não pode ser correlacionada com a instabilidade da união parafusada.

EKFELDT; CARLSSON; BORJESSON ${ }^{23}, 1994$ em um estudo retrospectivo onde 77 pacientes receberam 93 implantes para a realização de coroas unitárias, somente dois implantes foram perdido, sendo um antes da instalação do abutment e outro após um ano da prótese em função. Embora os pacientes estivessem satisfeitos com os aspectos estéticos e funcionais dos resultados alcançados, a complicação predominante foi mais uma vez o afrouxamento do parafuso do abutment que ocorreu em 40 restaurações (43\%), sendo que em 28 casos esse afrouxamento ocorreu uma vez, e em 12, 
duas vezes ou mais. Segundo os autores, uma das razões dessa alta taxa de incidência de afrouxamento dos parafusos foi provavelmente devido ao fato de o parafuso ser feito de titânio, já que o problema parece ter sido resolvido após a substituição destes por parafusos de ouro.

\section{Para entender melhor como o processo de afrouxamento de um parafuso se dá, é necessário compreender certos princípios de engenharia.}

Quando duas partes ou estruturas são mantidas unidas por um parafuso, essa nova unidade passa então a ser chamada de união ou junta parafusada. O parafuso somente afrouxa se uma força externa a essa união tentar separar as partes. Essas forças de separação não têm como ser eliminadas para prevenir o afrouxamento. A única forma dessa condição ser evitada é apenas se a força que mantém as partes unidas se mantiver sempre maior que a força que tentam separá-las. Diante disso, os dois principais fatores que envolvem a manutenção dos parafusos dos implantes apertados são a maximização da força de união das partes e a minimização das forças de separação (MCGLUMPHY; MENDEL; HOLLOWAY ${ }^{47}$, 1998), sendo que geralmente essa força de união é proporcional ao torque aplicado para o apertamento do parafuso. O torque é um fator mensurável médio, de tensão gerada para o apertamento dos parafusos. Se esse valor de torque for pequeno, pode haver separação da união, resultado da fadiga do parafuso, falha na união ou afrouxamento. Se esse torque também for excessivo, pode haver falha do parafuso pela falta de resistência ou decapagem (descascamento) de suas roscas.

Quando um parafuso é apertado por meio de um torque, uma tensão inicial denominada de pré-carga é gerada no interior desse parafuso. Um específico torque é recomendado para cada parafuso de acordo com os diferentes sistemas de implantes de diferentes fabricantes de parafusos, com base nas características estruturais de desenho e composição dos mesmos (BURGUETE et al. ${ }^{14}$, 1994; JÖRNEUS; JEMT; CARLSSON ${ }^{37}$, 1992). A função dessa pré-carga é manter as partes unidas, o abutment e o implante, comprimidos entre si, como resultado da fricção entre o parafuso e as roscas do implante, entre a cabeça do parafuso e o abutment e entre o topo do 
implante e a superfície interna do abutment. Essa compressão promove resistência às forças externas de separação, aumentando a resistência à fadiga da união abutment/implante. O parafuso alonga e coloca seu "pescoço", porção isenta de roscas, e suas roscas sob tensão (HAACK et al. ${ }^{29}$, 1995). A pré-carga deve ser mantida e variar o menos possível para prevenir a separação da união (DIXON et al. ${ }^{22}$, 1995). Conseqüentemente, quanto maior a pré-carga, maior a resistência ao afrouxamento e maior a estabilidade da união parafusada.

Para que a pré-carga seja transmitida de forma correta à união parafusada, os fabricantes de componentes e implantes tornaram disponíveis os dispositivos aplicadores de torque, denominados de torquímetros. Esse dispositivo mecânico pode ser manual ou elétrico e tem como função transmitir aos componentes a quantidade de torque precisa e aferida, recomendada pelos fabricantes, embora os ótimos valores de pré-carga, nos quais os parafusos de retenção e dos abutments devam ser apertados, ainda permaneçam desconhecidos JAARDA; RAZZOOG; GRATTON ${ }^{33}, 1994$.

Vários fatores inter-relacionados podem interferir de forma crítica na estabilidade da união parafusada. Dentre eles podemos citar os efeitos de acomodação das superfícies contactantes, a pré-carga e a geometria tanto dos parafusos como dos componentes presentes nessa área de união (JÖRNEUS; JEMT; CARLSSON $\left.{ }^{37}, 1992\right)$.

São 2 os principais mecanismos de afrouxamento dos parafusos das restaurações implantossuportadas que devem ser compreendidos: excessivo "dobramento" da união parafusada (quando uma força lateral incide na prótese, tentando "abrir" ou separar os componentes em um dos lado da união parafusada, comprimindo os mesmos simultaneamente no lado oposto) e acomodação das superfícies contactantes. Se uma força de dobramento (cargas horizontais) incide em uma restauração unitária sobre implante e é maior que a resistência à tensão do parafuso, este sofrerá uma deformação plástica permanente, resultando em perda daquela força de tensão no pescoço do parafuso (pré-carga). Como resultado, haverá uma redução da força de contato entre o abutment e o implante e, conseqüentemente, a união parafusada estará mais susceptível ao afrouxamento.

O outro mecanismo de afrouxamento do parafuso deve-se ao fato de que nenhuma superfície é perfeitamente lisa. Mesmo uma superfície 
cuidadosamente usinada, como a dos implantes e seus componentes, quando observadas por um microscópio apresentam rugosidades superficiais identificadas no microscópio como picos e vales estruturais. Quando os picos nas superfícies opostas entram em contato, por meio do encaixe dos componentes e mais intensamente ainda quando a pré-carga (apertamento) é gerada, há uma tendência natural, em virtude da força de apreensão entre as estruturas, de ocorrer um aplainamento, ou mesmo desgaste desses picos, fenômeno esse denominado embedment relaxation, fazendo com que as estruturas se aproximem mais, se acomodando. Com isso, ocorre uma perda gradual da pré-carga, com conseqüente afrouxamento do parafuso de união (Figura 2). 


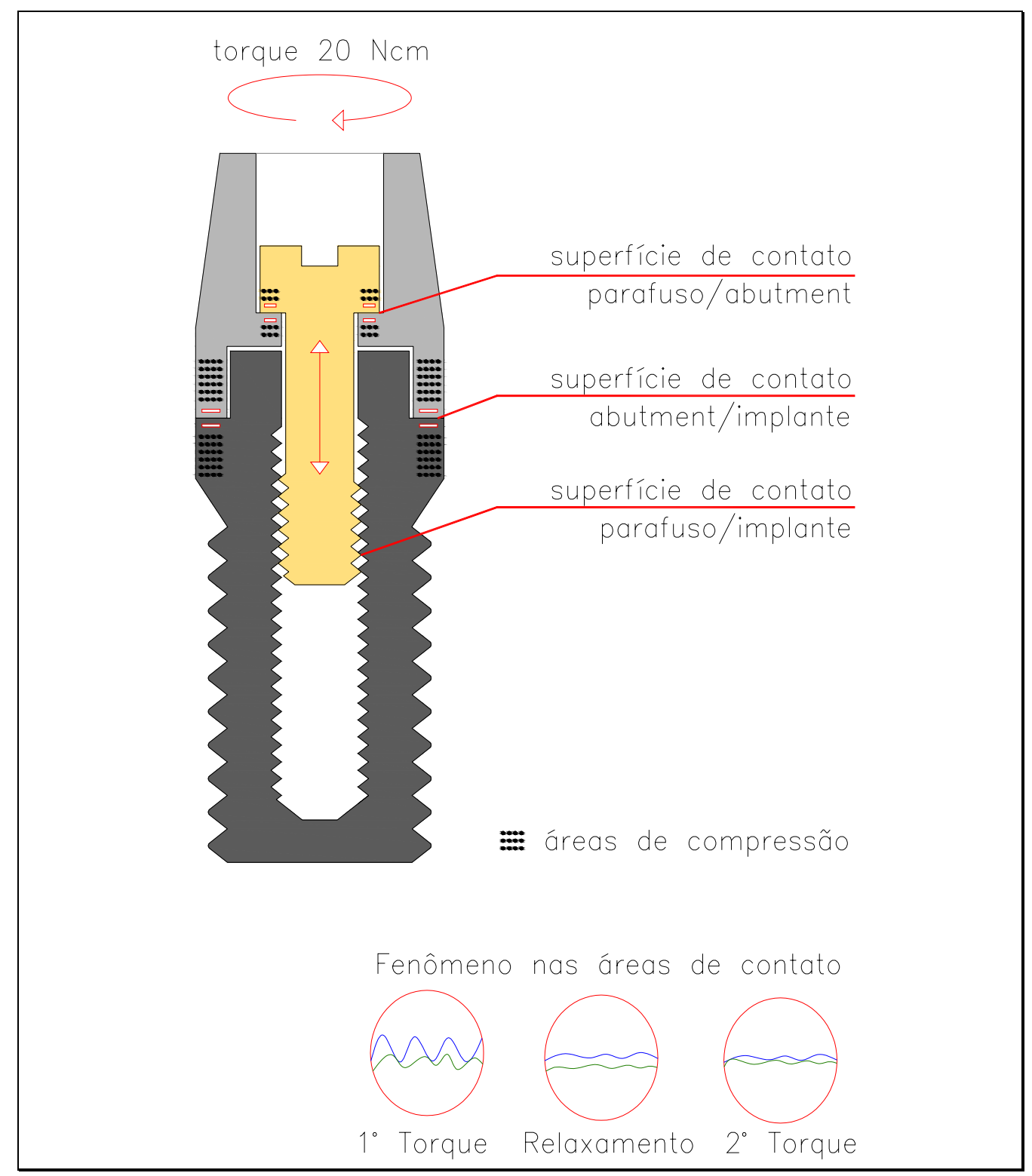

Figura 2 - Desenho esquemático representando a teoria de acomodação das superfícies, embedment relaxation, que ocorre na região da união parafusada. Após o $1^{\circ}$ torque, picos estruturais em contato se aplainam devido à força de apreensão entre os componentes, oriunda da pré-carga gerada no interior do parafuso, sendo necessário um $2^{\circ}$ torque a fim de aproximar mais uma vez os componentes.

Acredita-se que $2 \%$ a $10 \%$ da pré-carga são perdidas, devido aos efeitos de acomodação das superfícies. Além disso, também acredita-se que a fricção entre as roscas, em virtude do atrito, seja maior para o primeiro apertamento e afrouxamento dos parafusos. Assim, depois de repetidos ciclos de apertamento e afrouxamento, a fricção diminui (DIXON et al. ${ }^{22}$, 1995). O resultado desse efeito de acomodação das estruturas é, também, que o torque necessário para remover um parafuso é sempre menor que o torque inicialmente usado para apertá-lo (JAARDA; RAZZOOG; GRATTON ${ }^{34}$, 1995). 
Como ocorre esse efeito de acomodação, sugere-se que após o aperto inicial de uma união parafusada, esta deva ser reapertada novamente, em um curto período de tempo (JAARDA; RAZZOOG; GRATTON ${ }^{33}$, 1994; SIAMOS; WINKLER; BOBERICK $\left.{ }^{60}, 2002\right)$.

Resumidamente, a quantidade de embedment relaxation ou aplainamento das superfícies depende, então, não só da rugosidade das superfícies contactantes, mas também da dureza superficial do implante, do abutment e do parafuso e da quantidade de carga aplicada à união parafusada (JÖRNEUS; JEMT; CARLSSON ${ }^{37}$, 1992). Após a ocorrência desse fenômeno, uma vez aplicado outro torque de apertamento teremos a recuperação da précarga com menor quantidade de fricção entre os componentes (BINON ${ }^{10}$, 2000).

A pré-carga, então, também pode ser influenciada por diversos fatores. Dentre eles podemos citar o material constituinte do parafuso e dos componentes (HAACK et al. ${ }^{29}$, 1995; MARTIN et al. ${ }^{46}, 2001$ ), controle de quantidade do fabricante dos mesmos, dispositivo aplicador de torque e o torque aplicado (TAN; NICHOLLS $\left.{ }^{63}, 2001\right)$, desenho do parafuso e, como já citado anteriormente, da rugosidade superficial das partes envolvidas (CARR; BRUNSKI; HURLEY ${ }^{18}$, 1996). Ótima pré-carga é obtida quando o parafuso alonga, entretanto sem exceder seu coeficiente de elasticidade dependente de seu material de constituição. Para isso, seu desenho deve favorecer o alongamento, o que significa ter menor quantidade de roscas e um pescoço mais longo (BYRNE et al. ${ }^{15}$, 2006; BINON et al. ${ }^{11}$, 1994).

Teoricamente, a máxima pré-carga que um parafuso pode atingir é obtida momentos antes de ocorrer fratura por torção ocorrer (MCGLUMPHY; MENDEL; HOLLOWAY ${ }^{47}$, 1998).

Da mesma forma que determinados fatores interferem na pré-carga, esses diretamente interferem com o afrouxamento dos parafusos como se pode observar adiante. Podemos citar um inadequado apertamento dos mesmos por inexperiência do operador, ou mesmo pela não-utilização de um dispositivo controlador de torque (torquímetro) (PESUN et al. ${ }^{52}, 2001$ ), detalhes associados ao desenho dos parafusos (forma da cabeça, corpo e das roscas) e sua natureza (material de composição) (JÖRNEUS; JEMT; CARLSSON ${ }^{37}$, 
1992; KALLUS; BESSING ${ }^{38}$, 1994). A geometria da interface implante/abutment, tamanho da plataforma protética, quantidade de tolerância de adaptação entre esses componentes, assim como a adaptação não passiva dos mesmos sobre os implantes também são citados como fatores facilitadores do afrouxamento (BINON ${ }^{10}, 2000 ; \mathrm{CHO}$ et al. $\left.{ }^{20}, 2004\right)$. Em caso de estruturas não passivas MCGLUMPHY; MENDEL; HOLLOWAY47, 1998 sugerem que as mesmas sejam seccionadas e unidas para procedimento de soldagem. Outros possíveis fatores relacionados incluem estruturas em cantilevers, união entre dentre e implantes (MCGLUMPHY; MENDEL; HOLLOWAY47, 1998), tamanho da mesa oclusal, altura das cúspides, remodelação óssea, cargas não axiais sobre o implante (JÖRNEUS; JEMT; CARLSSON ${ }^{37}$, 1992) e bruxismo (GOODACRE; KAN; RUNGCHARASSAENG ${ }^{28}$, 1999; MCGLUMPHY; MENDEL; HOLLOWAY ${ }^{47}$, 1998; TOSUN; KARABUDA; CUHADAROGLU ${ }^{66}$, 2003).

\section{Diante da problemática acima mencionada, a descrição de alguns}

trabalhos a respeito do assunto se faz necessária para maior entendimento e aprofundamento no assunto.

Com o objetivo de avaliar a estabilidade dos parafusos de retenção do abutment em próteses unitárias, uma vez que estão mais susceptíveis a ação das cargas, JÖRNEUS; JEMT; CARLSSON ${ }^{37}$, 1992, avaliaram 4 tipos de parafusos de abutment em um teste laboratorial com objetivo de se observar a estabilidade de união da junta parafusada, em relação a estes dois mecanismos de afrouxamento dos parafusos: dobramento e acomodação das superfícies não totalmente lisas, como já descrito anteriormente. Os parafusos eram: (1) titânio grau 1 com cabeça cônica, (2) titânio grau 1 com cabeça plana, (3) titânio grau 3 com cabeça plana e (4) liga de ouro com cabeça plana. Para avaliar os efeitos da acomodação das superfícies, um implante de $10 \mathrm{~mm}$ foi montado em um bloco de resina e sobre este um abutment, sendo os parafusos submetidos ao apertamento com torques específicos, que variavam de $20 \mathrm{Ncm}$ a $35 \mathrm{Ncm}$. O torque necessário para rotacionar o abutment dentro do hexágono de adaptação do implante foi utilizado como medida de estabilidade da junta parafusada. Cada desenho de parafuso foi testado imediatamente 
após o apertamento (antes da sua acomodação), sendo esse procedimento repetido 5 vezes. Para estudar o efeito do dobramento, um teste de carga foi realizado com uma força de $70 \mathrm{~N}$ incidindo perpendicularmente ao longo eixo do implante, 9,5mm da interface entre o abutment e o implante. Essa força foi repetida por 100 vezes, sendo aplicada por mais 100 vezes do lado oposto do implante. Segundo os autores, o desenho da "cabeça" do parafuso é significativo para permitir maior introdução de torque no "pescoço" do parafuso. Um parafuso de cabeça cônica perde maior quantidade de torque devido ao atrito da sua "cabeça" com a porção interna do abutment, resultando em menos força nas suas roscas, assim como foi demonstrado no teste de estabilidade da junta parafusada, nesse estudo. Além disso, demonstrou-se que, após a acomodação inicial, o torque necessário para promover o assentamento do parafuso é menor. Quanto ao teste de dobramento, os autores entendem que se uma força não axial exceder o limite de escoamento do material do parafuso, esta Ihe causará uma deformação permanente. Com isso haverá perda na tensão do parafuso (pré-carga), reduzindo a força de contato entre abutment e implante, tornando a união mais susceptível ao afrouxamento. Assim, quanto maior o limite de escoamento do material constituinte do parafuso, maior sua resistência ao dobramento e, conseqüentemente, menor o afrouxamento. Ao final do estudo, os autores concluíram que os parafusos de ouro, com cabeça plana e torque de $35 \mathrm{Ncm}$, foram os que produziram os melhores resultados em relação às condições estudadas. Entretanto, de maneira geral, os resultados mostraram que quanto maior o valor de torque aplicado ao parafuso, menor é o risco de afrouxamento.

BURGUETE et al. ${ }^{14}$, 1994 realizaram uma revisão a respeito das características do apertamento para uniões parafusadas em implantes osseointegrados, procurando dar algumas informações técnicas sobre 0 apertamento desses parafusos, e qual a quantidade desejável desse procedimento. Segundo eles, existe a crença de que, para se evitar o afrouxamento de um parafuso, este deve ser apertado o máximo possível. BICKFORD $^{7}$, 1981, citado em sua revisão, descreveu com detalhes como é o mecanismo de afrouxamento dos parafusos, o que, para ele, ocorre em duas etapas. Inicialmente, forças externas aplicadas a uma união parafusada, como durante a mastigação, levam a uma efetiva erosão da pré-carga na união. 0 
parafuso, nessa situação, funcionaria como uma mola, esticado pela pré-carga na qual esse estiramento é mantido por forças de fricção de suas roscas. Qualquer força externa, seja ela axial ou transversal, causa uma pequena quantidade de deslizamento entre as roscas, sem problemas quando pequeno, liberando uma pequena quantidade de pré-carga. Nesse momento, quanto maior a pré-carga na união, maior será a resistência ao afrouxamento devido a força de fricção entre as roscas ser maior e uma maior força externa ser requerida para causar o deslize dessas roscas. Num segundo estágio do afrouxamento, a pré-carga está abaixo de um valor crítico, o que deixa a união entre as roscas menos intensa. Uma vez atingido esse estágio, a união parafusada torna-se mais susceptível à abertura e, consequentemente, a falhas. Outro fator importante, relacionado ao fato da seleção de um adequado nível de apertamento, está relacionado à fadiga do parafuso. Se um parafuso é apertado até se obter uma união firme, ou seja, significando que todas as regiões da união estão em contato, todas as cargas provenientes do meio externo de certa forma atuaram para separar essa união. Entretanto, como o torque de apertamento é aumentado acima do nível de adaptação das partes, a pré-carga aumenta e o parafuso ou ambos os componentes irão gradualmente receber proteção adicional contra as cargas externas. Essa proteção é um beneficio adicional contra a fadiga do parafuso até o ponto em que o total de carga recebida pelo parafuso (pré-carga mais as cargas recebidas do meio externo) seja aproximadamente igual à resistência do parafuso. Quando o nível de carga é excedido, a resistência à fadiga do parafuso diminui drasticamente. Assim, idealmente, quando se aperta uma união parafusada, objetiva-se uma ótima pré-carga que maximize o tempo de fadiga do parafuso e que ofereça razoáveis graus de proteção contra o afrouxamento. Para os autores, o relacionamento entre a pré-carga e o torque no parafuso depende do coeficiente de fricção entre as roscas, da geometria delas e das propriedades dos materiais envolvidos, sendo que o coeficiente de fricção também é dependente da dureza das roscas, do polimento superficial, das propriedades e qualidades de um eventual agente lubrificante e da velocidade de apertamento. O coeficiente de fricção aumenta conforme a dureza do material e a rugosidade superficial. Já o desenho dos sistemas de implante têm pouca influência sobre a lubrificação ou velocidade de apertamento dos parafusos, apenas sobre sua 
dureza. Assim, para manter uma velocidade de apertamento dentro dos limites, os autores aconselham o uso de um controlador de torque eletrônico. Ainda, segundo os autores, existem 3 métodos para se apertar um parafuso: usando um torquímetro, usando um medidor de ângulo, onde se observa a deformação angular necessária do parafuso para seu apertamento, ou usando um torquímetro associado a um medidor de ângulo, o que tornaria a aplicação de torque mais precisa. Infelizmente, até então, apenas o primeiro é utilizado para o aperto dos parafusos das próteses sobre implantes. Na prática, isso seria bastante relevante para quando não tivermos uma adaptação totalmente passiva entre os componentes. Para os autores, se não temos um completo assentamento dos componentes, um torquímetro durante o aperto não será capaz de identificar o problema. Entretanto, se trabalharmos conjuntamente com um medidor de ângulo, podemos ser capazes de identificar tal problema já que será necessário uma maior quantidade de rotação do parafuso para fazer com que a estrutura se torne totalmente assentada, deixando claro que aquele medidor servirá, também, como um elemento de diagnóstico da adaptação. Assim, é sugerido pelos autores o desenvolvimento de um dispositivo capaz de transmitir adequado torque aos parafusos, avaliando a quantidade de graus necessária para o apertamento dos mesmos.

HAACK et al. ${ }^{29}, 1995$ realizaram um estudo onde desenvolveram um método de avaliar os estresses em parafusos de abutments tipo UCLA, usando medidas de alongamento e determinando o máximo torque de apertamento sem causar deformação plástica nos mesmos. Medidas do comprimento dos parafusos foram feitas a partir da exposição de metade de sua cabeça no abutment e das 3 últimas roscas mais apicais no implante. Abutments UCLA de ouro com hexágono anti-rotacional foram então assentados sobre os implantes, usando parafusos para abutmens UCLA de ouro e de titânio, sendo o torque aplicado por meio de um torquímetro digital e as medidas de alongamento do parafuso realizadas através de um micrômetro. Os parafusos de ouro foram medidos antes e após o torque de $5 \mathrm{Ncm}$ e a cada incremento de $2 \mathrm{Ncm}$ de torque a partir de $10 \mathrm{Ncm}$ até $32 \mathrm{Ncm}$. Similarmente, os parafusos de titânio foram medidos antes e após aplicação do torque de 4Ncm e a cada incremento de $2 \mathrm{Ncm}$ de torque a partir de $8 \mathrm{Ncm}$ até $20 \mathrm{Ncm}$. O valor de destorque foi medido apenas após o torque máximo de $32 \mathrm{Ncm}$ e $20 \mathrm{Ncm}$ para os parafusos 
de ouro e titânio, respectivamente, sendo esse procedimento realizado 5 vezes para cada parafuso sobre o mesmo implante. Os resultados mostraram que as maiores medidas de alongamento ocorreram no momento em que maior quantidade de torque foi aplicada. Quanto aos valores de destoque, nas 5 repetições do experimento não houve diferença estatisticamente significante em nenhum momento para o parafuso de ouro. Entretanto, entre os ensaios $1 \mathrm{e}$ 2, para o parafuso de titânio, houve diferença estatisticamente significante. As medidas de alongamento dos parafusos foram convertidas em estresses gerados sobre os mesmos. Os estresses calculados para os parafusos de ouro e titânio em relação ao torque máximo recomendado para apertamento foram menores que $60 \%$ da sua resistência de escoamento e, com base nas análises estatísticas, os autores afirmam que os parafusos podem sem apertados com um torque além daquele recomendado pelo fabricante, sem o risco de deformação plástica permanente. Os autores ainda salientam que a força de apreensão entre abutment/implante vai sendo gradativamente diminuída à medida que cargas axiais compressivas excedem a força de apreensão, fazendo com que, gradativamente, se tenha uma erosão da pré-carga. Os autores concluíram que o alongamento dos parafusos ocorreu dentro de sua variação elástica, e que os mesmos podem ser apertados com torques ligeiramente acima dos recomendados pelos fabricantes a fim de se evitar o afrouxamento. Contudo, as forças mastigatórias em demasia podem exceder as forças de apreensão entre os componentes, o que pode levar os mesmos a afrouxarem.

JAARDA; RAZZOOG; GRATTON ${ }^{34}$, 1995 fizeram uma comparação morfológica de cinco parafusos de retenção de próteses considerados intercambiáveis entre si, onde os parafusos, a priori, apresentavam características macroscópicas semelhantes e chegaram a dados bastante interessantes. Embora se trate de parafusos para retenção de próteses, algumas extrapolações puderam ser feitas para outros tipos de parafusos, tomando-se como base suas características morfológicas. Os parafusos foram avaliados por meio de MEV (Microscopia Eletrônica de Varredura) e comparados frente nos seguintes aspectos: (A) diâmetro da "cabeça", (B) comprimento do parafuso, pico das roscas (C), diâmetro externo das roscas (D), diâmetro do "pescoço" (E), comprimento do "pescoço" (F), largura da crista 
da rosca $(G)$ e largura do intervalo entre as roscas $(H)$. Os resultados das análises revelaram diferenças estatisticamente significante entre todos os parafusos, exceto nos parâmetros C e G. Com relação às diferenças encontradas em relação às características morfológicas e suas conseqüências, podemos citar os seguintes aspectos: Quanto ao diâmetro da "cabeça" dos parafusos, quando esta é excessiva, poderá resultar em um maior contado dela com a porção interna do cilindro protético, o que resultaria em maior atrito e conseqüente perda da pré-carga gerada com o aperto do mesmo. Quanto ao comprimento dos parafusos, este também influenciará diretamente na quantidade de área contactante entre as estruturas, o que resultará em menor pré-carga. Parafusos mais curtos e submetidos ao mesmo torque de apertamento resultaram em maior alongamento do corpo do parafuso, principalmente se o mesmo apresentar um "pescoço" mais longo, diminuindo a área de contato entre os componentes. Além disso, as variações no comprimento do "pescoço", assim como sua largura, segundo os autores, influenciam diretamente na resistência máxima à tensão dos mesmos, influenciando as transmissões de carga para o complexo implante/próteses. Com base nesses resultados, pode-se concluir que o intercâmbio de componentes entre marcas ditas compatíveis entre si pode introduzir variáveis desconhecidas no tratamento dos nossos pacientes. Embasados nos princípios de engenharia, a respeito do desenho dos parafusos e sua relação com o torque empregado para o apertamento dos mesmos, os autores contestam que os valores de torque fornecidos por um fabricante sejam usados como valor padrão para todos os outros, devido às características individuais de cada sistema.

SAKAGUCHI; BORGERSEN ${ }^{57}, 1995$ realizaram um trabalho que analisou, por meio de elemento finito, o mecanismo de transferência de cargas entre os componentes protéticos de uma prótese sobre implante, causado pela aplicação do torque de apertamento sobre os parafusos que compunham a união parafusada. O modelo de elemento finito utilizado baseou-se nos componentes da empresa 3 I (Implant Innovation Inc), sendo adotado como módulo de elasticidade os valores de 99.3 GPa para componentes de liga de ouro e 110 GPa para o titânio comercialmente puro. A simulação utilizou torques de $20 \mathrm{Ncm}$ e $10 \mathrm{Ncm}$ para o parafuso de titânio do abutment e o 
parafuso de retenção de ouro da coroa respectivamente. Os resultados mostraram o seguinte comportamento da união parafusada: o torque de apertamento do parafuso do abutment criou uma força de apreensão entre o abutment e o implante. Quando o parafuso de retenção foi apertado contra o cilindro de ouro, essa força de apreensão citada anteriormente aumentou de 188.3N para $226.4 \mathrm{~N}$, seguindo o longo eixo dos componentes. Então, a força de apreensão gerada pelo apertamento do parafuso de ouro foi adicionada à força de união entre o abutment e o implante, resultado do apertamento do parafuso do abutment. Porém, o aumento dessa força de união entre os componentes ocorreu graças à uma diminuição da força de união entre o parafuso do abutment (base da sua cabeça) e o próprio abutment (superfície interna deste onde ocorre o assentamento da cabeça de seu respectivo parafuso). Esse efeito produziu uma diminuição de $49.8 \%$ do total da força de união que ocorria nessa interface devido a uma tensão introduzida na cabeça do parafuso do abutment, no momento em que as roscas do parafuso de retenção eram introduzidas aí, gerando o apertamento do mesmo. Segundo os autores, se o aspecto externo dos componentes protéticos for considerado como um corpo único, pode-se dizer que a resistência compressiva e as cargas aumentam quando os dois parafusos são apertados. No entanto, a força de união interna entre o parafuso do abutment e o próprio abutment é reduzida quando o parafuso de retenção de ouro é torqueado. Além disso, os resultados dessa análise em elemento finito indicaram, também, que ocorre uma diminuição no diâmetro da região entre a "cabeça" do parafuso do abutment e suas roscas devido ao "escoamento" do material. Já no parafuso de retenção da prótese, altas concentrações de estresses foram também encontradas no seu "pescoço", entre sua "cabeça" e suas roscas. Embora para os autores o torque de apertamento do parafuso possa ser ligeiramente aumentado, além do recomendado pelo fabricante, esse aumento deve ocorrer dentro de seu limite elástico. Para isso seria interessante uma análise associada à performance mastigatória, visto que forças provenientes da mesma por si só aumentam a incidência de cargas na união parafusada e, conseqüentemente, colocam os parafusos sob maior tensão.

BINON $^{8}, 1996$ desenvolveu um estudo para determinar a influência da liberdade rotacional entre o hexágono interno do intermediário e o hexágono 
externo do implante no que diz respeito à estabilidade do parafuso dessa conexão. Para isso, uma série de abutments com dimensão crescente de seu hexágono interno foram submetidos à carga de $133 \mathrm{~N}$ e a uma freqüência de 1150 ciclos por minuto e 28 rotações por minuto em sentido anti-horário da ponta que realizava a aplicação da carga, até a falha da conexão, a qual foi determinada pelo afrouxamento do parafuso. Para o estudo foram confeccionados 50 abutments tipo UCLA, em forma cônica, com $8 \mathrm{~mm}$ de altura e 8mm de diâmetro na sua porção mais superior. Cinco grupos de 10 intermediários foram confeccionados com a medida do hexágono interno com variações crescentes. A liberdade rotacional de cada grupo foi verificada antes da aplicação de carga. Após análise da liberdade rotacional, os intermediários foram parafusados com parafuso de titânio grau 3, a um torque de $30 \mathrm{Ncm}$, utilizando um torquímetro. As amostras foram então fixadas na máquina de ensaios especialmente desenvolvida para este teste e submetidas à carga cíclica até a falha da conexão. Os resultados mostraram que existe uma correlação direta entre a liberdade rotacional e o afrouxamento do parafuso. Quanto menor a liberdade rotacional, mais resistente é a conexão e menor é a probabilidade de afrouxamento dos parafusos. Os grupos com desajuste rotacional inferior a dois graus apresentaram uma maior resistência ao afrouxamento (média de 6,7 milhões de ciclos), cerca de 26\% maior que a resistência apresentada pelos grupos com desajuste rotacional superior a $2^{\circ}$. Além disso, os sete grupos com liberdade rotacional maior que $5^{\circ}$ apresentaram um comportamento semelhante, com a falha dos parafusos ocorrendo entre 2,5 e 1,1 milhões de ciclos, ou seja, uma redução de 63\% quando comparado ao grupo com menor liberdade rotacional. O autor concluiu que a presença do hexágono aumenta significativamente a resistência ao afrouxamento dos parafusos e que a eliminação da liberdade rotacional resultou em uma conexão mais rígida e mais resistente ao afrouxamento.

CARR; BRUNSKI; HURLEY ${ }^{18}, 1996$ realizam um estudo que revisou conceitos fundamentais até a presente data, relacionados aos procedimentos de obtenção, acabamento e polimento de abutments protéticos de próteses sobre implantes, observando a geração de pré-carga, por meio de straingauge, durante o procedimento de apertamento dos parafusos protéticos, variando o tipo de abutment (de ouro pré-fabricado, com cinta em ouro a ser 
sobrefundido e cilindros calcináveis de plástico). Os resultados mostraram que a pré-carga, na interface cilindro/abutment, pode ser afetada pelos procedimentos de fundição, pela escolha do tipo de cilindro, pelo tipo de revestimento, acabamento e polimento desse cilindro. Significantes valores de pré-carga maiores foram obtidos pelos abutments pré-fabricados quando comparados aos produzidos por padrões plásticos. Avaliando apenas os padrões plásticos, os resultados revelam que maiores valores de pré-carga ocorreram com os abutments obtidos a partir do uso de uma liga de baixa fusão comparados a uma de alta fusão, embora o uso de diferentes tipos de revestimentos não tenha causado diferença neste grupo. Os dados obtidos ainda indicam que quando abutments plásticos são usados como parte da infra-estrutura protética, o acabamento e polimento dos mesmos promovem um aumento na pré-carga comparado com a ausência desses procedimentos. Abutments pré-fabricados também exibiram diferentes valores de pré-cargas entre diferentes fabricantes. Os autores sugerem que quando máxima précarga é desejada, o uso de abutments metálicos pré-fabricados oferece vantagens quando comparados a abutments plásticos, principalmente quanto à magnitude de pré-carga obtida e precisão de adaptação.

Como forma de diminuir, ou mesmo evitar a ocorrência do afrouxamento dos parafusos que compõem as próteses sobre implantes, KORIOTH; CARDOSO; VERSLUIS ${ }^{41}, 1999$ propuseram um estudo com o objetivo de testar a hipótese de que a introdução de uma ruela entre a cabeça do parafuso e sua base de assentamento, no interior do abutment, aumentaria o deslocamento axial necessário para o completo afrouxamento do parafuso protético de uma prótese sobre implante. Para isso, dois implantes de plataforma regular foram montados em um bloco de resina, separados a uma distância mésio-distal equivalente a um pré-molar. Dois abutments tipo standard foram então conectados a esses implantes por meio de seu parafuso e apertados a $20 \mathrm{Ncm}$. Uma estrutura semelhante a uma prótese fixa posterior de 3 elementos foi então encerada e fundida. Após fundição verificou-se a ausência de irregularidades que prejudicassem o assentamento do parafuso protético, por meio de análise visual e táctil. Quatro ensaios diferentes foram realizados com a presença da ruela que consistiam de pequenas lâminas metálicas de espessura aproximada de $0,2 \mathrm{~mm}$ : ruelas colocadas bilateralmente 
em ambos os implantes (A), unilateralmente sendo ou no implante mesial (B) ou no distal (C), ou não colocada em nenhum dos implantes (D). O torque dos parafusos protéticos seguiu recomendação do fabricante e foi de $10 \mathrm{Ncm}$. Os resultados mostraram que houve um significante aumento no deslocamento axial dos parafusos para promover o afrouxamento dos mesmos quando as ruelas estavam presentes, já que foi necessário girá-los aproximadamente $30 \%$ - 35\% mais, antes de tornar os parafusos frouxos. Essas diferenças foram notadas principalmente nos ensaios (B) e (C) onde a discrepância se acentuou entre os implantes. Embora tenha sido estatisticamente significante entre os ensaios (A) e (D), não houve diferença estatisticamente significante entre os implantes mesial ou distal. Os autores concluíram que a introdução de uma ruela entre a cabeça do parafuso de ouro e sua base de assentamento pode deter o afrouxamento do parafuso devido à necessidade do mesmo girar mais para apresentar-se frouxo.

Uma avaliação sobre a estabilidade da interface em implantes com conexão com hexágono externo foi discutida por BINON ${ }^{10}, 2000$. O conceito de uma conexão parafusada foi apresentado em relação ao torque e à pré-carga aos fatores que afetam a estabilidade da conexão: rugosidade de superfície, acomodação das superfícies de contato, interação elástica, fricção, temperatura, fluidos corrosivos, dobramento, desadaptação, falta de alinhamento entre os componentes, vibração, cargas cíclicas, fadiga, desenho dos parafusos, proteção dos parafusos e compatibilidade dos parafusos. Segundo o autor, em relação ao torque, apenas cerca de 10\% dele é usado para manter a estabilidade da conexão, sendo o restante perdido pela fricção e por qualquer componente que possa impedir o adequado assentamento entre os componentes como desajustes e falta de alinhamento. As condições das superfícies de contato têm influência direta e significante na estabilidade da conexão. O processo conhecido como relaxamento ou acomodação das superfícies embedement relaxation ocorre devido à presença de microirregularidades causando uma acomodação entre as superfícies de contato. Após a aplicação do torque, a compressão gerada começa a aplainar as microirregularidades, causando uma acomodação entre as superfícies de contato o que diminui a distância entre elas. Com isso diminui-se a tensão no parafuso e, conseqüentemente, a pré-carga. O relaxamento é dependente do 
tempo, do material e das rugosidades das superfícies. O autor ainda dá sua opinião sobre o que se constitui um parafuso frouxo: "Qualquer parafuso que requer um quarto de volta ou mais pra atingir a sua pré-carga ideal, embora a prótese ou o intermediário possam não apresentar mobilidade detectável clinicamente". O autor recomenda, também, que se verifique os parafusos a cada 12 ou 18 meses para se restabelecer a pré-carga ideal tentando-se, assim, evitar problemas mecânicos relacionados aos componentes.

MARTIN et al. ${ }^{46}, 2001$ realizam um estudo com o objetivo de avaliar o material e o tipo de superfície de 4 parafusos de abutment comercialmente disponíveis, quanto ao ângulo de rotação para o apertamento e à quantidade de pré-carga gerada. Foram então avaliados os seguintes parafusos: Gold-Tite (3I), parafuso com superfície de ouro e paládio alterada pela adição de um lubrificante sólido; Torq-tite (Nobelbiocare), com superfície tratada através de um processo especial para redução da fricção; parafuso de ouro (3I) e parafuso de titânio (3I). Vinte parafusos de cada tipo foram utilizados e, de forma randomizada, divididos em dois grupos com 10 de cada, sendo um grupo o dos parafusos que receberiam torque de aperto de $20 \mathrm{Ncm}$ e outro recebendo $32 \mathrm{Ncm}$. Para cada parafuso testado foi utilizado um implante de $3,75 \times 15 \mathrm{~mm}(3 \mathrm{I})$ incluído em um bloco de resina e um pilar de titânio convencional para a análise da rotação do parafuso e da pré-carga. A amostra era posicionada num aparelho de medidas angulares e com um torquímetro eletrônico digital aplicava-se um torque inicial de $5 \mathrm{Ncm}$. Após a aplicação desse pré-torque, a posição inicial do parafuso era registrada como zero. O torque desejado, de acordo com o grupo da amostra, era então aplicado, sendo registrado o grau de rotação do parafuso. Aguardava-se um período de 5 minutos e novamente um torque no valor desejado era aplicado e, o ângulo novamente registrado. Após esses consecutivos apertos, era realizado o desparafusamento do parafuso por meio de um destorque, e o pico do valor obtido era então registrado. Essas mensurações eram, então, repetidas por mais 4 vezes a fim de que fossem registradas eventuais variações nos graus de rotação dos parafusos, depois de 5 repetidos ciclos de torque e destorque, e possibilitar também o cálculo da pré-carga. Os resultados mostraram que, para o torque de $20 \mathrm{Ncm}$, a maior rotação foi apresentada pelos parafusos Torq-tite $\left(19,3^{\circ}\right)$, seguidos pelos Gold-tite $\left(14,9^{\circ}\right)$, de ouro $\left(9,8^{\circ}\right)$ e titânio $\left(9,8^{\circ}\right)$, sendo que a 
diferença entre os parafusos de titânio e ouro e Gold-tite foi estatisticamente significante. Também foi estatisticamente significante a diferença entre os parafusos Torq-tite e Gold-tite. Para o torque de 32Ncm, o grupo Torq-tite apresentou novamente o maior grau de rotação $\left(31,3^{\circ}\right)$, seguidos pelos Goldtite $\left(20,4^{\circ}\right)$, de ouro $\left(16,5^{\circ}\right)$ e titânio $\left(14,9^{\circ}\right)$. Todos os grupos mostraram-se estatisticamente diferentes entre si. Além disso, é importante citar que, com exceção do grupo composto dos parafusos de titânio apertado a $20 \mathrm{Ncm}$, todos os grupos mostraram maior rotação nos parafusos durante o primeiro aperto. $\mathrm{Na}$ avaliação da pré-carga gerada, para o grupo de $20 \mathrm{Ncm}$, esta foi obtida para os parafusos Gold-tite $(521,7 \mathrm{~N}$ a $596,8 \mathrm{~N})$, seguido pelos parafusos Torq-tite $(355,9 \mathrm{~N}$ a $470,2 \mathrm{~N})$, ouro $(430,8 \mathrm{~N}$ a $127,1 \mathrm{~N})$ e titânio $(347,8 \mathrm{~N}$ a $478,3 \mathrm{~N})$, não havendo diferença entre os parafusos Gold-tite e ouro. Para o grupo de 32Ncm, a maior pré-carga foi obtida para os parafusos Gold-tite $(928,4 \mathrm{~N}$ a $1010,3 \mathrm{~N})$, seguido pelos parafusos Torq-tite $(723,0 \mathrm{~N}$ a $877,1 \mathrm{~N})$, ouro $(573,0 \mathrm{~N}$ a $833,8 \mathrm{~N})$ e titânio $(434,8 \mathrm{~N}$ a $636,1 \mathrm{~N})$, havendo diferença entre os parafusos Gold-tite e demais tipos e, entre os parafusos Torq-tite e ouro em relação aos de titânio. Não houve diferença significante no grau de rotação e pré-carga tanto para $20 \mathrm{Ncm}$ como para $32 \mathrm{Ncm}$ entre as cinco medidas repetidas realizadas. Já uma análise em microscopia eletrônica de varredura (MEV) das superfícies dos parafusos, em um aumento de 17 a 80 vezes, não mostrou diferença visual entre os torques de $20 \mathrm{Ncm}$ e $32 \mathrm{Ncm}$. Todas as amostras analisadas demonstraram um mesmo padrão de contato entre as roscas, predominando o contato entre a superfície superior das roscas do parafuso e as roscas do implante na porção média das roscas contactantes. Os autores concluíram que os tratamentos superficiais dos parafusos foram capazes de reduzir a fricção, levando a valores de pré-carga maiores; no entanto, ressaltam que esses valores deveriam ser investigados sob carga cíclica.

Com o objetivo de avaliar a influência do operador na introdução de torque de aperto e afrouxamento dos parafusos, PESUN et al. ${ }^{52}, 2001$ realizaram um trabalho no qual avaliaram e compararam a quantidade de força compressiva que era introduzida durante o apertamento e o afrouxamento dos parafusos de retenção da coroa protética, entre operadores (dentistas) com diferentes graus de experiência clínica. Um implante de plataforma regular e $8 \mathrm{~mm}$ de comprimento foi fixado em um bloco de resina acrílica, recebendo 
sobre sua cabeça um abutment tipo standard fixado com torque de $20 \mathrm{Ncm}$. Uma coroa unitária metálica foi então adaptada ao abutment e nele fixada por meio de um parafuso de ouro, recebendo torque de $10 \mathrm{Ncm}$. 3 grupos de operadores (5 anos de experiência - 4 operadores, 2 anos de experiência - 4 operadores e nenhuma experiência - 6 operadores com próteses sobre implantes) realizaram repetidos torque de apertamento e afrouxamento em um novo parafuso de ouro no interior do abutment. A magnitude e duração da força axial compressiva, durante apertamento e afrouxamento dos parafusos, foram mensuradas por uma miniatura de célula de carga, adaptada a um torquímetro elétrico. Cada operador repetiu o procedimento de apertar e afrouxar os parafusos por 3 vezes, totalizando 42 análises a serem comparadas. Com base nos resultados, os autores puderam concluir que a quantidade de força aplicada durante o torque de aperto e o torque de afrouxamento dos parafusos foi mais consistente entre os operadores mais experientes (5 anos) e menos consistente entre aqueles que não tinham nenhuma experiência. Além disso, maior força axial compressiva foi aplicada durante o afrouxamento dos parafusos e não durante seu apertamento, o que os levaram a concluir que a força axial compressiva remove alguma quantidade de pré-carga, resultando em menor quantidade de torque requerido para remover o parafuso de ouro. Segundo eles, isso pode explicar porque os estudos de torque de remoção têm mostrado menores valores de torque durante a remoção do parafuso, comparado com o momento de aperto dos mesmos.

SAHIN; CEHRELI ${ }^{56}, 2001$ apresentaram uma revisão a respeito da significância clínica da adaptação passiva e dos fatores que influenciam essa adaptação. Tal adaptação passiva é definida pelos autores como uma situação onde a estrutura protética não induz qualquer tensão sobre os implantes e seus componentes, assim como na estrutura óssea ao redor daqueles. Embora se assuma que a adaptação passiva seja um dos pré-requisitos mais importantes para manutenção da osseointegração, faltam estudos longitudinais clínicos que suportem essa afirmação, assim como aqueles que mostrem como obtermos uma adaptação totalmente passiva nessas próteses. Falhas mecânicas no sistema de próteses sobre implantes têm sido relacionadas à falta de adaptação das próteses, tais como afrouxamento e/ou fratura do parafuso de fixação (ouro) e do abutment, dos cilindros protéticos e das estruturas em si. 
Dessa forma, a avaliação clínica da adaptação da peça deve ser realizada minuciosamente, a fim de se evitem esses tipos de falhas, aceitando o mínimo de desadaptação possível ou uma adaptação não detectável clinicamente, já que para isso seria requerido um grande tempo clínico associado ao uso de dispositivos de tecnologia como os strain-gauges. Embora a secção e solda da infra-estrutura não resulte em uma peça absolutamente passiva, adotando esse tipo de procedimento como rotina obtém-se uma redução geral nos estresses aplicados aos componentes e parafusos, diminuindo sua freqüência de afrouxamento. Os autores ressaltam que todos os procedimentos protéticos influenciam a adaptação final da peça, desde os componentes utilizados, materiais empregados e técnicas escolhidas.

SIAMOS; WINKLER; BOBERICK ${ }^{60}, 2002$ realizaram um estudo com o propósito de determinar se a variação da pré-carga no complexo implantelabutment poderia facilitar o afrouxamento do parafuso do abutment simulando condição de carga. Para isso, um implante de plataforma regular e $13 \mathrm{~mm}$ de comprimento foi montado em um bloco de resina, e um abutment foi parafusado em sua cabeça, primeiramente por um aperto bi-digital e posteriormente pela ação de um torquímetro. 40 corpos de prova foram avaliados e divididos em 3 grupos experimentais que continham 4 sub-grupos (torque de 25, 30, 35 e $40 \mathrm{Ncm}$ ). Os grupos (G) eram: $\mathrm{GI}$ - 2 corpos de prova por subgrupo receberam o torque recomendado, aguardaram-se 3 horas e realizou-se o destorque; GII -2 corpos de prova por subgrupo receberam o torque recomendado, 10 minutos foram aguardados, aplicou-se outro torque de igual valor; aguaram-se 3 horas e realizou-se o destorque; GIII - 6 corpos de prova por subgrupo receberam o torque recomendado, aguardaram-se 10 minutos, aplicou-se outro torque de igual valor, e por um período de 3 horas os corpos de prova foram submetidos à carga cíclica. Em seguida, foi realizado o destorque. Os resultados demonstraram que em todos os grupos o torque necessário para a remoção dos parafusos (destorque) foi sempre inferior ao torque aplicado inicialmente. Entretanto, os parafusos que receberam um segundo torque de igual valor, 10 minutos após o primeiro torque, apresentaram maior resistência ao destorque, o que faz os autores sugerirem que este procedimento deve ser tomado como rotina na conduta clínica. Os parafusos apertados acima do limite recomendado pelo fabricante (30Ncm) 
também apresentaram maior resistência ao destorque. Assim, os autores sugerem que os parafusos possam ser apertados com valores de torque ligeiramente acima daqueles recomendados.

$\mathrm{CHO}$ et al. ${ }^{20}, 2004$ realizaram um estudo clínico prospectivo, onde compararam a freqüência de afrouxamento de parafusos em implantes de diâmetro regular (3.75 e 4.0mm) e implantes com plataforma larga (5.0 e 6.0mm), avaliando também se o uso ou não de torquímetro durante 0 apertamento pode prevenir ou minimizar a recorrência desse afrouxamento. Foram feitas as seguintes comparações no estudo em relação à problemática do afrouxamento dos parafusos: implantes de plataforma regular com implantes plataforma larga, implantes localizados na região posterior com implantes realizados na região anterior, coroas unitárias com próteses parciais, abutments cônicos com abutment tipo UCLA. Todos os parafusos foram apertados com pressão digital, no dia da instalação das próteses, sendo a proposta de utilizar um torquímetro apenas para os parafusos que retornassem frouxos nos controles a serem realizados nos períodos de 3, 6, 12, 24, 36, 48 e 60 meses. Os resultados mostraram que, dos 213 implantes instalados, 24 parafusos (11.7\%) apresentaram-se frouxos, numa média de 3.2 anos após a instalação das próteses. Implantes de plataforma larga mostraram 5.8\% de afrouxamento dos parafusos (4/68), enquanto os de plataforma regular mostraram 14.5\% (21/145). Implantes na região anterior mostraram 7.7\% (2/26) enquanto que os posteriores mostraram 12.3\% (23/187). Reposições de elementos unitários mostraram 10.3\% (4/39), enquanto as próteses parciais mostraram 12.1\% (21/174). Finalmente, as próteses confeccionadas sobre abutments cônicos mostraram $12.6 \%$ de afrouxamento (8/63), enquanto aquelas sobre abutments tipo UCLA mostraram 11.3\% (17/150). Os parafusos identificados como frouxos foram, então, novamente apertados com torquímetro, com torques de 10 e $20 \mathrm{Ncm}$, segundo recomendação do fabricante dos componentes (3I). Nenhuma recorrência de afrouxamento ocorreu entre o período de 3 e 5 anos. Segundo os autores, baseados nos resultados obtidos, fica evidente que implantes de plataforma larga apresentam menor incidência de afrouxamento, assim como o uso de torquímetro minimiza os riscos dessa ocorrência. São sugeridas por eles, como fatores minimizadores do afrouxamento, algumas recomendações clínicas, tais como 
instalação do implante perpendicular ao plano oclusal, infra-estruturas com a mínima extensão de cantilever, componentes com baixa tolerância a desadaptações e uso de componentes com dispositivo anti-rotacional para próteses unitárias.

A fim de avaliar a perda da pré-carga em decorridos períodos de tempo, CANTWELL; HOBKIRK ${ }^{16}$, 2004 avaliaram a hipótese de que um sistema de implantes unitários apresenta perda dessa pré-carga mesmo com o aperto adequado do parafuso de ouro e sem a presença de cargas externas. Para a análise, um implante de plataforma regular e 10mm de comprimento, tipo hexágono externo, foi montado em um bloco de resina, e um intermediário do tipo standard de $7 \mathrm{~mm}$ foi conectado a esse implante por um parafuso a um torque de $20 \mathrm{Ncm}$. Conectado ao pilar havia 3 strain-gauges colocados em sua superfície externa e paralelos ao longo eixo do implante, os quais foram utilizados para medir a pré-carga gerada durante o aperto. Cinco conjuntos de parafusos de ouro e cilindros de ouro foram testados. Os parafusos foram apertados a um torque médio de $12,06 \mathrm{Ncm}$, com um torquímetro eletrônico, e a pré-carga foi então monitorada desde o primeiro segundo após o aperto até um período de 15 horas. A pré-carga média produzida foi de $319,6 \mathrm{~N} \pm 88 \mathrm{~N}$. Foi observada uma perda da pré-carga em todos os testes, sendo que a maior redução ocorreu dentro dos primeiros 2 segundos. Após 15 horas, ainda se observou uma perda gradual da pré-carga. A perda média dentro de 15 horas foi de $24,9 \% \pm 8,28 \%$, sendo que cerca de $40,2 \%$ dessa perda foi verificada dentro dos primeiros 10 segundos após o aperto. Os resultados das análises em MEV mostraram que as primeiras roscas do parafuso, roscas estas que exercem maior contato durante o apertamento, apresentavam sinais de rugosidade e brunidura. Com base nos resultados, fica claro que a pré-carga gerada a partir dos parafusos protéticos de ouro sob condições padronizadas é variável, e que, embora ela ocorra por até 15 horas, é nos primeiros 10 segundos que maior parte dela é perdida. O fenômeno conhecido como embedment relaxation e as deformações plásticas que ocorrem com os parafusos são apontadas pelos autores como as mais prováveis causas da perda de pré-carga.

KIM et al. ${ }^{40}, 2005$ realizaram um estudo com o objetivo de quantificar o afrouxamento de parafusos de abutments, mediante variação na superfície 
de contato entre o implante e o abutment. Para isso utilizaram 20 implantes de hexágono externo, sendo que 10 deles tiveram sua superfície, que entra em contato com o abutment, revestida com um lubrificante de superfície sólido (DLC -Diamond Like Carbon) o qual se refere a uma camada de diamante cristalizada, cujo objetivo é aumentar a dureza e a resistência ao desgaste das superfícies que recobre, como o titânio, além de diminuir o coeficiente de fricção entre superfícies contactantes. Além disso, foram utilizados 20 abutments tipo UCLA de titânio, confeccionados para serem submetidos a cargas cíclicas e 20 parafusos para esses respectivos pilares. Os abutments foram montados sobre os implantes e os parafusos apertados com um torque de $30 \mathrm{Ncm}$, conforme recomendação do fabricante. O conjunto então foi submetido a procedimento de carga cíclica, recebendo uma força vertical de $100 \mathrm{~N}$, a uma freqüência de $20 \mathrm{~Hz}$, até o momento em que o parafuso afrouxasse e uma fenda de $0.7 \mathrm{~mm}$ fosse criada. Após esse procedimento, os espécimes foram avaliados por MEV. Os resultados mostraram uma significante diferença na quantidade de ciclos necessários para promover o afrouxamento dos parafusos, comparando os implantes com interface tratada e não tratada $(P=0.002)$, indicando que os implantes que apresentavam superfícies tratadas com $D L C$ foram mais resistentes à aplicação de força que as superfícies não tratadas. Os dados da análise em MEV mostraram que a superfície de titânio dos implantes, não tratadas, apresentaram-se mais rugosas e menos resistentes ao desgaste, antes e após o procedimento de carga cíclica, sendo sugerido pelos autores o uso desse tipo de cobertura a fim de se evitar o afrouxamento dos parafusos.

Em mais um trabalho, cujo objetivo foi analisar a estabilidade da união parafusada de implante/abutment/parafuso, YOUSEF et al. ${ }^{67}$, 2005, propuseram-se a entender os parâmetros relacionados ao afrouxamento dos parafusos em um modelo in-vitro, incluindo análises da perda de torque, rotação da cabeça do parafuso, mudanças em suas dimensões e distorções na união com o implante. Para isso, implantes de plataforma regular e $10 \mathrm{~mm}$ de comprimento foram fixados em blocos de resina. Os implantes receberam 3 tipos de abutments diferentes, sendo 7 de cada tipo: Ceraone (Nobel Biocare) e seu respectivo parafuso de ouro, STA (3I) e seu respectivo parafuso de paládio e um abutment pré-fabricado (Bio-lock) com seu respectivo parafuso de titânio. 
Tais parafusos receberam torque segundo recomendação do fabricante, e coroas padronizadas foram então cimentadas sobre os mesmos para posterior simulação de carga cíclica com carga de $300 \mathrm{~N}$ e 50.000 ciclos. Verificações nos graus de torque foram feitas a 10.000, 25.000 e 50.000 ciclos e, ao final, a rotação no sentido anti-horário do parafuso foi medida. Os parafusos foram removidos e medidas foram realizadas para comparação com parafusos controles. Uma amostra de cada grupo foi também seccionada longitudinalmente e avaliada por MEV. Os resultados mostraram que o sistema Nobel Biocare apresentou uma perda de torque média de $9,4 \mathrm{Ncm}$, sendo tal acontecimento acompanhado por uma rotação média no sentido anti-horário do parafuso de $7^{\circ}$ e um alongamento médio de $200 \mu \mathrm{m}$. Além disso houve distorção da união parafusada, observada pela análise em MEV. Nos outro 2 grupos não foi observada nenhuma perda de torque, rotação no sentido antihorário ou mesmo alongamento dos parafusos. Adaptação íntima da união parafusada, sem distorções, foi constatada nas secções longitudinais. Com base nos resultados, os autores puderam concluir que o afrouxamento dos parafusos parece seguir parâmetros específicos que incluem rotação no sentido anti-horário, alongamento e deformações da união parafusada. Esse processo, provavelmente está associado tanto às propriedades físicas do parafuso quanto a sua configuração. Além disso, os autores enfatizam que, em uniões parafusadas estáveis, os parafusos jamais devam ser substituídos, sendo essa possibilidade apenas considerada em uniões instáveis e que demonstrem problemas crônicos de afrouxamento, já que mudanças entre os componentes irão requerer uma completa readaptação de todas as outras partes envolvidas no sistema.

KANO et al. ${ }^{39}$, 2006 realizou um estudo com o propósito de avaliar os efeitos do procedimento de fundição na perda do torque aplicado, por meio de destoque, utilizando para isso 48 implantes de hexágono externo e 12 abutments usinados em titânio (controle), 12 abutments com cinta metálica préusinada em paládio e sobre fundida com mesmo material e 24 abutments plásticos, 12 fundidos com liga de $\mathrm{Ni}-\mathrm{Cr}$ e 12 com liga de $\mathrm{Co}-\mathrm{Cr}$, sendo todos do tipo UCLA. Para cada combinação de implante e abutment, um parafuso de liga de titânio foi usado. Após as fundições, os abutments não sofreram acabamento nem polimento. Os abutments foram então montados sobre os 
implantes, submetidos a um torque a $30 \mathrm{Ncm}$, conforme recomendação do fabricante, e, após 3 minutos, foi aplicado o destoque sendo o valor em Ncm registrado. Esse mesmo procedimento foi repetido 3 vezes para cada amostra. Os resultados mostraram que os abutments usinados em titânio foram capazes de reter $92,3 \pm 2.9 \%$ dos $30 \mathrm{Ncm}$ inicialmente aplicado. Os abutments com cinta pré-usinada em paládio, reteriveram $81.6 \pm 5.0 \%$ do torque, enquanto os totalmente calcináveis com liga de $\mathrm{Ni}-\mathrm{Cr}$ e $\mathrm{Co}-\mathrm{Cr}$ retiveram respectivamente, $84.6 \pm 4.6 \%$ e $84.0 \pm 7.0 \%$ do torque aplicado. Com base nestes resultados, os abutments usinados em titânio retiveram uma significativa quantidade de torque quando comparado com todos os outros grupos submetidos aos procedimentos de fundição $(p<0.05)$. Nenhuma diferença foi encontrada entre os outros grupos. Os valores de destorque no grupo com cinta pré-usinada de paládio foram avaliados antes (86.6 \pm 4.87\%) e após a fundição (81.6 \pm 5.07\%), evidenciando diferença estatisticamente significante.

BYRNE et al. ${ }^{15}, 2006$ propuseram um estudo com dois objetivos: o primeiro foi comparar os valores de pré-carga gerada por 3 tipos de parafusos de abutment (liga de titânio, liga de ouro e liga de ouro com cobertura de ouro), quando repetidos torques de inserção de 10, 20 e $35 \mathrm{Ncm}$ foram usados. O segundo objetivo foi comparar as pré-cargas geradas com abutments préfabricados e abutments com cinta metálica de ouro e porção coronal calcinável, tipo UCLA, para os diferentes tipos de parafusos e torques de inserção. Para isso, um implante foi montado e com ele um dispositivo associado a um straingauge foi utilizado para aferição da pré-carga. Para os testes, os abutments eram então montados sobre o implante e fixados pelo parafuso do abutment. 10 parafusos foram utilizados para cada tipo de abutment, compondo uma amostra de 60 conjuntos (implante/abutment/parafuso). Um torque de $10 \mathrm{Ncm}$ era primeiramente aplicado a um conjunto e a pré-carga medida. O torque era, então, aumentado para $20 \mathrm{Ncm}$ e a pré-carga novamente medida, até mais um torque ser aplicado, agora de $35 \mathrm{Ncm}$ e a pré-carga mais uma vez registrada. $\mathrm{O}$ parafuso era, então, afrouxado e o procedimento repetido por mais duas vezes. Quanto ao efeito dos repetidos apertamentos, para cada tipo de parafuso, os resultados mostraram que, em geral, houve uma diminuição da pré-carga de acordo com o número de vezes que os parafusos foram apertados, sendo que os parafusos de ouro com superfície tratada apresentaram a maior tendência 
em diminuição dessa pré-carga, independente do tipo de abutment utilizado, embora tenha sido o tipo de parafuso com maiores valores de pré-carga obtidos, seguido dos parafusos de liga de titânio e, por fim, dos de liga de ouro. Quanto à geração de pré-carga, para os diferentes tipos de abutment, os resultados mostraram que os abutments sobrefundidos apresentaram cerca de $20 \%$ a mais de pré-carga que os abutments pré-fabricados. Já referente aos repetidos apertamentos, ambos os abutments demonstraram uma diminuição na pré-carga gerada, sendo esta mais acentuada para os abutments préfabricados. De forma resumida, os autores concluem que todos os tipos de parafusos demonstram uma diminuição na pré-carga com repetidos apertamentos, independente do tipo de abutment ou torque de inserção. 0 parafuso de ouro com cobertura também de ouro mostrou-se superior em gerar os valores de pré-cargas mais elevados, independente do tipo de abutment ou torque de inserção.

\subsection{O abutment UCLA}

Embora diversos artigos relatados anteriormente tenham citado esse tipo de abutment, cabem aqui algumas considerações sobre seu surgimento e evoluções referentes ao seu desenvolvimento.

Em face das dificuldades relacionadas à estética e ao espaço protético reduzido, foi desenvolvido na Universidade da Califórnia - Los Angeles, na década de 80, o pilar ou abutment UCLA. Inicialmente, tratava-se de um cilindro de plástico o qual se conectava diretamente a cabeça do implante e poderia ser modificado pelo técnico de laboratório por meio de etapas como enceramento, inclusão, fundição e aplicação de porcelana LEWIS et al. ${ }^{43}, 1988$. Assim, surgiu o abutment tipo UCLA, em 1988, quando LEWIS et al. ${ }^{43}, 1988$ descreveram essa nova possibilidade desenvolvida para confecção de restaurações implantossuportadas, sem a necessidade de se utilizar um pilar intermediário. Segundo o autor, seriam estas as duas maiores vantagens de eliminação desse componente: estética, pois permite que a porcelana possa emergir através dos tecidos moles, e a criação de um maior espaço de trabalho para fabricação da restauração. $\mathrm{O}$ baixo custo, a capacidade em superar 
problemas como a distância interoclusal limitada, bem como a possibilidade de compensação de erros de angulação dos mesmos, são também apontados como vantagens desse tipo de pilar. O abutment UCLA foi desenhado para se adaptar à cabeça do implante, apresentando um orifício central para alojar seu respectivo parafuso de titânio, permitindo que o mesmo seja aparafusado no interior do implante da mesma forma que os parafusos dos pilares convencionais. Embora apresente inúmeras vantagens, uma desvantagem de seu uso refere-se a sua adaptação com o implante, uma vez que as etapas laboratoriais podem induzir a um possível desajuste. Uma inadequada adaptação pode resultar em perda e/ou fratura dos parafusos e a possibilidade de perda e/ou fratura dos implantes. Por essas razões, uma adequada adaptação passiva se faz necessária (APARICIO ${ }^{4}$, 1995). É justamente por esse motivo que seus idealizadores recomendam o uso de um dispositivo para acabamento da porção que se adapta ao implante, a fim de garantir uma melhor adaptação da peça fundida. Inicialmente, esse abutment, em sua concepção original, estava indicado apenas para próteses parciais fixas, em virtude da ausência de um hexágono em sua porção interna que prevenisse a rotação do mesmo sobre o implante.

Ainda em 1988, LEWIS et al. ${ }^{44}, 1988$ publicaram os passos clínicos de confecção de uma prótese unitária parafusada diretamente sobre o implante utilizando o pilar UCLA. Segundo os autores, o uso desse pilar favorece a estética, por permitir a obtenção de um melhor perfil de emergência, além de oferecer uma maior flexibilidade na confecção das próteses, resolvendo problemas de inadequado posicionamento dos implantes e limitado espaço interoclusal. Entretanto, como tal pilar apresentava sua porção interna lisa, sem um desenho anti-rotacional, os autores recomendavam que a porção interna do pilar também fosse encerada, copiando a cabeça do implante, criando o mecanismo anti-rotacional desejado para as próteses unitárias.

Após alguns anos, LEWIS; LLAMAS; AVERA ${ }^{45}, 1992$ demonstraram uma variedade de opções para o uso clínico do abutment UCLA e relataram os resultados de um estudo após 4 anos de sua utilização. Conforme o conceito de que deva ser empregado diretamente sobre o implante, sem a necessidade de um pilar intermediário, esse abutment ficou reconhecido por sua versatilidade, podendo ser empregado em regiões com espaço oclusal 
reduzido e possibilitar adequado perfil de emergência subgengival, devido à cinta metálica adequada para aplicação da porcelana, o que possibilita uma melhora da estética. Além disso, já está comercialmente disponível, préfabricado, em liga de titânio, em plástico com cinta metálica pré-fabricada em ouro ou Co-Cr, ou como cilindro de plástico para ser fundido e adaptado à condição clínica, principalmente onde a angulação dos implantes é desfavorável ou estes se encontram muito próximos, o que exige adaptações. Como já citado anteriormente, pode ser empregado para próteses unitárias, apresentando hexágono em sua porção interna, que atua como elemento antirotacional, ou para próteses parciais onde a porção interna é lisa sem a presença do hexágono. Quando utilizado para esse tipo de prótese, os autores sugerem que as porções sejam fundidas independentes e unidas na boca para posterior soldagem a fim de se evitar um assentamento não passivo com conseqüente sobrecarga. Os resultados clínicos do estudo apresentado pelos autores foram obtidos através do tratamento de 46 pacientes que receberam 59 restaurações utilizando 118 abutment tipo UCLA, sendo 65 na maxila e 53 na mandíbula. Das próteses, 12 eram tipo overdenture, 2 eram próteses totais fixas e 46 eram próteses parciais fixas. Dos 65 pilares maxilares, 5 falharam representando uma taxa de sucesso de 92,3\%. Três dessas falhas ocorreram em um único paciente e duas falhas em outro, sendo que ambos haviam recebido próteses parciais fixas metalocerâmicas na região posterior de maxila, ocorrendo as falhas num período de 6 semanas de função das próteses. Tais falhas sugerem que os implantes não estavam devidamente osseointegrados, tendo os pilares pouca significância em relação a elas. Nenhuma falha foi encontrada na mandíbula sendo a taxa de sucesso considerada de 100\%, e a taxa média de sucesso dos tratamentos de 95,8\%. 


\subsection{Podem os parafusos permanecer sempre apertados? Como evitar o afrouxamento dos parafusos. Interpretação dos autores.}

BINON et al. ${ }^{11}$, 1994 realizaram uma mesa-redonda, com diversos cirurgiões-dentistas, onde discutiram a respeito de suas experiências clinicas sobre se um parafuso, componente de uma prótese sobre implante, poderia permanecer sempre apertado, ou seja, se poderia estar livre da problemática do afrouxamento. A opinião dos autores é que parafusos permanentemente apertados implicam em ausência de reversibilidade da prótese, o que não é desejável, visto esta ser a grande vantagem de se ter próteses retidas por parafusos. Em virtude de muitos fatores complicadores e limitantes, impostos pelo tamanho dos parafusos, qualidade do tecido ósseo do leito receptor dos implantes, distribuição e localização dos mesmos e quantidade e intensidade das cargas que incidem na união parafusada, um aperto permanente dos parafusos torna-se muito difícil de obter. Dentro dos limites da realidade, segundo os autores, uma união parafusada pode permanecer devidamente apertada, mas não de forma permanente. Para isso, ainda assim serão necessários outros requisitos, tais como precisão de adaptação entre a infraestrutura protética e os componentes e entre estes e os implantes, adequados procedimentos de fundição quando necessários, utilização de adequado torque de apertamento a fim de obter-se ótima pré-carga e correto direcionamento e equilíbrio das cargas funcionais. Tudo isso diante de fatores que fogem do controle do profissional, tais com os fenômenos de acomodação entre componentes (embedment relaxation), desenho dos componentes e parafusos e até mesmo a elasticidade do tecido ósseo.

CAVAZOS; BELL ${ }^{19}, 1996$ desenvolveram uma técnica com o objetivo de se tentar prevenir o afrouxamento do parafuso do abutment, devido a esta grande problemática que acomete as próteses sobre implante. A técnica consistia em realizar na porção interna do abutment pequenas perfurações numa região acima da cabeça do parafuso. O abutment era então posicionado sobre o implante e o parafuso apertado com o torque máximo dos dedos. Após, aproximadamente, 5 minutos o mesmo era reapertado. Então, uma seringa dispensava sobre a cabeça do parafuso uma porção de material de borracha à base de poli-vinil-siloxano (Extrude; Kerr), ao mesmo tempo em que era 
aspirado por outra seringa, a fim de permitir que o material ocupasse todas as reentrâncias ali presentes. Antes da presa do material, uma pequena bolinha de algodão era colocada sobre o mesmo e condensada com um condensador. Uma porção de cimento provisório era então colocado sobre esses materiais, fotoativado e, após um período de 10 dias ou 2 semanas, substituído por uma resina definitiva. Segundo os autores, tal técnica poderia também ser realizada sobre abutments angulados. Posteriormente, essa seqüência de procedimento seria avaliada por outro autor, observando sua real efetividade.

BINON $^{9}, 1998$ avaliou a efetividade de um protocolo de estabilização dos parafusos em relação à aplicação de carga cíclica. Para isso um implantepadrão de $3.75 \times 10 \mathrm{~mm}$ com hexágono externo foi incluído em um bloco de resina, e um abutment tipo UCLA foi confeccionado de forma a permitir aplicação de carga cíclica. Após o abutment ser adaptado ao implante, seu conduto para o parafuso recebeu 4 perfurações com intervalo de $90^{\circ}$ entre elas, acima da região onde estaria a cabeça do parafuso após o seu aperto. Após a limpeza das cavidades criadas, com jatos de ar, o abutment foi então recolocado sobre o implante e parafusado ao torque máximo possível dado com os dedos. Após 10 minutos, mais um torque era dado. Com uma seringa introduzida no espaço da chave na cabeça do parafuso, um material de moldagem à base de borracha (Impregum) foi depositado procurando preencher a cavidade e as perfurações e, sobre ele uma bolinha de algodão condensada. Já no grupo controle foram usados os mesmos tipos de componente, porém o parafuso apertado a $20 \mathrm{Ncm}$ com uso de um torquímetro manual. Nenhum material de moldagem ou plug de algodão foi utilizado. Submetidos à carga cíclica, os espécimes do grupo teste suportaram uma quantidade menor de ciclos antes do afrouxamento que os do grupo controle, sendo tal resultado atribuído ao fato de aquele grupo (teste) ter sofrido um apertamento digital dos seus parafusos. Segundo o autor, o material de moldagem, por mais que apresente uma boa rigidez, não é capaz de impedir a movimentação dos componentes quando submetidos à tensão. Contudo, 0 material de moldagem poderia ser indicado como um bom material de vedação após a introdução do parafuso.

ARTZI; DREIANGEL ${ }^{5}, 1999$ também publicaram uma técnica que, segundo eles, impede o afrouxamento do parafuso do abutment em próteses 
unitárias. A técnica consiste na colocação de uma barra de titânio, hexagonal, devidamente adaptada ao orifício para introdução da chave no parafuso e, ao seu redor, realizava-se a condensação de resina fotopolimerizável. Dessa forma, o parafuso fica impedido de girar e, conseqüentemente, de afrouxar. Contudo, os autores enfocam a necessidade desta prótese apresentar total passividade de adaptação. Para isso, antes da colocação da barra, o paciente permanecia com a prótese em função durante um período de 1 mês como diagnóstico. Os resultados apresentados da utilização da técnica compreendem mais de três anos de utilização e confecção de 120 coroas sobre implantes, em 100 pacientes, distribuídas da seguinte forma: 65 substituindo primeiro e segundo pré-molares, 40 na região de incisivos e 15 na região de molares. Dentre essas próteses, e dentro do período compreendido, não houve nenhum afrouxamento e/ou fratura de nenhum parafuso. Como os parafusos rotineiramente se tornam enfraquecidos diante das cargas mastigatórias, levantou-se a hipótese de a interface entre o tecido ósseo e o implante ser sobrecarregada, mas os autores também afirmam que não tiveram nenhum caso de perda da osseointegração. 
3 - PROPOSIÇÃO 


\section{PROPOSIÇÃO}

3.1 Avaliar o ângulo formado na cabeça dos parafusos de titânio na condição de torque em peças fundidas em monobloco, com liga de $\mathrm{Ni}-\mathrm{Cr}$, utilizando abutments UCLA totalmente calcináveis e com cinta usinada em Co-Cr.

3.2 Avaliar o ângulo formado na cabeça dos parafusos de titânio na condição de re-torque em peças fundidas em monobloco, com liga de $\mathrm{Ni}-\mathrm{Cr}$, utilizando abutments UCLA totalmente calcináveis e com cinta usinada em Co-Cr.

3.3 Avaliar os valores de destorque em peças fundidas em monobloco, com liga de $\mathrm{Ni}$-Cr, utilizando abutments UCLA totalmente calcináveis e com cinta usinada em Co-Cr.

3.4 Avaliação comparativa por meio de MEV das superfícies das bases de assentamento dos abutments tipo UCLA, fundidos em monobloco com liga de $\mathrm{Ni}-\mathrm{Cr}$, utilizando abutments tipo UCLA totalmente calcináveis e com cinta usinada em Co-Cr, antes e após a realização dos testes de torque, re-torque e destorque.

3.5 Avaliação da superfície dos parafusos de titânio por meio de MEV, antes e após a realização dos testes de torque, re-torque e destorque. 
4 - MATERIAL E MÉTODOS 


\section{MATERIAL E MÉTODOS}

\subsection{Dispositivo de avaliação dos graus de rotação dos parafusos}

Especialmente para este estudo, foi desenvolvido e confeccionado um dispositivo (SENAI - Bauru-SP, Brasil) com o objetivo de avaliar e quantificar os graus necessários para apertar os parafusos das próteses sobre implantes, sejam eles parafusos de abutments ou mesmo parafusos protéticos.

Esse dispositivo (Figuras 3, 4, 5, e 6) é constituído de uma base circular de alumínio, medindo aproximadamente $15 \mathrm{~cm}$ de diâmetro, e que apresenta 5 cilindros de latão com roscas internas de $3,75 \mathrm{~mm}$ de diâmetro, confeccionados para abrigar os implantes dentais que foram utilizados no estudo. Os orifícios de latão estão dispostos num raio de circunferência de 4 $\mathrm{cm}$, a partir do centro dessa base, sendo a distância entre o centro de cada orifício equivalente a $7 \mathrm{~mm}$, o que representa a distância mínima aceitável entre implantes na cavidade bucal HOBO; ICHIDA; GARCIA ${ }^{31}$, 1990. Também faz parte do dispositivo uma haste vertical, seguida de outra paralela à base, a qual tem como função suportar um torquímetro (TOHNICHI - modelo BTG60CN-S, Ota-ku, Tóquio, Japan) e uma caixa acessória que porta um captador da quantidade de graus necessários para se apertar os parafusos que compõem as próteses sobre implantes. Dessa caixa parte um cabo que se liga a uma chave bi-polar, responsável por ativar e desativar a caixa acessória captadora. Da chave bi-polar parte um cabo (saída PS2) destinada a fazer a conexão com um computador, recebendo ao mesmo tempo a entrada de um mouse acessório para se trabalhar durante as leituras. 
Chave elétrica bipolar para acionar captador de graus e mouse do computador
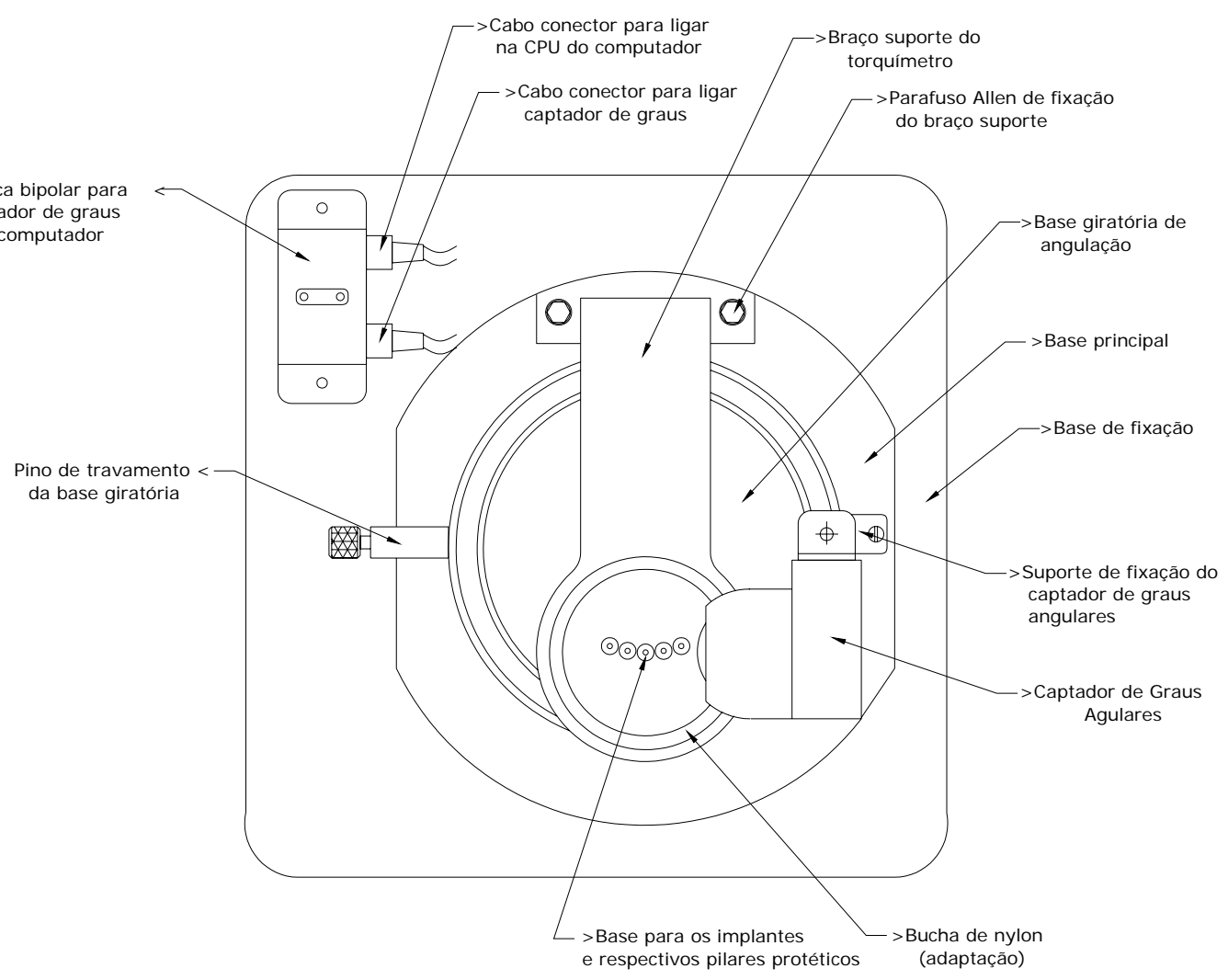

Figura 3 - Desenho esquemático do dispositivo de avaliação dos graus de rotação dos parafusos, antes de sua confecção: Projeto em AutoCAD - Vista superior.

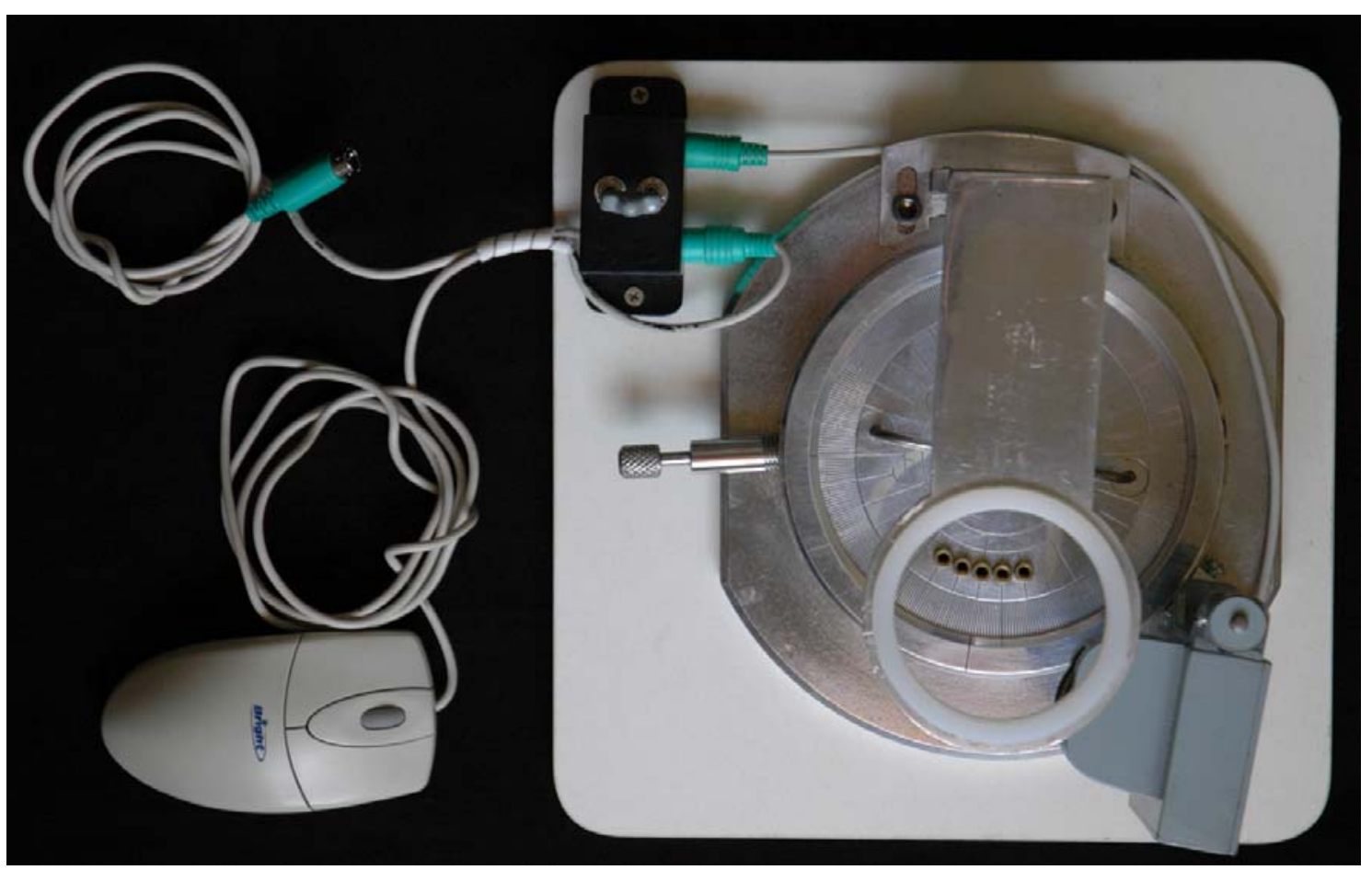

Figura 4 - Dispositivo de avaliação dos graus de rotação dos parafusos, após sua confecção, com mouse e cabo PS2 já conectados para conexão com computador. Vista superior. 


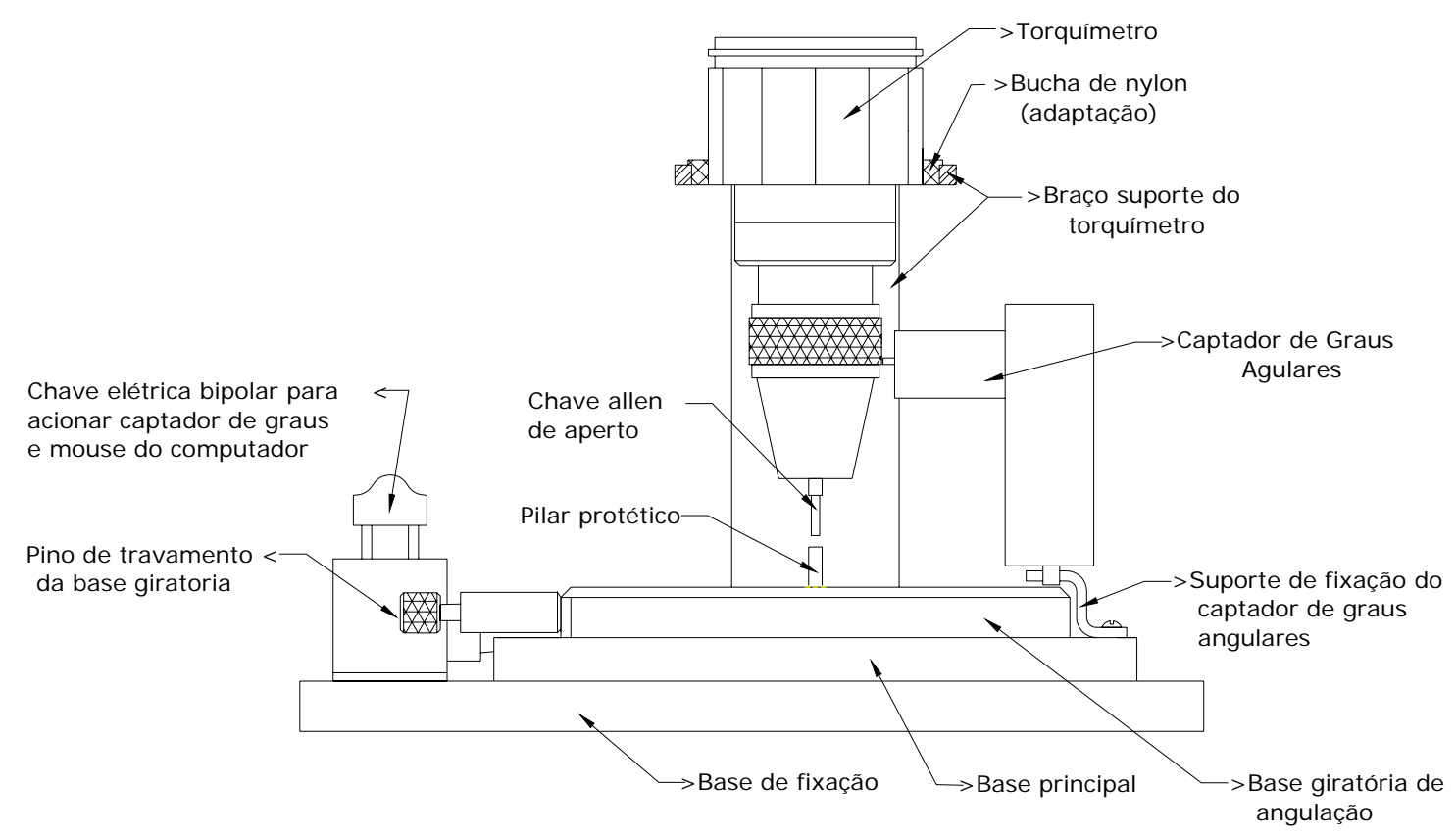

Figura 5 - Desenho esquemático do dispositivo de avaliação dos graus de rotação dos parafusos, antes de sua confecção: Projeto AutoCAD - Vista lateral.

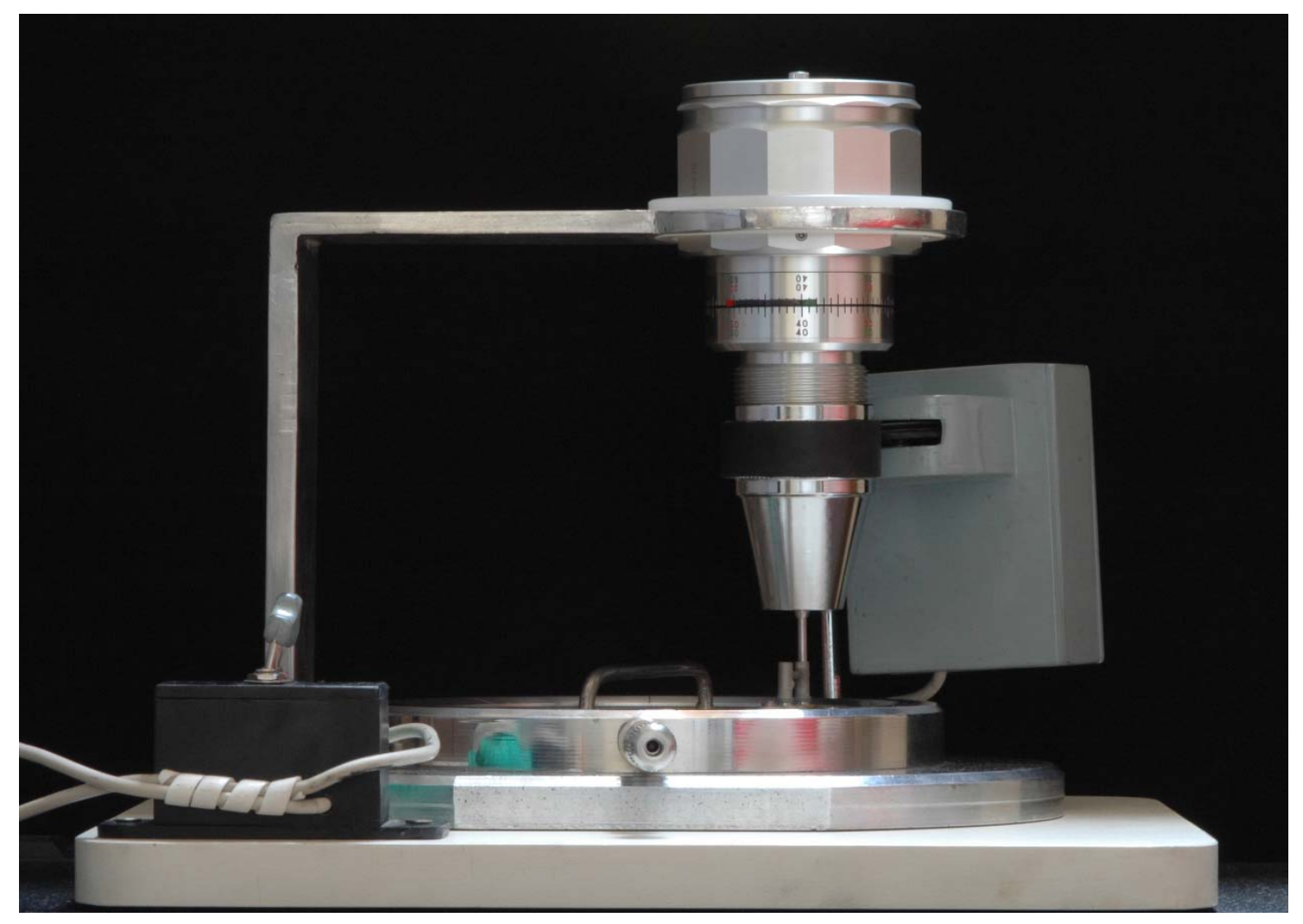

Figura 6 - Dispositivo de avaliação dos graus de rotação dos parafusos, após sua confecção. Vista lateral. 
Como já citado, esse dispositivo é conectado diretamente a um computador, sendo essa interface realizada por meio de um software denominado GRAUS, devidamente desenvolvido para esse fim. O mecanismo de funcionamento do dispositivo, referente à leitura da quantidade de graus necessária para o aperto dos parafusos, será explicado mais adiante no momento em que descreveremos a realização dos testes laboratoriais propriamente ditos por acharmos que naquele momento será mais facilmente compreendido.

\section{2 - Implantes e componentes protéticos}

Dois implantes Revolution fornecidos pela SIN (Sistema de Implante Nacional Ltda., São Paulo, SP, Brasil) de 3,75 mm de diâmetro e $13 \mathrm{~mm}$ de comprimento e plataforma protética com conexão tipo hexágono externo de $4,1 \mathrm{~mm}$ de diâmetro, foram fixados na base do dispositivo, nos cilindros de latão confeccionados para esse fim. Os implantes distanciavam $14 \mathrm{~mm}$ um do outro, medida esta entre os centros dos implantes. Para confecção das infraestruturas a serem testadas sobre os implantes, também foi fornecido pela empresa SIN 20 abutments UCLA com base de assentamento usinada em Cobalto-Cromo (Co-Cr), norma DIN 13912, sem hexágono e corpo calcinável em plástico (Delrin - Copolímero de Poliacetal) (referência: EUCLA 400), 20 abutments UCLA de plástico (Delrin - Copolímero de Poliacetal) sem hexágono (referência: UCLA 400) e 40 parafusos de titânio (Grau 5), norma ASTM F13602A, com encaixe para chave quadrada (referência: PTQ 2008) para retenção dos abutments (Figura 7). 


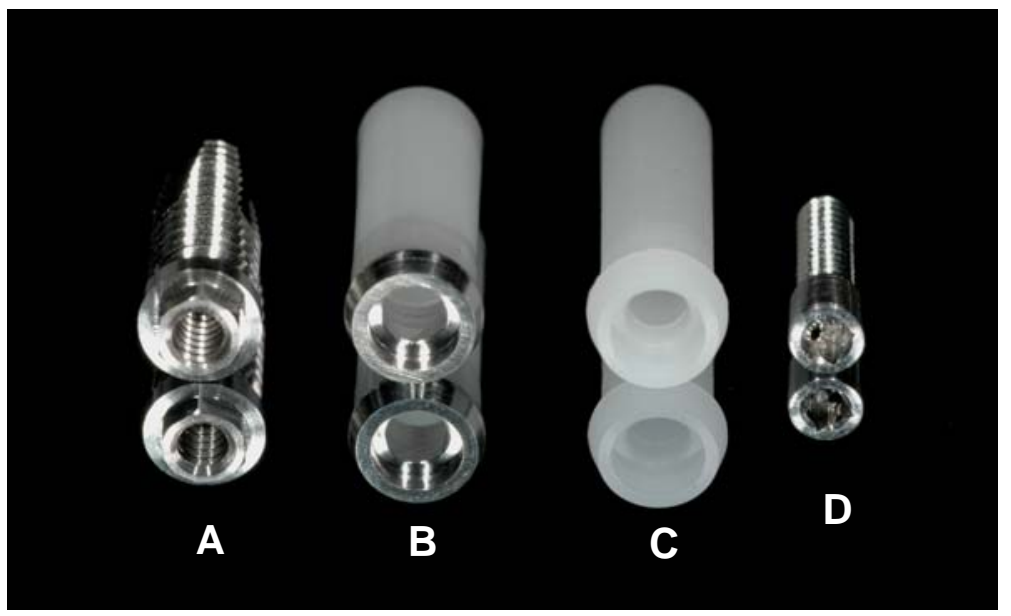

Figura 7 - Implante e componentes utilizados durante o experimento, (SIN - Sistema de Implante). A - Implante Revolution; B - Abutment UCLA com base usinada em Co-Cr; C Abutment UCLA de plástico; D - parafuso de titânio com encaixe para chave quadrada.

\section{3- Confecção dos corpos de prova}

Devido ao fato de a porção acrílica dos abutments protéticos apresentar alturas diferentes, foi necessário realizar uma padronização das mesmas. Para isso, um análogo de titânio dos implantes utilizados (Ref. AN 4100) foi incluído em um bloco de gesso, utilizando-se os braços paralelos de uma fresadora. Após confecção dessa base, os abutments protéticos foram ali fixados, um a um, para a realização do corte de sua porção mais coronal, com disco de carborundum (Figura 8). Para o experimento, foi padronizada uma altura de $6 \mathrm{~mm}$ para todos os abutments.

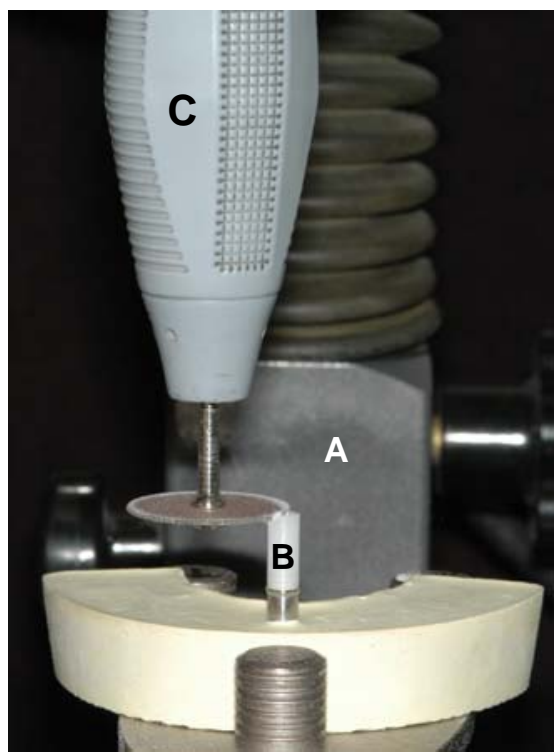

Figura 8 - Uso de fresadora (A) para padronização do tamanho dos abutments (B) e micro motor acoplado (C). 
Dois abutments protéticos do mesmo grupo (Acrílico Calcinável e/ou Co-Cr) foram então montados sobre os respectivos implantes na base do dispositivo, e uma barra de acrílico (DELRIN - Copolímero de Poliacetal) (Conexão Sistema de Prótese, São Paulo, SP, Brasil) de 2mm de espessura foi utilizada pra fazer a união entre os componentes. O comprimento dessas barras foi sempre o compreendido entre as áreas agora designadas como internas nos abutments. Para se ter uma padronização do posicionamento dessa barra, que uniu os cilindros, mais 2 implantes foram montados adjacentes aos utilizados no experimento e sobre eles foi parafusado um parafuso de trabalho. Esse procedimento objetivou a criação de uma matriz de silicona de condensação laboratorial (Zetalabor - Zhermack® Badia Polesine, Itália) a qual, com sua entrada e saída direcionada pelos parafusos de trabalho, passou a orientar o posicionamento padronizado das barras e conseqüente união das mesmas aos componentes protéticos, sendo esta realizada por meio de uma resina acrílica autopolimerizável de precisão (Pattern Resin LS; GC América Inc., Alsip, USA). A altura da barra, em relação à base dos componentes protéticos foi estabelecida em 6,8mm. Após a fixação da porção anterior da barra aos componentes protéticos, a matriz foi então removida e a complementação dessa união era realizada. De uma vista anterior, os abutments, posicionados à esquerda do observador, foram marcados com um pingo de cera na face "vestibular" de cada um dos padrões para fundição, para posterior orientação quanto ao lado de posicionamento e diferenciação dos parafusos durante os testes (Figuras $9-13$ ).

Os padrões para fundição foram então removidos da base do dispositivo por desparafusamento e a cada 2 conjuntos confeccionados, aqueles eram então fixados a uma base formadora de cadinho e posicionados centralmente em um anel de silicone para inclusão do revestimento (Figura 14).. 


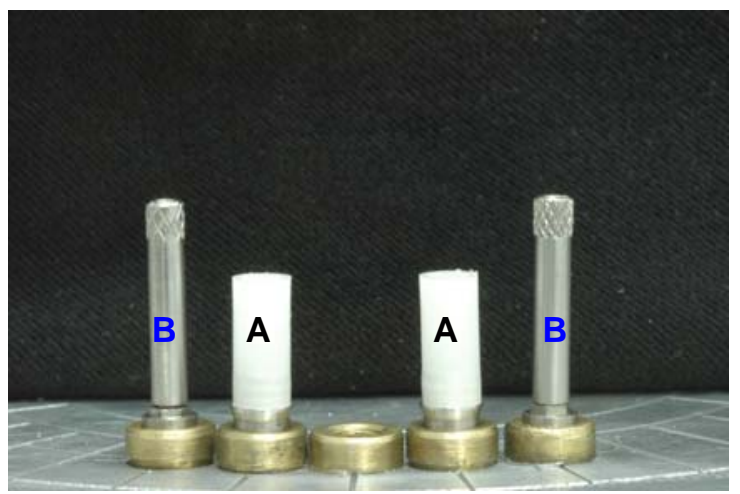

Figura 9 - Abutments parafusados sobre os implantes (A) para enceramento dos padrões para fundição e obtenção dos corpos de prova. Parafusos de trabalho para orientar inserção e remoção da matriz de silicona (B).

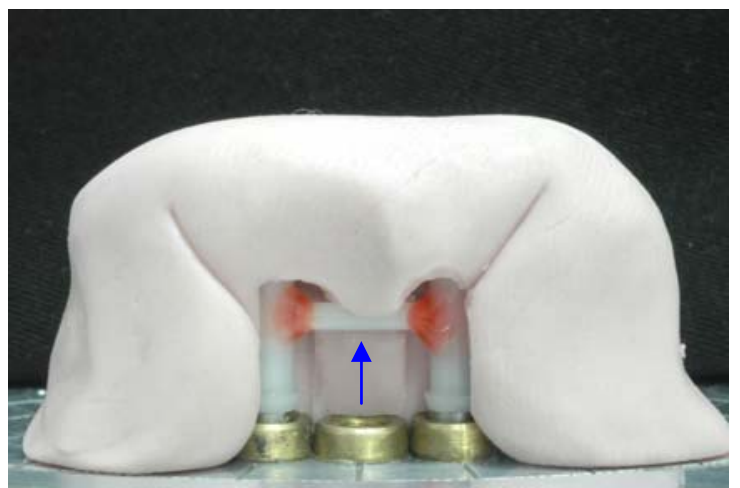

Figura 11 - Fixação da barra (seta) aos abutments por meio de resina acrílica.

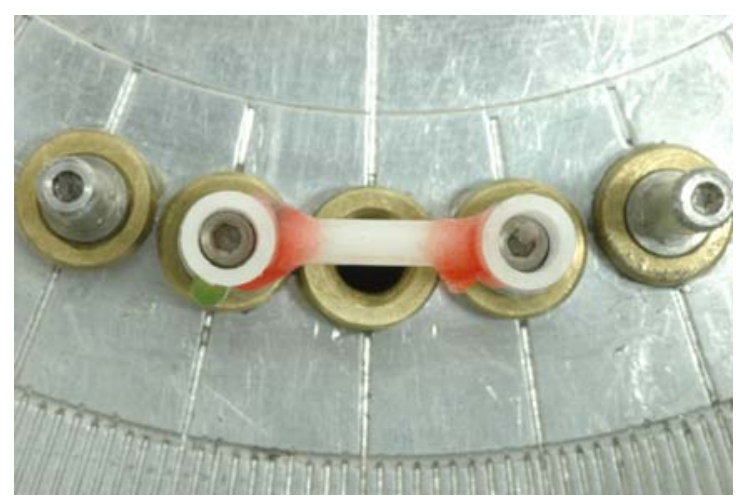

Figura 13 - Vista oclusal do padrão para fundição preparado no dispositivo.

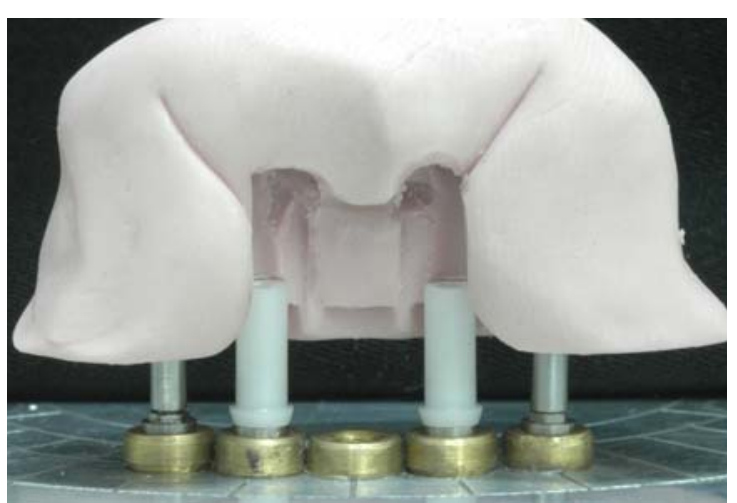

Figura 10 - Introdução da matriz de silicona para orientar fixação da barra.

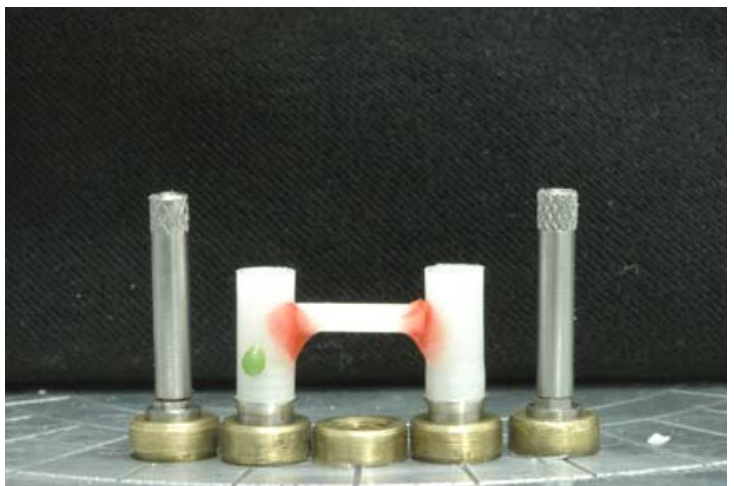

Figura 12 - Vista frontal do padrão para fundição finalizado no dispositivo. Notar marcação no abutment esquerdo em sua face "vestibular".

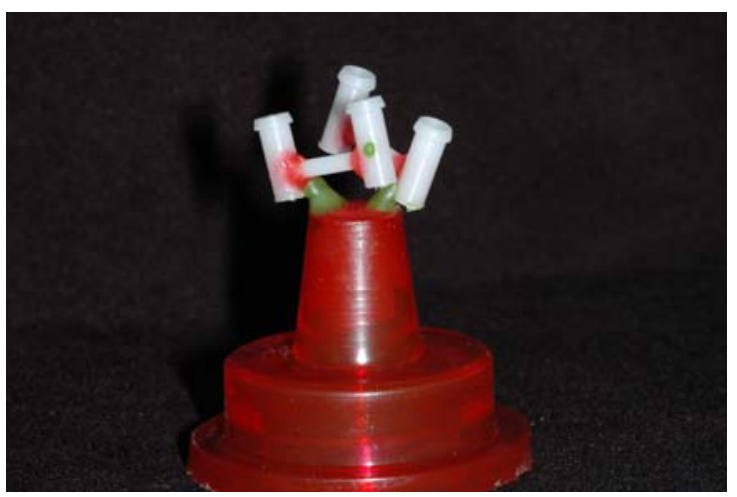

Figura 14 - Dois padrões para fundição unidos à base formadora de cadinho antes da inclusão em revestimento para o procedimento de fundição propriamente dito. 


\subsection{1- Inclusão, fundição, desinclusão e acabamento dos corpos de prova}

A inclusão foi realizada após a pesagem do revestimento [Microfine 1700 (Talladium, Inc. Valencia, CA, USA)] em balança apropriada, utilizando somente líquido especial do revestimento durante sua manipulação a fim de se obter expansão máxima do mesmo. A espatulação do revestimento seguiu as normas do fabricante e foi realizada manualmente por 10 segundos e a vácuo, a 425 rotações por minuto (rpm) por mais 40 segundos (Espatuladora Polidental modelo AQ1776/02 ind. e comércio Ltda.; Cotia-SP). Depois de vazado o revestimento no interior do anel, preenchendo totalmente os padrões para fundição até o topo do mesmo, aguardou-se um período de 20 minutos para presa adequada do revestimento. Removeu-se o anel de silicone (Figura 15) e então o bloco de revestimento foi inserido no forno (Bravac analógico 184), em temperatura ambiente. Aqueceu-se o forno até $400^{\circ} \mathrm{C}$, o qual foi mantido nessa temperatura por 40 minutos, período esse necessário para que os materiais calcináveis que compunham os padrões para fundição evaporassem sem deixar resíduos na condição máxima de expansão do revestimento. Elevou-se a temperatura do forno para $600^{\circ} \mathrm{C}$, aguardando-se mais 15 minutos para a definitiva evaporação dos materiais. Por fim, elevou-se a temperatura do forno para $900^{\circ} \mathrm{C}$, onde o bloco permaneceu por 20 minutos para então proceder à fundição propriamente dita, a qual foi realizada com uma liga de Níquel-Cromo (Ni-Cr), (DURABOND Universal, São Paulo, SP, Brasil), por meio de força centrífuga e força proveniente de 3 voltas de seu eixo (Centrifuga VH para Ni-Cr; Araraquara-SP) (Figura 16).

Para o cálculo da liga, seguiram-se as normas do fabricante baseada na seguinte fórmula:

$$
P P \times D L=X+10 \%
$$

Onde:

PP - peso do padrão a ser incluído, em gramas;

$\mathrm{DL}$ - densidade da liga, em gramas $/ \mathrm{cm}^{3}$, que no caso do Ni-Cr é 8,2;

X - Quantidade de liga em gramas para fundição. 


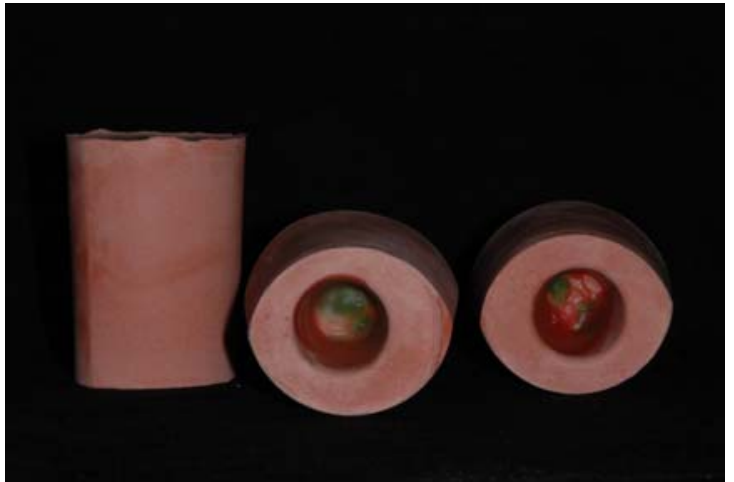

Figura 15 - Após presa, os blocos de revestimento são removidos do anel e estão prontos para serem levados ao forno.

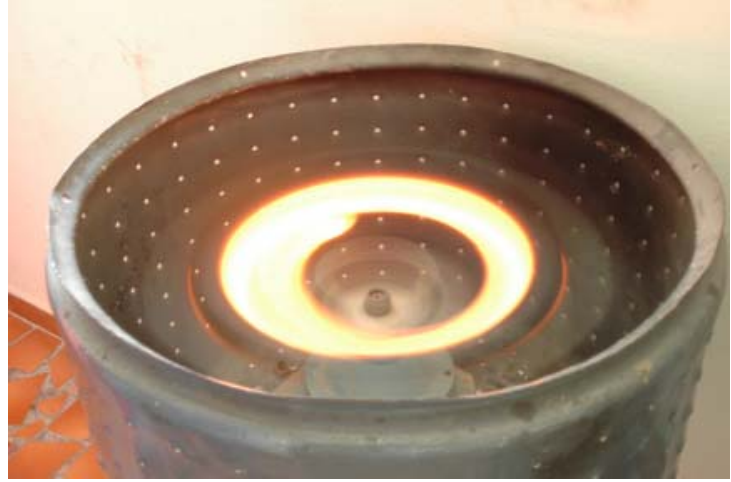

Figura 16 - Visão da liga liquefeita incandesceste, no interior do cadinho, no momento da sua centrifugação.

Após o procedimento de fundição, que se deu por meio de uma centrífuga padrão, os padrões para fundição passaram a ser denominados de corpos de prova.

Assim, aguardou-se o completo esfriamento da liga no interior do revestimento para realizar as desinclusões dos corpos de prova. O revestimento ao redor dos mesmos foi primeiramente removido com brocas e, posteriormente, com jatos de óxido de alumínio $(50 \mu \mathrm{m})$, através de um jateador (Trijato Odonto Larcon; Maringá-PR), com pressão de até 70Psi e a uma distância de 5cm por um tempo aproximado de 45 segundos (Figuras 17 e 18), quando então as peças foram cortadas dos seus condutos de alimentação por meio de discos de carborundum e submetidas à verificação de adaptação sobre os implantes, feita de maneira rotineira em laboratórios comerciais, com eventuais pequenas usinagens internas, não interferindo nas áreas de assentamento das peças.

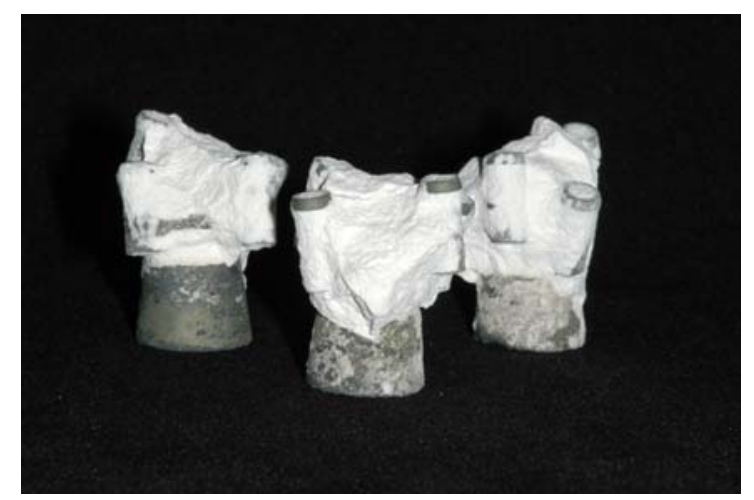

Figura 17 - Início da desinclusão dos corpos de prova, ainda cobertos em parte pelo revestimento.

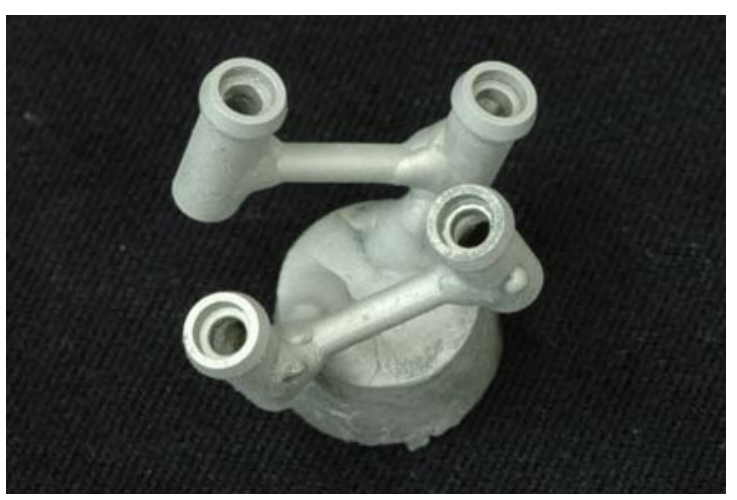

Figura 18 - Corpos de prova após a desinclusão e limpeza por jateamento, antes dos cortes dos condutos de alimentação. 
É importante citar que todos os corpos de provas obtidos a partir de componentes totalmente calcináveis necessitaram ser submetidos a uma usinagem mínima de sua base de assentamento, em baixa rotação, acompanhados por lupas de aumento - 4x (BIO-ART, São Carlos, SP, Brasil) para se adaptar aos implantes montados no dispositivo. Entretanto os corpos de prova obtidos a partir de componentes que antes da fundição já apresentavam sua base de assentamento usinada em Co-Cr, não necessitaram ser submetidos a nenhum procedimento de usinagem para essa condição de adaptação sobre os mesmos implantes após a fundição. A aferição de que os corpos de prova estavam adaptados foi realizada através de inspeção visual e sensibilidade táctil do operador, sendo considerado como padrão a não-existência de resistência para o assentamento e remoção das peças sobre os implantes, antes e após parafusamento.

Após o procedimento de usinagem dos corpos de prova, estes foram novamente jateados com óxido de alumínio nas mesmas condições já descritas, em relação à distância e ao tempo de operação, e submetidos a uma limpeza em cuba ultrassônica, com álcool isopropílico, por 10 minutos, com o objetivo de promover limpeza adequada para o procedimento de análise em MEV. Assim, temos estabelecidos os 2 grupos experimentais: grupo Acrílico Calcinável (Figura 19) e grupo Co-Cr (Figura 20).

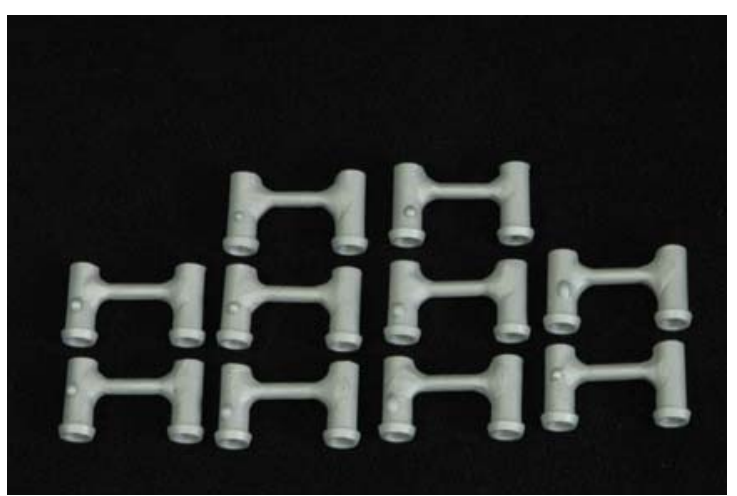

Figura 19 - Grupo Acrílico Calcinável.

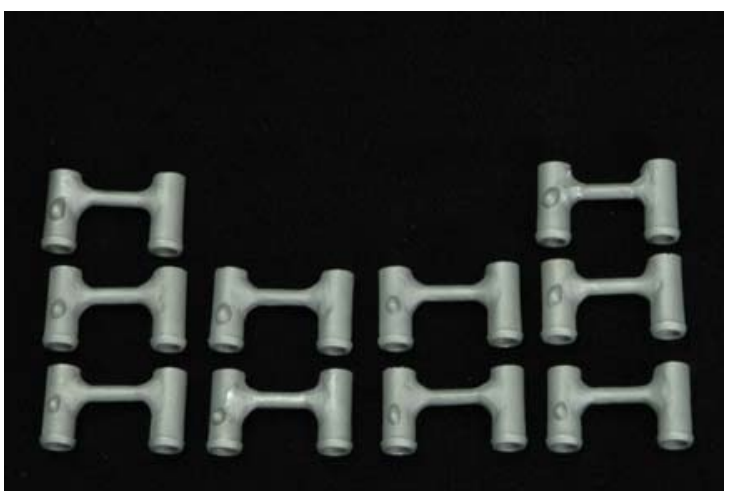

Figura 20 - Grupo Co-Cr. 


\section{4 - Análise por meio de Microscopia Eletrônica de Varredura (MEV)}

A fim de observar eventuais deformações que as bases de assentamento dos abutments pudessem sofrer durante os testes de torque e destorque dos parafusos, assim como a deformação que estes também sofreriam durante esses procedimentos, os corpos de provas foram submetidos a uma análise por meio de MEV, sendo esta realizada nas dependências do CCDM (Centro de Caracterização de Materiais), localizado na Universidade Federal de São Carlos - SP, (UFSCar). Cinco corpos de prova de cada grupo experimental e um parafuso de abutment foram submetidos a uma primeira análise, aleatoriamente, antes dos testes laboratoriais de torque e destorque. Os espécimes foram fixados em uma base de alumínio do MEV por meio de uma fita carbonada dupla face destinada especificamente para esse fim (Figura 21). Posteriormente, esses mesmos espécimes foram novamente avaliados com o objetivo de encontrar eventuais deformações em sua microestrutura. Essa análise foi realizada em um microscópio eletrônico de varredura (LEICA Cambrige Stereoscan 440®, United Kingdom, ano de fabricação:1994) (Figura 22), e os valores de magnificação para os espécimes foram de 65x, 500x e 2500x para as bases de assentamento dos abutments e 150x, 500x, 1000x e 1500x para as regiões dos parafusos (cabeça, pescoço e roscas).

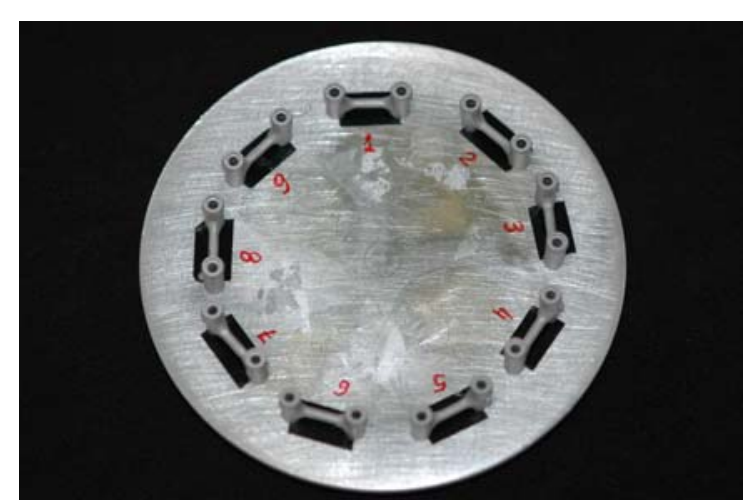

Figura 21 - Corpos de prova fixados em dispositivo para realização da MEV.

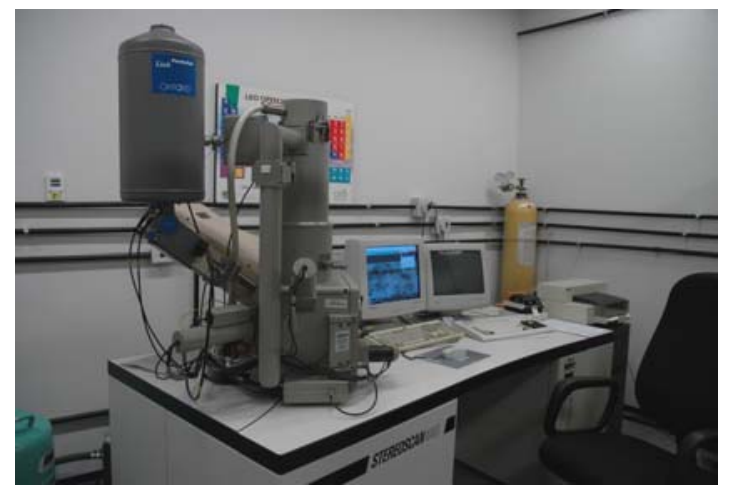

Figura 22 - Microscópio Eletrônico de Varredura, CCDM - UFSCAR. 


\subsection{1 - Teste EDS (ESPECTROMETRIA DE ENERGIA DISPERSIVA DE RAIOS-X )}

O EDS ou EDX (energy dispersive $x$-ray detector) é um acessório essencial no estudo de caracterização microscópica de materiais. Durante o procedimento de MEV, quando o feixe de elétrons incide sobre um mineral, os elétrons mais externos dos átomos e os íons constituintes são excitados, mudando de níveis energéticos. Ao retornarem para sua posição inicial, liberam a energia adquirida a qual é emitida em comprimento de onda no espectro de raios-x. Um detector instalado na câmara de vácuo do MEV mede a energia associada a esse elétron. Como os elétrons de um determinado átomo possuem energias distintas, é possível, no ponto de incidência do feixe, determinar quais os elementos químicos presentes naquele local e assim identificar em instantes que minerais estão sendo observados. O diâmetro reduzido do feixe permite a determinação da composição mineral em amostras de tamanhos muito reduzidos, menores que $5 \mu \mathrm{m}$, permitindo uma análise quase que pontual.

Enquanto o MEV proporciona nítidas imagens (ainda que virtuais, pois o que se vê no monitor do computador é a transcodificação da energia emitida pelas partículas, em vez da radiação emitida pela luz, ao qual estamos habitualmente acostumados), o EDS permite sua imediata identificação. Além da identificação mineral, o equipamento ainda permite o mapeamento da distribuição de elementos químicos por minerais, gerando mapas composicionais dos elementos desejados.

Neste trabalho, o EDS foi realizado na base de assentamento dos abutments (1 de cada grupo) e na superfície de um parafuso, sendo realizada uma nova leitura após a realização dos testes laboratoriais de torque, destorque e obtenção das variações angulares.

\section{5 - Teste laboratorial}

O início desta etapa do trabalho principiou com a conexão do dispositivo de avaliação dos graus de rotação dos parafusos a um computador. O primeiro grupo a ser testado foi o grupo Acrílico Calcinável, seguido pelo 
grupo Co-Cr. A seqüência do teste se deu da seguinte maneira para todos os corpos de prova:

Primeiramente, o corpo de prova era posicionado sobre os implantes na base do dispositivo, para então receber os 2 parafusos responsáveis pela fixação dos mesmos. A fim de se saber qual parafuso foi utilizado em cada abutment, e para não haver a troca dos mesmos, estes foram marcados com caneta de tinta permanente, sendo a cor preta adotada para marcar os parafusos utilizados no abutment localizado à esquerda do operador do dispositivo, abutment este que, durante o enceramento das infra-estruturas, recebeu uma marcação característica em alto relevo, sendo então a cor vermelha adotada para o outro abutment, localizado sempre à direita do operador (Figura 23). Após a introdução dos parafusos aos seus respectivos abutments, os mesmos foram apertados bidigitalmente com uma chave de encaixe quadrado (SIN), até haver a $1^{\mathrm{a}}$ resistência a esse aperto (Figura 24). Então, com o uso de um torquímetro analógico de precisão (TOHNICHI modelo BTG60CN-S, Ota-ku, Tóquio, Japan) (Figura 25 e 26) e a chave digital com encaixe quadrada (SIN) presa a sua extremidade, os parafusos foram apertados a $6 \mathrm{Ncm}$, visto esta ser a primeira marcação do torquímetro. Ambos os parafusos foram submetidos a esse torque de apertamento inicial, sendo primeiramente realizado no parafuso da esquerda do operador e, posteriormente, no parafuso da direita. O objetivo desse apertamento foi a obtenção de um ponto de partida comum de ambos, para avaliação do grau de rotação nos torques subseqüentes.

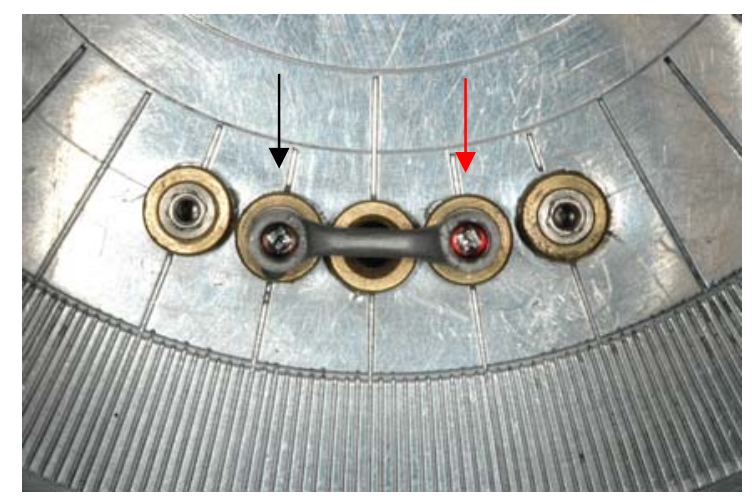

Figura 23 - Diferenciação dos parafusos com caneta de tinta permanente (setas) preta (esquerdo) e vermelha (direito) e os mesmos localizados no interior dos abutments.

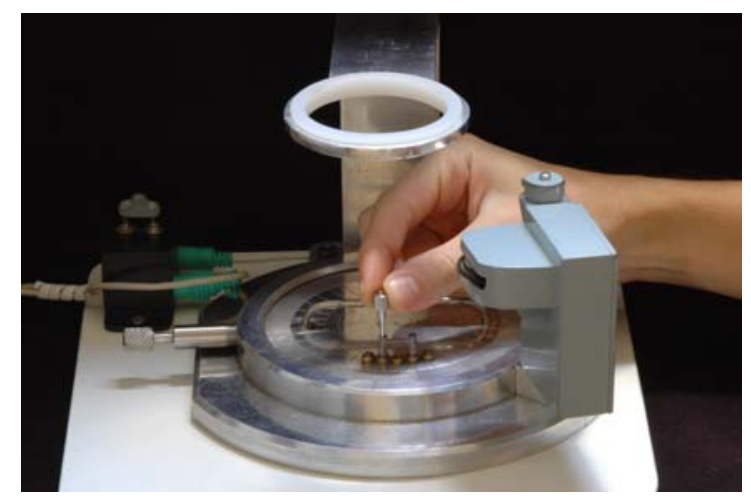

Figura 24 - Aperto bidigital dos parafusos no interior dos abutments, até encontrar a primeira resistência. 


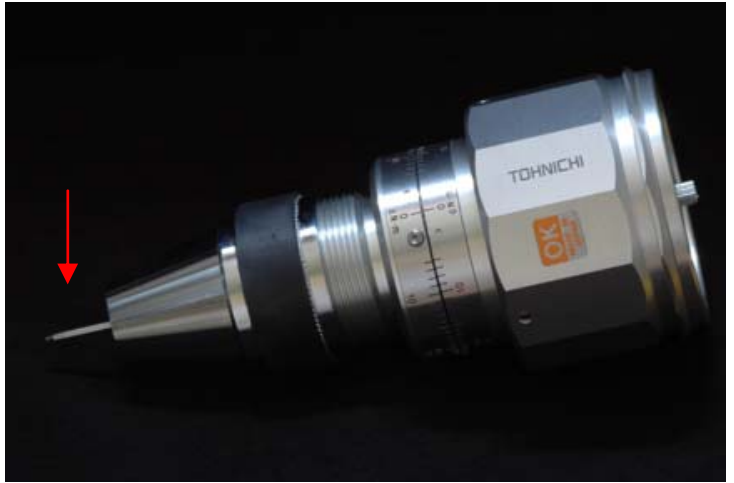

Figura 25 - Torquímetro com chave bidigital adaptada em sua extremidade inferior (seta).

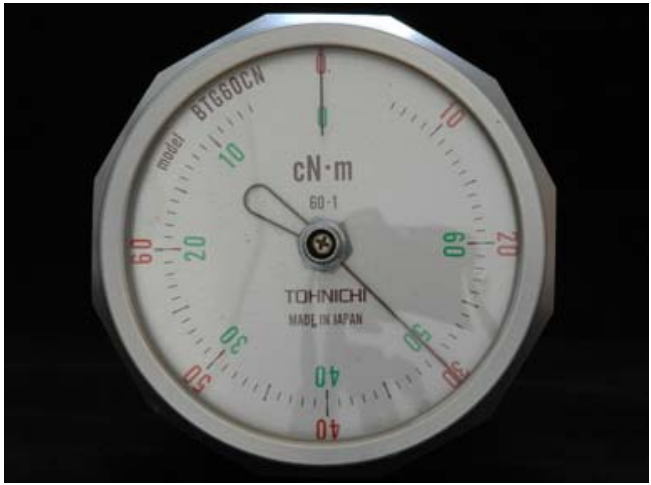

Figura 26 - Vista superior do torquímetro. Agulha cega mostrando a quantidade de Newtons obtida.

Com o torquímetro e a chave de apertamento devidamente adaptados à cabeça do parafuso do abutment da esquerda do operador, e com o software GRAUS realizando a interface do dispositivo com o computador, foi dado então um torque, realizado com velocidade constante por um operador devidamente calibrado, de $30 \mathrm{Ncm}$ (de acordo com a recomendação do fabricante) ao parafuso e, conseqüentemente, a leitura da quantidade de graus que o parafuso rotacionou para realizar o aperto foi registrado pelo software. Nesse momento, foi ativado um cronômetro com contagem regressiva de 10 minutos. Então, imediatamente, o conjunto torquímetro e chave foram retirados desse abutment, a base do dispositivo foi rotacionada e o conjunto torquímetro e chave montado sobre o outro abutment, a fim de se dar o mesmo valor de torque $(30 \mathrm{Ncm})$ e se registrar também a quantidade de graus necessária para aperto desse parafuso (Figura 27). Passados os 10 minutos marcados no cronômetro, o conjunto torquímetro e chave foi novamente posicionado sobre 0 primeiro abutment apertado, para dar um novo aperto (re-torque) de $30 \mathrm{Ncm}$ e se registrar uma nova quantidade de graus de rotação do parafuso, necessária para o re-aperto do mesmo. O mesmo procedimento foi realizado no outro abutment, em seguida e da mesma maneira.

Após os sucessivos torques aplicados, os mesmos parafusos foram imediatamente submetidos ao destorque, porém agora avaliando apenas a quantidade de força necessária ( $\mathrm{Ncm}$ ) para desapertar o parafuso do abutment.

A seqüência de procedimento descrita anteriormente foi realizada 3 vezes para cada componente do corpo de prova, procurando simular algumas 
etapas de aperto e desaperto desses parafusos, semelhantes a situações clínicas rotineiras. Os dados numéricos obtidos foram então anotados em fichas previamente idealizadas para essas condições. Os dados foram então tabulados e submetidos à análise estatística.

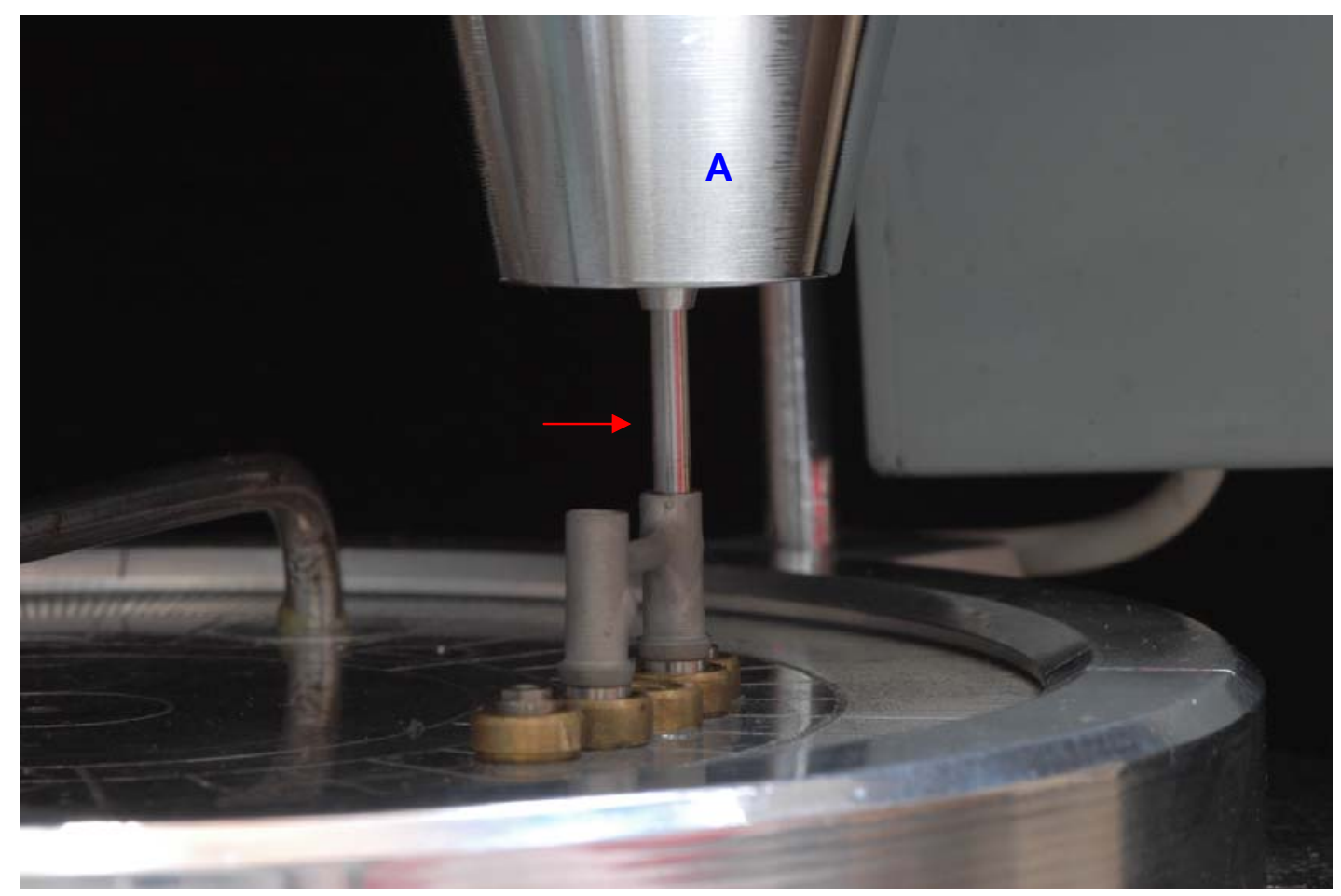

Figura 27 - Chave bidigital (seta) adaptada ao torquímetro (A), realizando aperto do parafuso do abutment durante realização dos testes.

\subsubsection{Funcionamento do dispositivo}

Conforme dito anteriormente, o mecanismo de funcionamento do dispositivo, referente à leitura da quantidade de graus necessária para o aperto dos parafusos dos abutments, sob determinado torque recomendado pelo fabricante, será explicado neste momento a fim de facilitar seu entendimento. Esse mecanismo está centrado basicamente na caixa acessória captadora de graus angulares. Assim, esse dispositivo de leitura é composto por um conjunto mecânico constituído de uma polia cilíndrica (torquímetro), conjugada a duas polias de canal em "V" com o objetivo de girar um leitor óptico infravermelho contido no interior da caixa (Figura 28). Esse leitor, em conjunto com a CPU (Unidade Central de Processamento) do computador, tem como 
finalidade transformar pulsos elétricos em pixel, que, por definição, refere-se ao menor ponto que forma uma imagem digital. Assim, por meio do software GRAUS realizou-se a transformação do movimento de rotação no leitor óptico infravermelho em graus angulares.

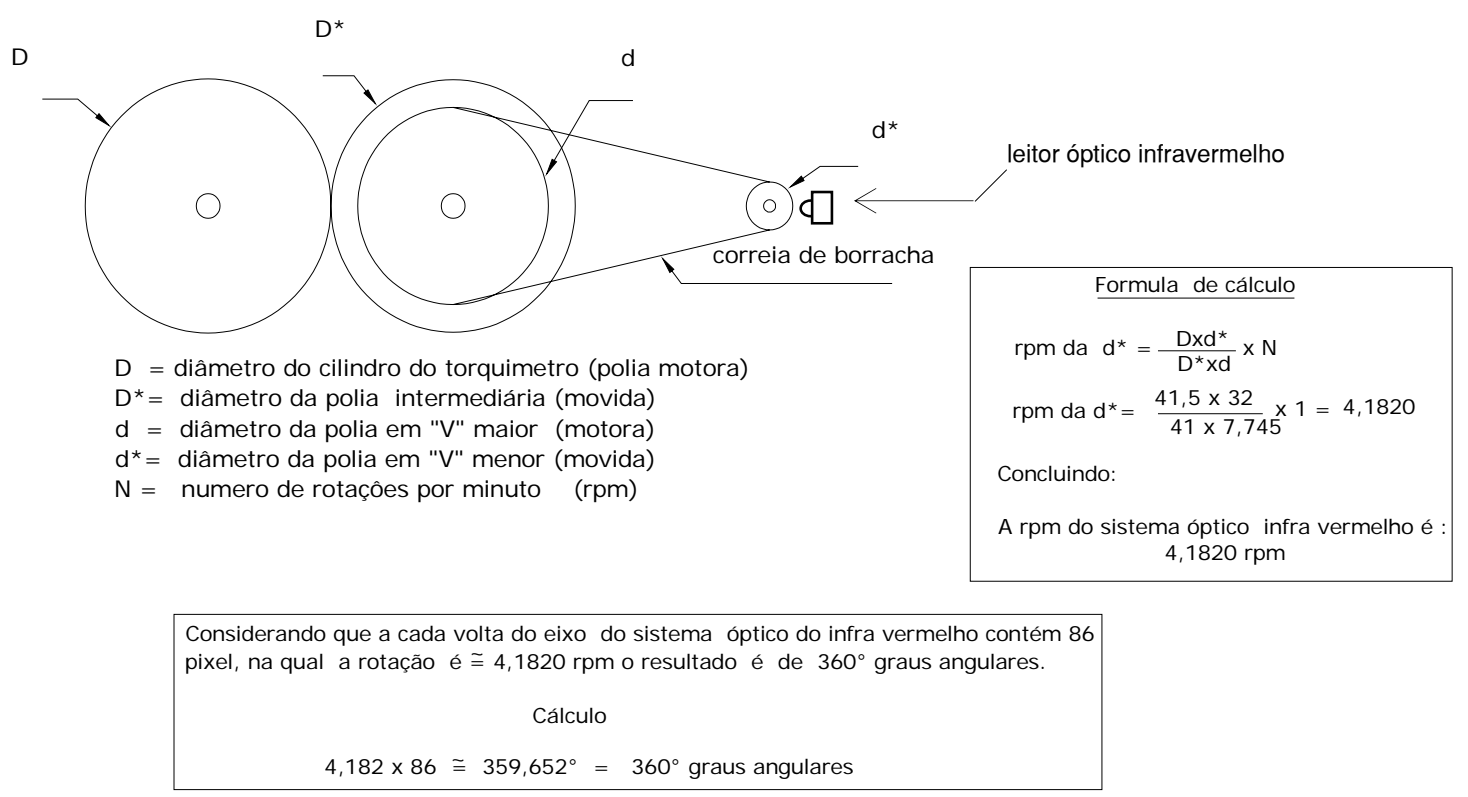

Figura 28 - Conjunto de polias de acionamento do sistema leitor óptico infravermelho, os cálculos matemáticos e os resultados.

Nota: as dimensões das polias estão em milésimos de milímetros.

Ao encostar a polia intermediária na porção cilíndrica do torquímetro (Figura 29) e rotacionar o mesmo, durante o aperto de um parafuso, conseqüentemente se transmite o movimento de rotação para as polias em "V" do conjunto do sistema, localizadas no interior da caixa acessória, fazendo girar o leitor óptico infravermelho, permitindo assim enviar um pulso elétrico o qual por meio do software, será transformado em pixel. Na tela do computador o software se abre em uma janela com divisões de graus em graus angulares, que variam de $0^{\circ}$ a $180^{\circ}$, onde é feita a leitura, demonstrando simultaneamente ao operador a quantidade de graus angulares necessária para o aperto dos parafusos (Figura 30). 


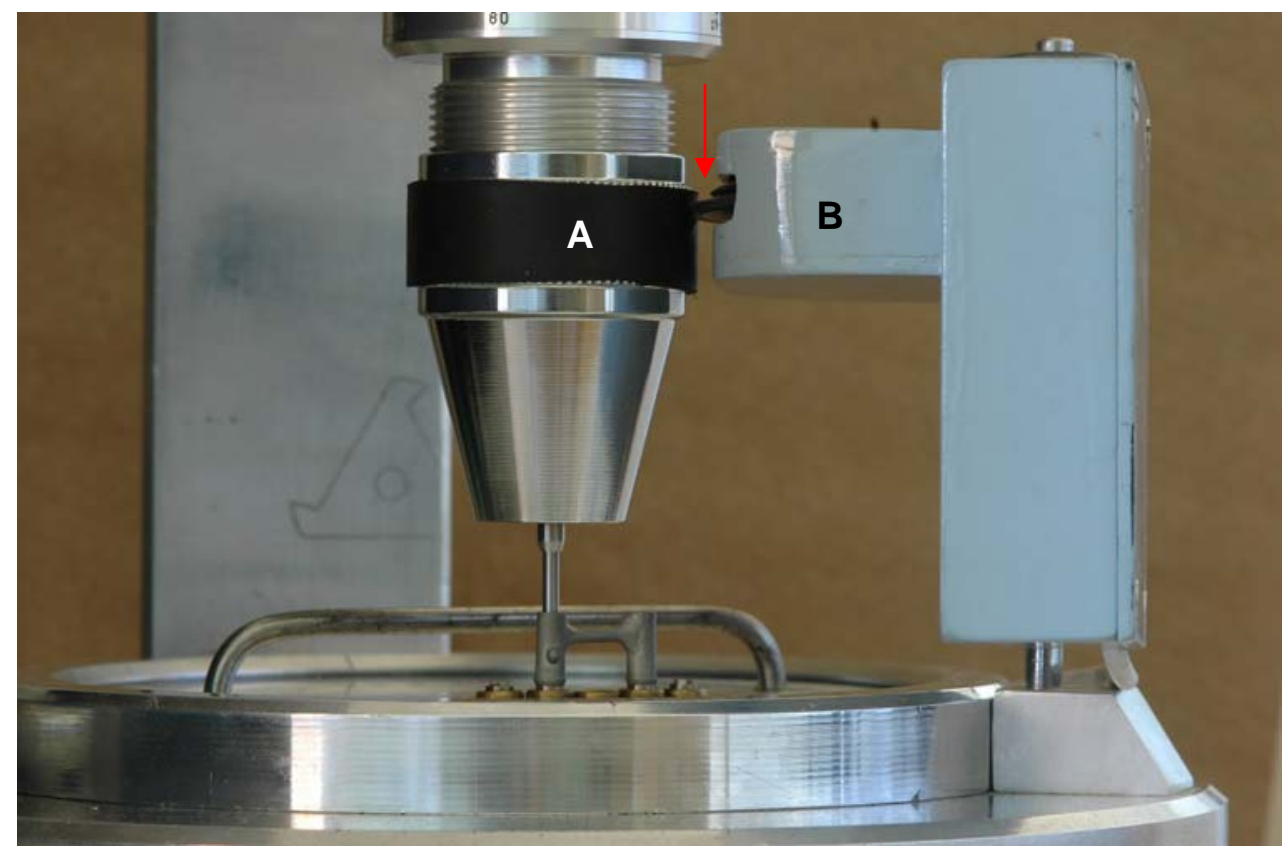

Figura 29 - Contato (seta) entre porção cilíndrica do torquímetro (A) e polia intermediaria da caixa acessória (B). Quando o torquímetro é ativado, durante o torque, a polia intermediária se movimenta, registrando a quantidade de graus necessária para o aperto do parafuso.

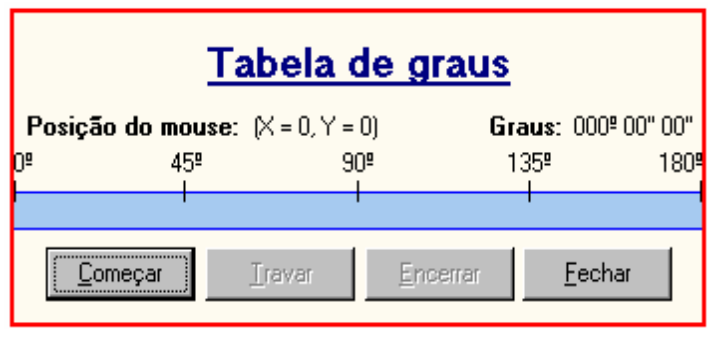

Fig. 30 a

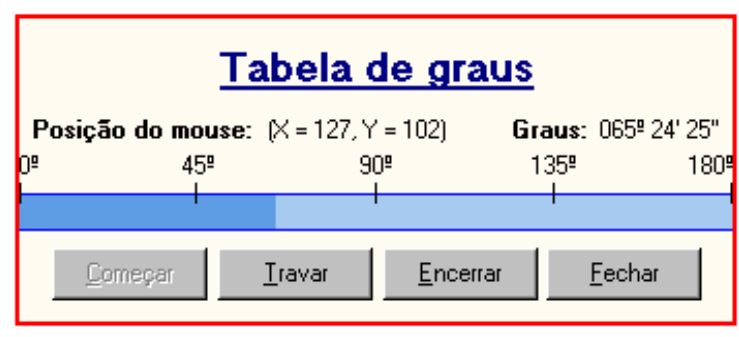

Fig. $30 \mathrm{~b}$

Figura 30 - Interface com o software GRAUS antes (30a) e durante (30b) a leitura da quantidade de graus que identifique o aperto dos parafusos de fixação, na condição de Newtons recomendados pelo fabricante. 


\subsection{Análise estatística}

Os grupos Acrílico Calcinável e Co-Cr foram submetidos a uma comparação nos 3 ensaios realizados para os diferentes momentos de torque, re-torque e destorque, sendo a análise estatística realizada para essa comparação o teste " $t$ ” de Student, com nível de significância de 5\%.

Para a análise do comportamento dos parafusos em relação à seqüência de ensaios, dentro de seu próprio grupo, foi realizada uma análise de variância (ANOVA) a um critério, (ensaio), com nível de significância de 5\%. 


\section{RESULTADOS}

Os valores em graus $\left({ }^{\circ}\right)$, minutos ( ') e segundos ("), necessários para que haja o apertamento dos parafusos obtidos durante os momentos de torque e re-torque, assim como a quantidade de força necessária para o seu afrouxamento (destorque) em $\mathrm{Ncm}$ foram todos registrados e agrupados nas seguintes tabelas: 
Tabela 1 - Resultados para o grupo Acrílico Calcinável. Os corpos de prova seguidos de linha (N') referem-se aos parafusos do abutment esquerdo, conforme citado anteriormente no capítulo Material e Métodos.

\begin{tabular}{|c|c|c|c|c|c|c|c|c|c|c|}
\hline \multirow{2}{*}{\multicolumn{2}{|c|}{$\begin{array}{c}\text { Grupo } \\
\text { Acrílico } \\
\text { Calcinável }\end{array}$}} & \multicolumn{9}{|c|}{ Ensaio } \\
\hline & & \multicolumn{3}{|c|}{$1^{\circ}$} & \multicolumn{3}{|c|}{$2^{\circ}$} & \multicolumn{3}{|c|}{$3^{\circ}$} \\
\hline \multicolumn{2}{|c|}{ Corpo de prova } & Torque & Re-torque & Destorque & Torque & Re-torque & Destorque & Torque & Re-torque & Destorque \\
\hline \multirow[t]{2}{*}{1} & $1^{\prime}$ & $62^{\circ} 47^{\prime} 27^{\prime \prime}$ & $19^{\circ} 21^{\prime} 38^{\prime \prime}$ & $29 \mathrm{Ncm}$ & $44^{\circ} 28^{\prime} 36^{\prime \prime}$ & $16^{\circ} 44^{\prime} 39^{\prime \prime}$ & $30,5 \mathrm{Ncm}$ & $45^{\circ} 31^{\prime} 24^{\prime \prime}$ & $10^{\circ} 59^{\prime} 18^{\prime \prime}$ & $29,5 \mathrm{Ncm}$ \\
\hline & 1 & $72^{\circ} 43^{\prime} 57^{\prime \prime}$ & $20^{\circ} 24^{\prime} 25^{\prime \prime}$ & $29 \mathrm{Ncm}$ & $47^{\circ} 36^{\prime} 59^{\prime \prime}$ & $20^{\circ} 24^{\prime} 25^{\prime \prime}$ & $29 \mathrm{Ncm}$ & $47^{\circ} 05^{\prime} 35^{\prime \prime}$ & $12^{\circ} 02^{\prime} 06^{\prime \prime}$ & $26 \mathrm{Ncm}$ \\
\hline \multirow{2}{*}{2} & 2' & $60^{\circ} 41^{\prime} 52^{\prime \prime}$ & $15^{\circ} 10^{\prime} 28^{\prime \prime}$ & $25 \mathrm{Ncm}$ & $55^{\circ} 59^{\prime} 18^{\prime \prime}$ & $13^{\circ} 04^{\prime} 53^{\prime \prime}$ & $26 \mathrm{Ncm}$ & $53^{\circ} 22^{\prime} 20^{\prime \prime}$ & $11^{\circ} 30^{\prime} 42^{\prime \prime}$ & $32 \mathrm{Ncm}$ \\
\hline & 2 & $48^{\circ} 08^{\prime} 22^{\prime \prime}$ & $14^{\circ} 39^{\prime} 04^{\prime \prime}$ & $30,5 \mathrm{Ncm}$ & $52^{\circ} 50^{\prime} 56^{\prime \prime}$ & $10^{\circ} 59^{\prime} 18^{\prime \prime}$ & $28 \mathrm{Ncm}$ & $44^{\circ} 57^{\prime} 13^{\prime \prime}$ & $13^{\circ} 04^{\prime} 53^{\prime \prime}$ & $27 \mathrm{Ncm}$ \\
\hline \multirow[t]{2}{*}{3} & 31 & $68^{\circ} 32^{\prime} 47^{\prime \prime}$ & $13^{\circ} 36^{\prime} 17^{\prime \prime}$ & $27 \mathrm{Ncm}$ & $55^{\circ} 27^{\prime} 54^{\prime \prime}$ & $9^{\circ} 25^{\prime} 07^{\prime \prime}$ & $32 \mathrm{Ncm}$ & $47^{\circ} 36^{\prime} 59^{\prime \prime}$ & $10^{\circ} 27^{\prime} 54^{\prime \prime}$ & $30 \mathrm{Ncm}$ \\
\hline & 3 & $60^{\circ} 10^{\prime} 28^{\prime \prime}$ & $10^{\circ} 27^{\prime} 54^{\prime \prime}$ & $25 \mathrm{Ncm}$ & $39^{\circ} 14^{\prime} 39^{\prime \prime}$ & $9^{\circ} 56^{\prime} 31^{\prime \prime}$ & $25 \mathrm{Ncm}$ & $36^{\circ} 06^{\prime} 17^{\prime \prime}$ & $13^{\circ} 36^{\prime} 17^{\prime \prime}$ & $25 \mathrm{Ncm}$ \\
\hline \multirow{2}{*}{4} & 4' & $58^{\circ} 36^{\prime} 17^{\prime \prime}$ & $19^{\circ} 21^{\prime} 38^{\prime \prime}$ & $30 \mathrm{Ncm}$ & $39^{\circ} 46^{\prime} 06^{\prime \prime}$ & $9^{\circ} 56^{\prime} 31^{\prime \prime}$ & $25 \mathrm{Ncm}$ & $42^{\circ} 54^{\prime} 25^{\prime \prime}$ & $6^{\circ} 48^{\prime} 08^{\prime \prime}$ & $30 \mathrm{Ncm}$ \\
\hline & 4 & $53^{\circ} 53^{\prime} 43^{\prime \prime}$ & $9^{\circ} 25^{\prime} 07^{\prime \prime}$ & $28,5 \mathrm{Ncm}$ & $37^{\circ} 40^{\prime} 28^{\prime \prime}$ & $9^{\circ} 25^{\prime} 07^{\prime \prime}$ & $30 \mathrm{Ncm}$ & $36^{\circ} 06^{\prime} 17^{\prime \prime}$ & $6^{\circ} 16^{\prime} 45^{\prime \prime}$ & $26 \mathrm{Ncm}$ \\
\hline \multirow{2}{*}{5} & $5^{\prime}$ & $75^{\circ} 20^{\prime} 56^{\prime \prime}$ & $17^{\circ} 16^{\prime} 03^{\prime \prime}$ & $28 \mathrm{Ncm}$ & $53^{\circ} 53^{\prime} 43^{\prime \prime}$ & $10^{\circ} 59^{\prime} 18^{\prime \prime}$ & $28 \mathrm{Ncm}$ & $49^{\circ} 11^{\prime} 10^{\prime \prime}$ & $8^{\circ} 53^{\prime} 43^{\prime \prime}$ & $26 \mathrm{Ncm}$ \\
\hline & 5 & $46^{\circ} 02^{\prime} 47^{\prime \prime}$ & $14^{\circ} 07^{\prime} 40^{\prime \prime}$ & $24,5 \mathrm{Ncm}$ & $40^{\circ} 48^{\prime} 50^{\prime \prime}$ & $7^{\circ} 19^{\prime} 32^{\prime \prime}$ & $25 \mathrm{Ncm}$ & $41^{\circ} 51^{\prime} 38^{\prime \prime}$ & $9^{\circ} 56^{\prime} 31^{\prime \prime}$ & $28,5 \mathrm{Ncm}$ \\
\hline \multirow{2}{*}{6} & $6^{\prime}$ & $61^{\circ} 44^{\prime} 39^{\prime \prime}$ & $16^{\circ} 13^{\prime} 15^{\prime \prime}$ & $27,5 \mathrm{Ncm}$ & $48^{\circ} 39^{\prime} 46^{\prime \prime}$ & $9^{\circ} 56^{\prime} 31 "$ & $25,5 \mathrm{Ncm}$ & $65^{\circ} 55^{\prime} 44^{\prime \prime}$ & $10^{\circ} 27^{\prime} 54^{\prime \prime}$ & $29 \mathrm{Ncm}$ \\
\hline & 6 & $63^{\circ} 50^{\prime} 14^{\prime \prime}$ & $13^{\circ} 04^{\prime} 53^{\prime \prime}$ & $29 \mathrm{Ncm}$ & $40^{\circ} 17^{\prime} 27^{\prime \prime}$ & $17^{\circ} 16^{\prime} 03^{\prime \prime}$ & $28 \mathrm{Ncm}$ & $47^{\circ} 36^{\prime} 57^{\prime \prime}$ & $13^{\circ} 36^{\prime} 17^{\prime \prime}$ & $28 \mathrm{Ncm}$ \\
\hline \multirow{2}{*}{7} & $7^{\prime}$ & $62^{\circ} 16^{\prime} 03^{\prime \prime}$ & $6^{\circ} 48^{\prime} 08^{\prime \prime}$ & $26 \mathrm{Ncm}$ & $50^{\circ} 13^{\prime} 57^{\prime \prime}$ & $10^{\circ} 27^{\prime} 54^{\prime \prime}$ & $26,5 \mathrm{Ncm}$ & $49^{\circ} 42^{\prime} 33^{\prime \prime}$ & $9^{\circ} 25^{\prime} 07^{\prime \prime}$ & $26 \mathrm{Ncm}$ \\
\hline & 7 & $51^{\circ} 48^{\prime} 08^{\prime \prime}$ & $9^{\circ} 25^{\prime} 07^{\prime \prime}$ & $28 \mathrm{Ncm}$ & $38^{\circ} 11^{\prime} 52^{\prime \prime}$ & $7^{\circ} 19^{\prime} 32 "$ & $29 \mathrm{Ncm}$ & $38^{\circ} 11^{\prime} 52^{\prime \prime}$ & $6^{\circ} 48^{\prime} 08^{\prime \prime}$ & $26 \mathrm{Ncm}$ \\
\hline \multirow[t]{2}{*}{8} & 8' & $65^{\circ} 24^{\prime} 25^{\prime \prime}$ & $13^{\circ} 36^{\prime} 17^{\prime \prime}$ & $31 \mathrm{Ncm}$ & $47^{\circ} 36^{\prime} 59^{\prime \prime}$ & $9^{\circ} 56^{\prime} 31^{\prime \prime}$ & $27,5 \mathrm{Ncm}$ & $52^{\circ} 50^{\prime} 56^{\prime \prime}$ & $9^{\circ} 25^{\prime} 07^{\prime \prime}$ & $25 \mathrm{Ncm}$ \\
\hline & 8 & $73^{\circ} 46^{\prime} 45^{\prime \prime}$ & $14^{\circ} 07^{\prime} 40^{\prime \prime}$ & $24 \mathrm{Ncm}$ & $51^{\circ} 16^{\prime} 45^{\prime \prime}$ & $26^{\circ} 09^{\prime} 46^{\prime \prime}$ & $26 \mathrm{Ncm}$ & $48^{\circ} 39^{\prime} 46^{\prime \prime}$ & $11^{\circ} 30^{\prime} 42^{\prime \prime}$ & $27 \mathrm{Ncm}$ \\
\hline \multirow[t]{2}{*}{9} & 9' & $77^{\circ} 26^{\prime} 31^{\prime \prime}$ & $24^{\circ} 04^{\prime} 11^{\prime \prime}$ & $28 \mathrm{Ncm}$ & $51^{\circ} 16^{\prime} 45^{\prime \prime}$ & $16^{\circ} 13^{\prime} 15^{\prime \prime}$ & $28 \mathrm{Ncm}$ & $54^{\circ} 25^{\prime} 07^{\prime \prime}$ & $15^{\circ} 10^{\prime} 28^{\prime \prime}$ & $28,5 \mathrm{Ncm}$ \\
\hline & 9 & $54^{\circ} 56^{\prime} 31^{\prime \prime}$ & $18^{\circ} 50^{\prime} 14^{\prime \prime}$ & $18 \mathrm{Ncm}$ & $55^{\circ} 27^{\prime} 54^{\prime \prime}$ & $15^{\circ} 41^{\prime} 52^{\prime \prime}$ & $19 \mathrm{Ncm}$ & $52^{\circ} 19^{\prime} 32^{\prime \prime}$ & $24^{\circ} 04^{\prime} 11^{\prime \prime}$ & $21 \mathrm{Ncm}$ \\
\hline \multirow{2}{*}{10} & $10^{\prime}$ & $59^{\circ} 07^{\prime} 40^{\prime \prime}$ & $13^{\circ} 36^{\prime} 17^{\prime \prime}$ & $29,5 \mathrm{Ncm}$ & $52^{\circ} 19^{\prime} 32^{\prime \prime}$ & $22^{\circ} 30^{\prime} 00^{\prime \prime}$ & $29 \mathrm{Ncm}$ & $40^{\circ} 48^{\prime} 50^{\prime \prime}$ & $14^{\circ} 07^{\prime} 40^{\prime \prime}$ & $25 \mathrm{Ncm}$ \\
\hline & 10 & $60^{\circ} 10^{\prime} 28^{\prime \prime}$ & $11^{\circ} 30^{\prime} 42^{\prime \prime}$ & $29 \mathrm{Ncm}$ & $55^{\circ} 27^{\prime} 54^{\prime \prime}$ & $10^{\circ} 27^{\prime} 54^{\prime \prime}$ & $24 \mathrm{Ncm}$ & $46^{\circ} 34^{\prime} 11^{\prime \prime}$ & $47^{\circ} 36^{\prime} 59^{\prime \prime}$ & $25 \mathrm{Ncm}$ \\
\hline
\end{tabular}


Tabela 2 - Resultados para o grupo Cobalto - Cromo (Co-Cr). Assim como na tabela anterior, os corpos de prova seguidos de linha ( $N$ ') referem-se aos parafusos do abutment esquerdo, conforme citado anteriormente no capítulo Material e Métodos.

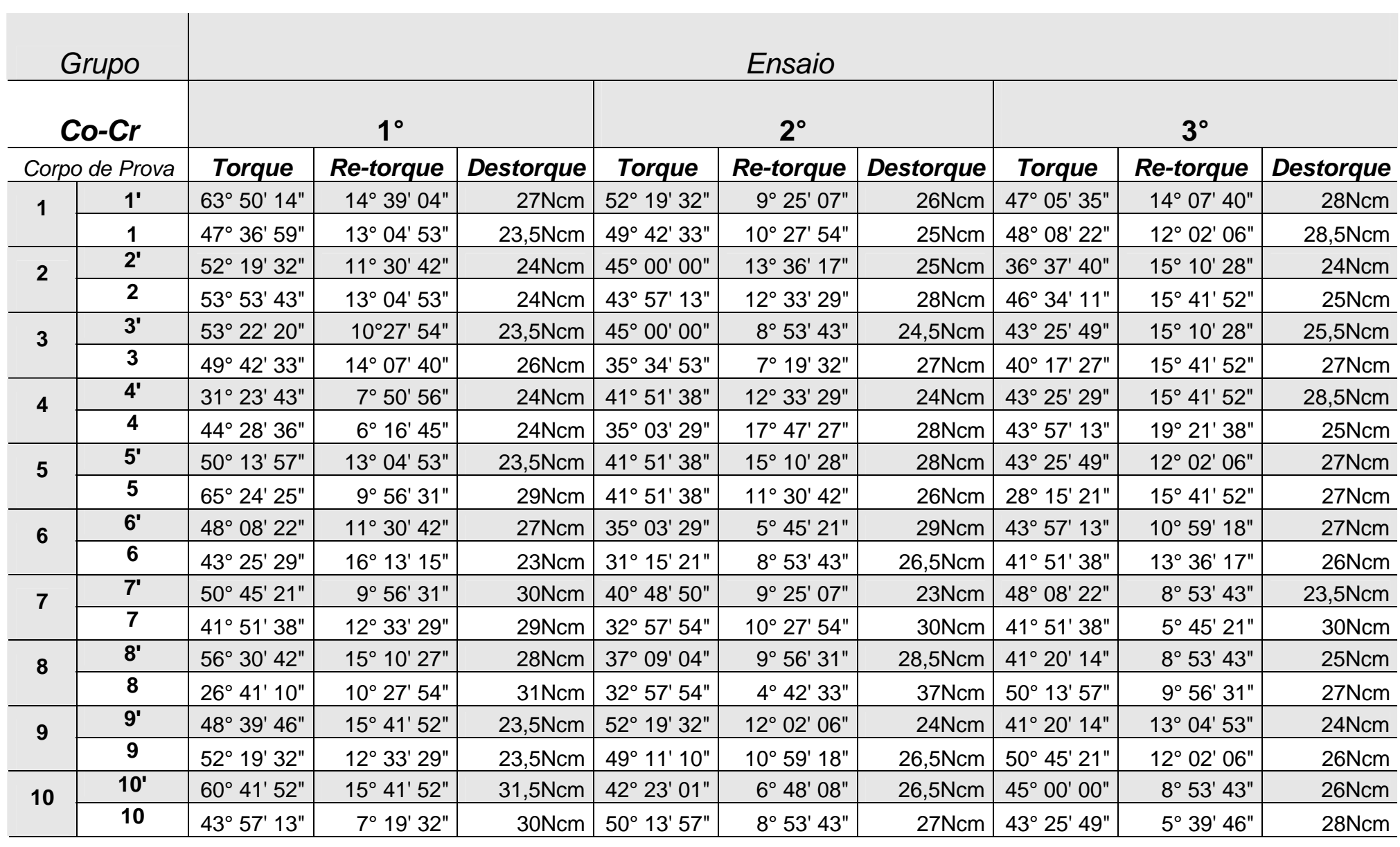


A fim de favorecer a análise estatística, os valores obtidos em graus $\left({ }^{\circ}\right)$, minutos ( ') e segundos ( ") foram convertidos em valores numéricos apenas de graus, com objetivo de obter valores para se tomar as médias dos grupos, sendo os mesmos agrupados nas seguintes tabelas: 
Tabela 3 - Valores convertidos em graus no grupo Acrílico Calcinável, para obtenção das médias da quantidade de graus necessários para o aperto dos parafusos durante os momentos de torque e re-torque.

\begin{tabular}{|c|c|c|c|c|c|c|c|c|c|c|}
\hline \multirow{2}{*}{\multicolumn{2}{|c|}{$\begin{array}{c}\text { Grupo } \\
\text { Acrílico } \\
\text { Calcinável }\end{array}$}} & \multicolumn{9}{|c|}{ Ensaio } \\
\hline & & \multicolumn{3}{|c|}{$1^{\circ}$} & \multicolumn{3}{|c|}{$2^{\circ}$} & \multicolumn{3}{|c|}{$3^{\circ}$} \\
\hline \multicolumn{2}{|c|}{ Corpo de prova } & Torque & Re-torque & Destorque & Torque & Re-torque & Destorque & Torque & Re-torque & Destorque \\
\hline 1 & $1^{\prime}$ & $62,4745^{\circ}$ & $19,2163^{\circ}$ & $29 \mathrm{Ncm}$ & $44,286^{\circ}$ & $16,4465^{\circ}$ & $30,5 \mathrm{Ncm}$ & $45,314^{\circ}$ & $10,593^{\circ}$ & $29,5 \mathrm{Ncm}$ \\
\hline 2 & 2 & $48,0836^{\circ}$ & $14,3606^{\circ}$ & $30,5 \mathrm{Ncm}$ & $52,5093^{\circ}$ & $10,593^{\circ}$ & $28 \mathrm{Ncm}$ & $44,5721^{\circ}$ & $13,0488^{\circ}$ & $27 \mathrm{Ncm}$ \\
\hline \multirow[t]{2}{*}{3} & 31 & $68,3278^{\circ}$ & $13,3628^{\circ}$ & $27 \mathrm{Ncm}$ & $55,279^{\circ}$ & $9,2511^{\circ}$ & $32 \mathrm{Ncm}$ & $47,3698^{\circ}$ & $10,279^{\circ}$ & $30 \mathrm{Ncm}$ \\
\hline & 3 & $60,1046^{\circ}$ & $10,279^{\circ}$ & $25 \mathrm{Ncm}$ & $39,1465^{\circ}$ & $9,5651^{\circ}$ & $25 \mathrm{Ncm}$ & $36,0617^{\circ}$ & $13,3628^{\circ}$ & $25 \mathrm{Ncm}$ \\
\hline \multirow{2}{*}{4} & $4^{\prime}$ & $58,3628^{\circ}$ & $19,2163^{\circ}$ & $30 \mathrm{Ncm}$ & $39,461^{\circ}$ & $9,5651^{\circ}$ & $25 \mathrm{Ncm}$ & $42,5441^{\circ}$ & $6,4813^{\circ}$ & $30 \mathrm{Ncm}$ \\
\hline & 4 & $53,5371^{\circ}$ & $9,2511^{\circ}$ & $28,5 \mathrm{Ncm}$ & $37,4046^{\circ}$ & $9,2511^{\circ}$ & $30 \mathrm{Ncm}$ & $36,0628^{\circ}$ & $6,1675^{\circ}$ & $26 \mathrm{Ncm}$ \\
\hline 6 & 6 & $63,5023^{\circ}$ & $13,0488^{\circ}$ & $29 \mathrm{Ncm}$ & $40,1745^{\circ}$ & $17,1605^{\circ}$ & $28 \mathrm{Ncm}$ & $47,3695^{\circ}$ & $13,3628^{\circ}$ & $28 \mathrm{Ncm}$ \\
\hline \multirow[t]{2}{*}{7} & $7^{\prime}$ & $62,1605^{\circ}$ & $6,4813^{\circ}$ & $26 \mathrm{Ncm}$ & $50,1395^{\circ}$ & $10,279^{\circ}$ & $26,5 \mathrm{Ncm}$ & $49,4255^{\circ}$ & $9,2511^{\circ}$ & $26 \mathrm{Ncm}$ \\
\hline & 7 & $51,4813^{\circ}$ & $9,2511^{\circ}$ & $28 \mathrm{Ncm}$ & $38,1186^{\circ}$ & $7,1953^{\circ}$ & $29 \mathrm{Ncm}$ & $38,1186^{\circ}$ & $6,4813^{\circ}$ & $26 \mathrm{Ncm}$ \\
\hline \multirow[t]{2}{*}{8} & 8' & $65,2441^{\circ}$ & $13,3628^{\circ}$ & $31 \mathrm{Ncm}$ & $47,3698^{\circ}$ & $9,5651^{\circ}$ & $27,5 \mathrm{Ncm}$ & $52,5093^{\circ}$ & $9,2811^{\circ}$ & $25 \mathrm{Ncm}$ \\
\hline & 8 & $73,4675^{\circ}$ & $14,0766^{\circ}$ & $24 \mathrm{Ncm}$ & $51,1675^{\circ}$ & $26,0976^{\circ}$ & $26 \mathrm{Ncm}$ & $48,3976^{\circ}$ & $11,307^{\circ}$ & $27 \mathrm{Ncm}$ \\
\hline \multirow[t]{2}{*}{9} & 9' & $77,2651^{\circ}$ & $24,0418^{\circ}$ & $28 \mathrm{Ncm}$ & $51,1675^{\circ}$ & $16,1325^{\circ}$ & $28 \mathrm{Ncm}$ & $54,2511^{\circ}$ & $15,1046^{\circ}$ & $28,5 \mathrm{Ncm}$ \\
\hline & 9 & $54,5651^{\circ}$ & $18,5023^{\circ}$ & $18 \mathrm{Ncm}$ & $55,279^{\circ}$ & $15,4186^{\circ}$ & $19 \mathrm{Ncm}$ & $52,1953^{\circ}$ & $24,0418^{\circ}$ & $21 \mathrm{Ncm}$ \\
\hline \multirow[t]{2}{*}{10} & $10^{\prime}$ & $59,0766^{\circ}$ & $13,3628^{\circ}$ & $29,5 \mathrm{Ncm}$ & $52,1953^{\circ}$ & $22,3^{\circ}$ & $29 \mathrm{Ncm}$ & $40,4883^{\circ}$ & $14,0766^{\circ}$ & $25 \mathrm{Ncm}$ \\
\hline & 10 & $60,1046^{\circ}$ & $11,307^{\circ}$ & $29 \mathrm{Ncm}$ & $55,279^{\circ}$ & $10,279^{\circ}$ & $24 \mathrm{Ncm}$ & $46,3418^{\circ}$ & $47,3698^{\circ}$ & $25 \mathrm{Ncm}$ \\
\hline
\end{tabular}


Tabela 4 - Valores convertidos em graus no grupo Cobalto - Cromo (Co-Cr), para obtenção das médias da quantidade de graus necessários para o aperto dos parafusos durante os momentos de torque e re-torque.

\begin{tabular}{|c|c|c|c|c|c|c|c|c|c|c|}
\hline \multirow{2}{*}{\multicolumn{2}{|c|}{$\begin{array}{l}\text { Grupo } \\
\mathrm{Co}-\mathrm{Cr}\end{array}$}} & \multicolumn{9}{|c|}{ Ensaio } \\
\hline & & \multicolumn{3}{|c|}{$1^{\circ}$} & \multicolumn{3}{|c|}{$2^{\circ}$} & \multicolumn{3}{|c|}{$3^{\circ}$} \\
\hline \multicolumn{2}{|c|}{ Corpo de Prova } & Torque & Re-torque & Destorque & Torque & Re-torque & Destorque & Torque & Re-torque & Destorque \\
\hline \multirow[t]{2}{*}{1} & $1^{\prime}$ & $63,5023^{\circ}$ & $14,3906^{\circ}$ & $27 \mathrm{Ncm}$ & $52,1953^{\circ}$ & $9,2511^{\circ}$ & $26 \mathrm{Ncm}$ & $47,0558^{\circ}$ & $14,0766^{\circ}$ & $28 \mathrm{Ncm}$ \\
\hline & 1 & $47,3698^{\circ}$ & $13,0488^{\circ}$ & $23,5 \mathrm{Ncm}$ & $49,4255^{\circ}$ & $10,279^{\circ}$ & $25 \mathrm{Ncm}$ & $48,0836^{\circ}$ & $12,021^{\circ}$ & $28,5 \mathrm{Ncm}$ \\
\hline \multirow[t]{2}{*}{2} & $2^{\prime}$ & $52,1953^{\circ}$ & $11,307^{\circ}$ & $24 \mathrm{Ncm}$ & $45^{\circ}$ & $13,3628^{\circ}$ & $25 \mathrm{Ncm}$ & $36,3766^{\circ}$ & $15,1046^{\circ}$ & $24 \mathrm{Ncm}$ \\
\hline & 2 & $53,5371^{\circ}$ & $13,0488^{\circ}$ & $24 \mathrm{Ncm}$ & $43,5721^{\circ}$ & $12,3348^{\circ}$ & $28 \mathrm{Ncm}$ & $46,3418^{\circ}$ & $15,4186^{\circ}$ & $25 \mathrm{Ncm}$ \\
\hline \multirow[t]{2}{*}{3} & $3 '$ & $53,2233^{\circ}$ & $10,279^{\circ}$ & $23,5 \mathrm{Ncm}$ & $45^{\circ}$ & $8,5371^{\circ}$ & $24,5 \mathrm{Ncm}$ & $43,2581^{\circ}$ & $15,1046^{\circ}$ & $25,5 \mathrm{Ncm}$ \\
\hline & 3 & $49,4255^{\circ}$ & $14,0766^{\circ}$ & $26 \mathrm{Ncm}$ & $35,3488^{\circ}$ & $7,1953^{\circ}$ & $27 \mathrm{Ncm}$ & $40,1745^{\circ}$ & $15,4186^{\circ}$ & $27 \mathrm{Ncm}$ \\
\hline \multirow[t]{2}{*}{4} & $4^{\prime}$ & $31,2371^{\circ}$ & $7,5093^{\circ}$ & $24 \mathrm{Ncm}$ & $41,5163^{\circ}$ & $12,3348^{\circ}$ & $24 \mathrm{Ncm}$ & $43,2548^{\circ}$ & $15,4186^{\circ}$ & $28,5 \mathrm{Ncm}$ \\
\hline & 4 & $44,286^{\circ}$ & $6,1675^{\circ}$ & $24 \mathrm{Ncm}$ & $35,0348^{\circ}$ & $17,4745^{\circ}$ & $28 \mathrm{Ncm}$ & $43,5721^{\circ}$ & $19,2163^{\circ}$ & $25 \mathrm{Ncm}$ \\
\hline \multirow[t]{2}{*}{5} & $5^{\prime}$ & $50,1395^{\circ}$ & $13,0488^{\circ}$ & $23,5 \mathrm{Ncm}$ & $41,5163^{\circ}$ & $15,1046^{\circ}$ & $28 \mathrm{Ncm}$ & $43,2581^{\circ}$ & $12,021^{\circ}$ & $27 \mathrm{Ncm}$ \\
\hline & 5 & $65,2441^{\circ}$ & $9,5651^{\circ}$ & $29 \mathrm{Ncm}$ & $41,5163^{\circ}$ & $11,307^{\circ}$ & $26 \mathrm{Ncm}$ & $28,1535^{\circ}$ & $15,4186^{\circ}$ & $27 \mathrm{Ncm}$ \\
\hline \multirow[t]{2}{*}{6} & 6' & $48,0836^{\circ}$ & $11,307^{\circ}$ & $27 \mathrm{Ncm}$ & $35,0348^{\circ}$ & $5,4535^{\circ}$ & $29 \mathrm{Ncm}$ & $43,5721^{\circ}$ & $10,593^{\circ}$ & $27 \mathrm{Ncm}$ \\
\hline & 6 & $43,2548^{\circ}$ & $16,1325^{\circ}$ & $23 \mathrm{Ncm}$ & $31,1535^{\circ}$ & $8,5371^{\circ}$ & $26,5 \mathrm{Ncm}$ & $41,5163^{\circ}$ & $13,3628^{\circ}$ & $26 \mathrm{Ncm}$ \\
\hline \multirow[t]{2}{*}{7} & $7 '$ & $50,4535^{\circ}$ & $9,5651^{\circ}$ & $30 \mathrm{Ncm}$ & $40,4883^{\circ}$ & $9,2811^{\circ}$ & $23 \mathrm{Ncm}$ & $48,0836^{\circ}$ & $8,5371^{\circ}$ & $23,5 \mathrm{Ncm}$ \\
\hline & 7 & $41,5163^{\circ}$ & $12,3348^{\circ}$ & $29 \mathrm{Ncm}$ & $32,579^{\circ}$ & $10,279^{\circ}$ & $30 \mathrm{Ncm}$ & $41,5163^{\circ}$ & $5,4525^{\circ}$ & $30 \mathrm{Ncm}$ \\
\hline \multirow[t]{2}{*}{8} & 81 & $56,307^{\circ}$ & $15,1045^{\circ}$ & $28 \mathrm{Ncm}$ & $37,0906^{\circ}$ & $9,5651^{\circ}$ & $28,5 \mathrm{Ncm}$ & $41,2023^{\circ}$ & $8,5371^{\circ}$ & $25 \mathrm{Ncm}$ \\
\hline & 8 & $26,4116^{\circ}$ & $10,279^{\circ}$ & $31 \mathrm{Ncm}$ & $32,579^{\circ}$ & $4,4255^{\circ}$ & $37 \mathrm{Ncm}$ & $50,1395^{\circ}$ & $9,5651^{\circ}$ & $27 \mathrm{Ncm}$ \\
\hline \multirow[t]{2}{*}{9} & $9^{\prime}$ & $48,3976^{\circ}$ & $15,4186^{\circ}$ & $23,5 \mathrm{Ncm}$ & $52,1953^{\circ}$ & $12,021^{\circ}$ & $24 \mathrm{Ncm}$ & $41,2013^{\circ}$ & $13,0488^{\circ}$ & $24 \mathrm{Ncm}$ \\
\hline & 9 & $52,1953^{\circ}$ & $12,3348^{\circ}$ & $23,5 \mathrm{Ncm}$ & $49,1116^{\circ}$ & $10,593^{\circ}$ & $26,5 \mathrm{Ncm}$ & $50,4535^{\circ}$ & $12,021^{\circ}$ & $26 \mathrm{Ncm}$ \\
\hline \multirow[t]{2}{*}{10} & $10^{\prime}$ & $60,4186^{\circ}$ & $15,4186^{\circ}$ & $31,5 \mathrm{Ncm}$ & $42,2301^{\circ}$ & $6,4813^{\circ}$ & $26,5 \mathrm{Ncm}$ & $45^{\circ}$ & $8,5371^{\circ}$ & $26 \mathrm{Ncm}$ \\
\hline & 10 & $43,5721^{\circ}$ & $7,1953^{\circ}$ & $30 \mathrm{Ncm}$ & $50,1395^{\circ}$ & $8,5371^{\circ}$ & $27 \mathrm{Ncm}$ & $43,2581^{\circ}$ & $5,3965^{\circ}$ & $28 \mathrm{Ncm}$ \\
\hline
\end{tabular}


Os grupos foram submetidos a uma comparação nos 3 ensaios realizados para os diferentes momentos de torque, re-torque e destorque, sendo a análise estatística realizada para essa comparação o teste " $\mathrm{t}$ " de Student, com nível de significância de 5\%.

\subsection{Momento de Torque}

Tabela 5 - Comparação dos momentos de Torque entre grupos no ensaio 1

\begin{tabular}{l|c|c|c} 
Grupo & Média & Desvio-Padrão & $N^{\circ}$ de Parafusos \\
\hline Acrílico Calcinável & $61.66496^{*}$ & 8.635636 & 20 \\
\hline Co-Cr & $49.03852^{*}$ & 9.433093 & 20 \\
\hline
\end{tabular}

Probabilidade: 0.000080 (significante); $p<0,05$.

* Diferença estatisticamente significante.

Tabela 6 - Comparação dos momentos de Torque entre grupos no ensaio 2

\begin{tabular}{l|c|c|c} 
Grupo & Média & Desvio-Padrão & $N^{\circ}$ de Parafusos \\
\hline Acrílico Calcinável & $47.71814^{\star}$ & 6.496426 & 20 \\
\hline Co-Cr & $41.63635^{\star}$ & 6.732658 & 20 \\
\hline
\end{tabular}

Probabilidade: 0.006057 (significante); $p<0,05$.

* Diferença estatisticamente significante.

Tabela 7 - Comparação dos momentos de Torque entre grupos no ensaio 3

\begin{tabular}{l|c|c|c} 
Grupo & Média & Desvio-Padrão & $N^{\circ}$ de Parafusos \\
\hline Acrílico Calcinável & $47.37430^{\star}$ & 7.008730 & 20 \\
\hline Co-Cr & $43.27359^{\star}$ & 4.986263 & 20 \\
\hline
\end{tabular}

Probabilidade: 0.039525 (significante); $p<0,05$.

* Diferença estatisticamente significante. 


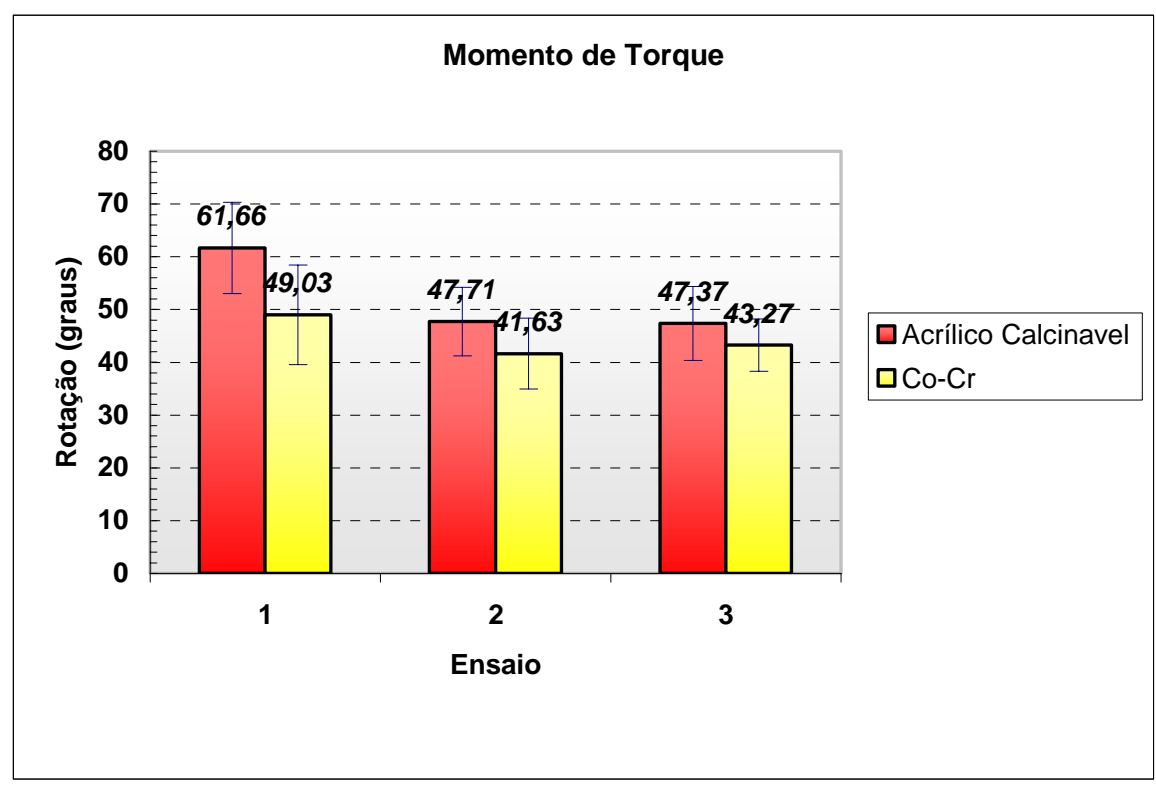

Gráfico 1 - Comparação dos valores médios de rotação dos parafusos, em graus, no Momento de Torque entre os dois grupos.

Observar que, nos 3 ensaios, os parafusos do grupo Acrílico Calcinável sofreram maior rotação para atingir o torque recomendado pelo fabricante de $30 \mathrm{Ncm}$.

Nos 3 ensaios para o momento de torque, a diferença entre os grupos foi estatisticamente significante; $P<0,05$.

\subsection{Momento de Re-torque}

Tabela 8 - Comparação dos momentos de Re-torque entre grupos no ensaio 1.

\begin{tabular}{l|c|c|c} 
Grupo & Média & Desvio-Padrão & $N^{\circ}$ de Parafusos \\
\hline Acrílico Calcinável & $14.59194^{\star}$ & 4.281311 & 20 \\
\hline Co-Cr & $11.48112^{\star}$ & 2.926706 & 20 \\
\hline
\end{tabular}

Probabilidade: 0.010754 (significante); $p<0,05$.

* Diferença estatisticamente significante. 
Tabela 9 - Comparação dos momentos de Re-torque entre grupos no ensaio 2.

\begin{tabular}{l|c|c|c} 
Grupo & Média & Desvio-Padrão & $N^{\circ}$ de Parafusos \\
\hline Acrílico Calcinável & $12.98729^{\star}$ & 5.253822 & 20 \\
\hline Co-Cr & $10.11773^{\star}$ & 3.160939 & 20 \\
\hline
\end{tabular}

Probabilidade: 0.043078 (significante); $p<0,05$.

* Diferença estatisticamente significante.

Tabela 10 - Comparação dos momentos de Re-torque entre grupos no ensaio 3.

\begin{tabular}{l|c|c|c} 
Grupo & Média & Desvio-Padrão & $N^{\circ}$ de Parafusos \\
\hline Acrílico Calcinável & 13.09598 & 8.966085 & 20 \\
\hline Co-Cr & 12.21347 & 3.662168 & 20 \\
\hline
\end{tabular}

Probabilidade: 0.685927 (não significante); $p<0,05$.

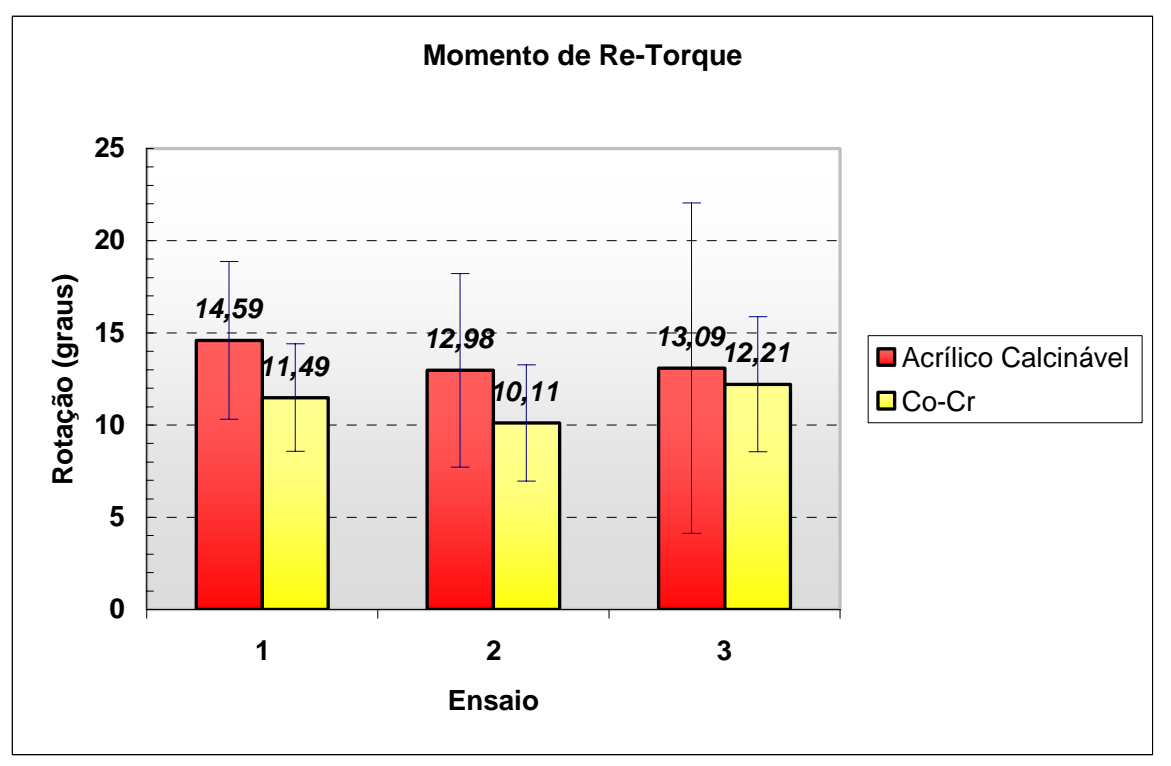

Gráfico 2 - Comparação dos valores médios de rotação dos parafusos no momento de re-torque entre os dois grupos.

Observar novamente que, nos 3 ensaios, os parafusos do grupo Acrílico Calcinável sofreram maior rotação para atingir o torque recomendado de $30 \mathrm{Ncm}$.

Durante o momento de re-torque, apenas nos ensaios 1 e 2 a diferença entre os grupos foi estatisticamente significante; $P<0,05$. 


\subsection{Destorque}

Tabela 11 - Comparação dos valores de Destorque entre grupos no ensaio 1.

\begin{tabular}{l|c|c|c} 
Grupo & Média & Desvio-Padrão & $N^{\circ}$ de Parafusos \\
\hline Acrílico Calcinável & 27.32500 & 2.974784 & 20 \\
\hline Co-Cr & 26.25000 & 2.958039 & 20 \\
\hline
\end{tabular}

Probabilidade: 0.258970 (não significante); $p<0,05$.

Tabela 12 - Comparação dos valores de Destorque entre grupos no ensaio 2.

\begin{tabular}{l|c|c|c} 
Grupo & Média & Desvio-Padrão & $N^{\circ}$ de Parafusos \\
\hline Acrílico Calcinável & 27.05000 & 2.827961 & 20 \\
\hline Co-Cr & 26.97500 & 2.984499 & 20 \\
\hline
\end{tabular}

Probabilidade: 0.925410 (não significante); $p<0,05$.

Tabela 13 - Comparação dos valores de Destorque entre grupos no ensaio 3.

\begin{tabular}{l|c|c|c} 
Grupo & Média & Desvio-Padrão & $N^{\circ}$ de Parafusos \\
\hline Acrílico Calcinável & 27.02500 & 2.468085 & 20 \\
\hline Co-Cr & 26.40000 & 1.713721 & 20 \\
\hline
\end{tabular}

Probabilidade: 0.358122 (não significante); $p<0,05$. 


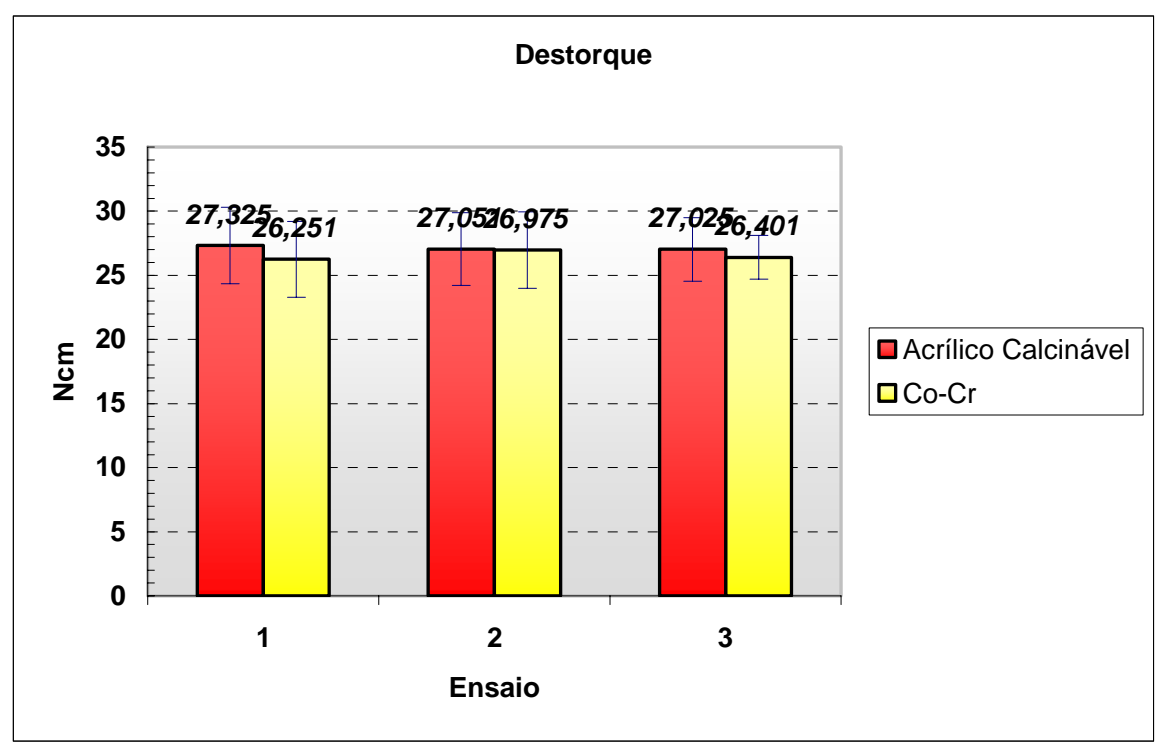

Gráfico 3 - Comparação dos valores médios de Destorque entre os grupos.

Embora os valores médios de destorque sejam maiores para o Grupo Acrílico Calcinável, não há diferença estatisticamente significante entre os grupos; $P<0,05$. 
Para uma análise do comportamento dos parafusos em relação à seqüência de ensaios, dentro de seu grupo, foi realizada uma análise de variância (ANOVA) a um critério, (ensaio), com nível de significância de 5\%.

\subsection{Comparação entre ensaios - Momento de Torque}

Tabela 14 - Comparação do momento de Torque entre ensaios no grupo Acrílico Calcinável.

\begin{tabular}{c|c|c} 
ENSAIO & Média (DP) & $N^{\circ}$ de Parafusos \\
\hline 1 & $61,66271(8.63)$ & 20 \\
\hline 2 & $47,71814(6.49)$ & 20 \\
\hline 3 & $46,87429(6.97)$ & 20 \\
\hline
\end{tabular}

Probabilidade: 0,0000; $p<0,05$.

Diferença significante na comparação entre os ensaios 1 × 2 e 1 × 3 .

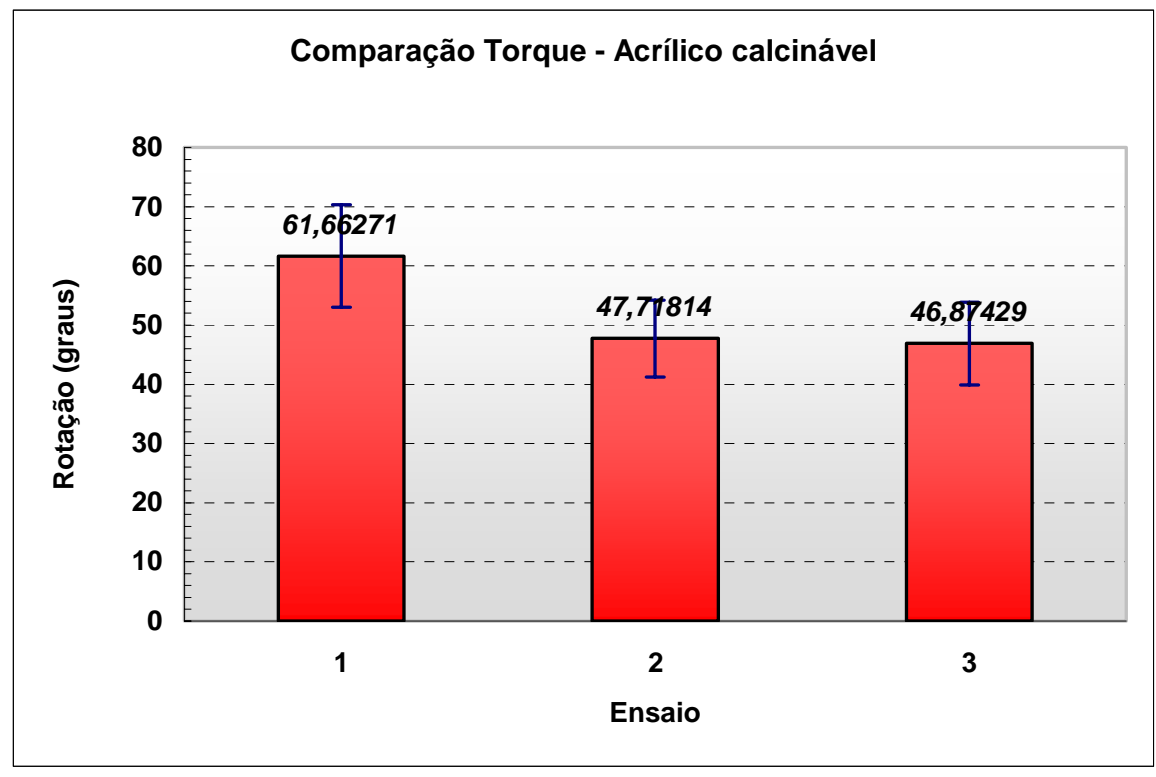

Gráfico 4 - Representação dos valores médios de rotação dos parafusos, durante o momento de torque, nos diferentes ensaios realizados para o grupo Acrílico calcinável.

Para o momento de torque, há diferença estatisticamente significante entre os ensaios 1 e 2 ; e 1 e $3: P<0,05$. 
Tabela 15 - Comparação do momento de Torque entre ensaios no grupo Co-Cr.

\begin{tabular}{c|c|c} 
ENSAIO & Média (DP) & $N^{\circ}$ de Parafusos \\
\hline 1 & $49,03852(9.43)$ & 20 \\
\hline 2 & $41,63635(6.73)$ & 20 \\
\hline 3 & $43,27134(4.98)$ & 20 \\
\hline
\end{tabular}

Probabilidade: 0,$00450 ; p<0,05$

Diferença significante na comparação entre os ensaios $1 \times 2$.

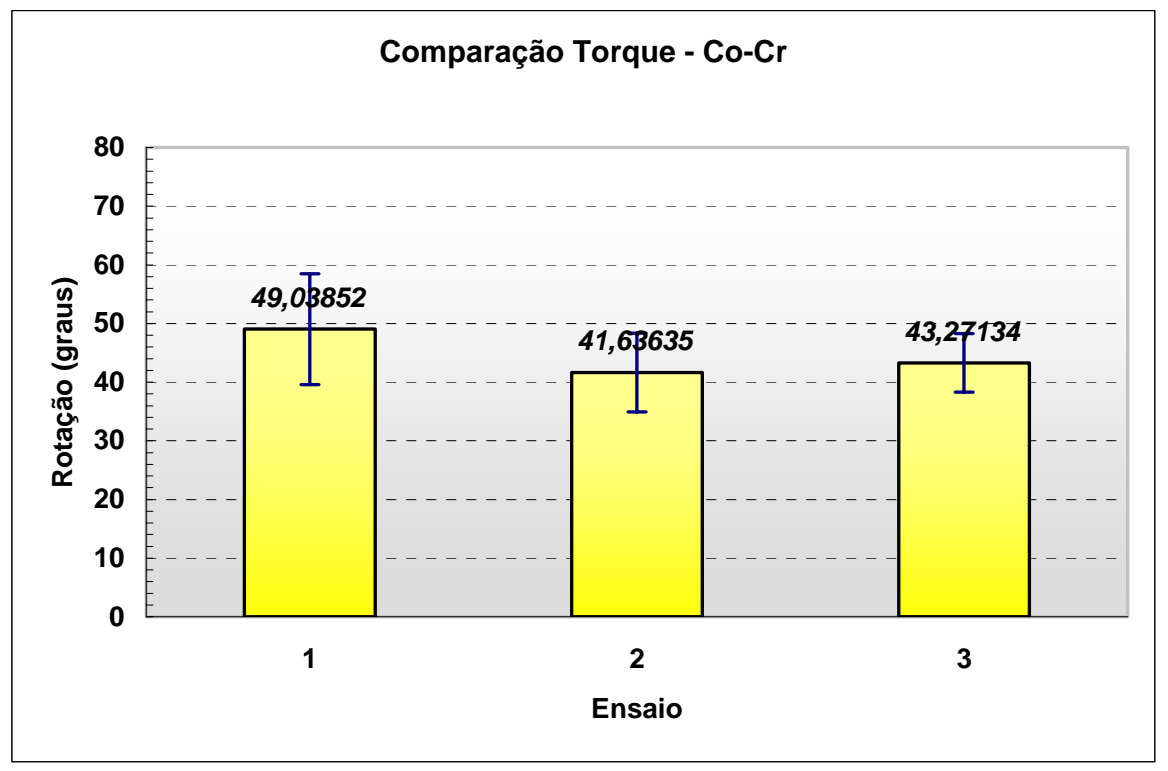

Gráfico 5 - Representação dos valores médios de rotação dos parafusos, durante o momento de torque, nos diferentes ensaios realizados para o grupo Co-Cr.

Para o momento de torque, há diferença estatisticamente significante apenas entre os ensaios 1 e 2: $P<0,05$. 


\subsection{Comparação entre ensaios - Momento de Re-torque}

Tabela 16 - Comparação do momento de Re-torque entre ensaios no grupo Acrílico Calcinável.

\begin{tabular}{c|c|c} 
ENSAIO & Média (DP) & $N^{\circ}$ de Parafusos \\
\hline 1 & $14,69194(4,22)$ & 20 \\
\hline 2 & $12,98729(5,25)$ & 20 \\
\hline 3 & $13,09588(8,96)$ & 20 \\
\hline
\end{tabular}

Probabilidade: 0,$61481 ; p<0,05$

Diferença não significante na comparação entre os ensaios.

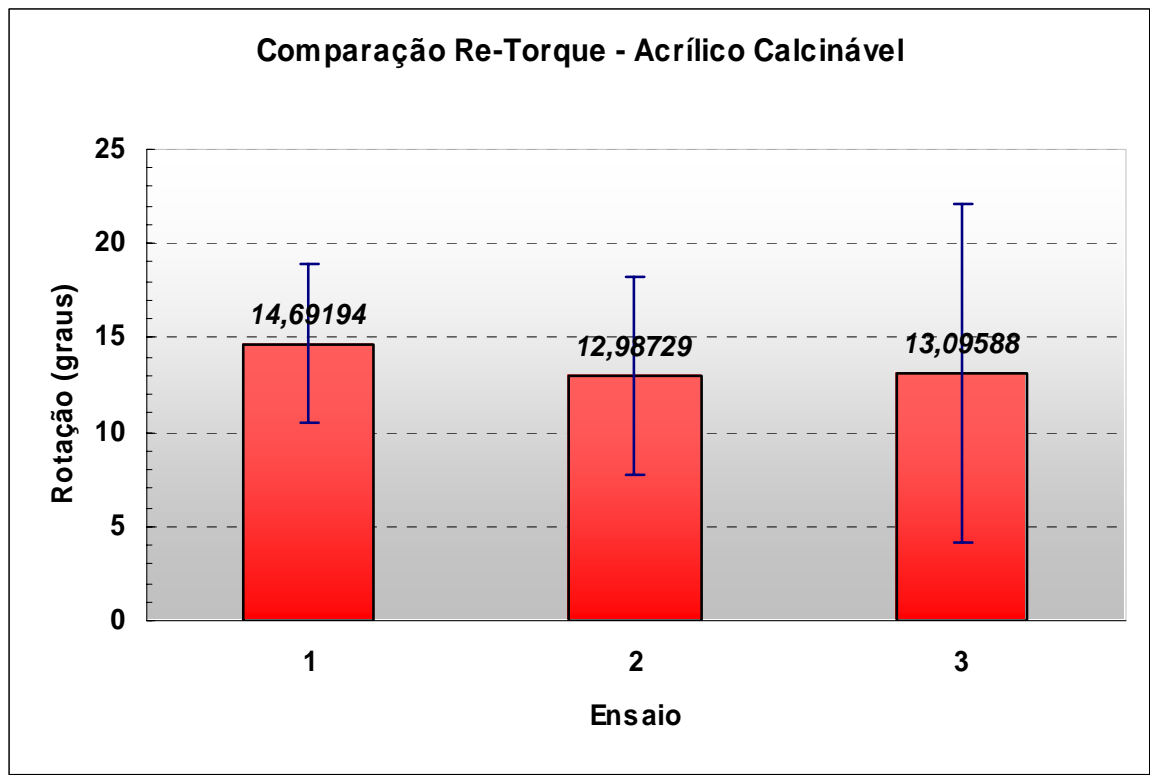

Gráfico 6 - Representação dos valores médios de rotação dos parafusos, durante o momento de re-torque, nos diferentes ensaios realizados para o grupo Acrílico Calcinável.

Não há diferença estatisticamente significante entre os ensaios realizados: $P<0,05$. 
Tabela 17 - Comparação do momento de Re-torque entre ensaios no grupo Co-Cr.

\begin{tabular}{c|c|c} 
ENSAIO & Média (DP) & $N^{\circ}$ de Parafusos \\
\hline 1 & $11,87658(2,89)$ & 20 \\
\hline 2 & $10,06773(3,08)$ & 20 \\
\hline 3 & $12,21347(3,66)$ & 20 \\
\hline
\end{tabular}

Probabilidade: 0,07845; $p<0,05$.

Diferença não significante na comparação entre os ensaios.

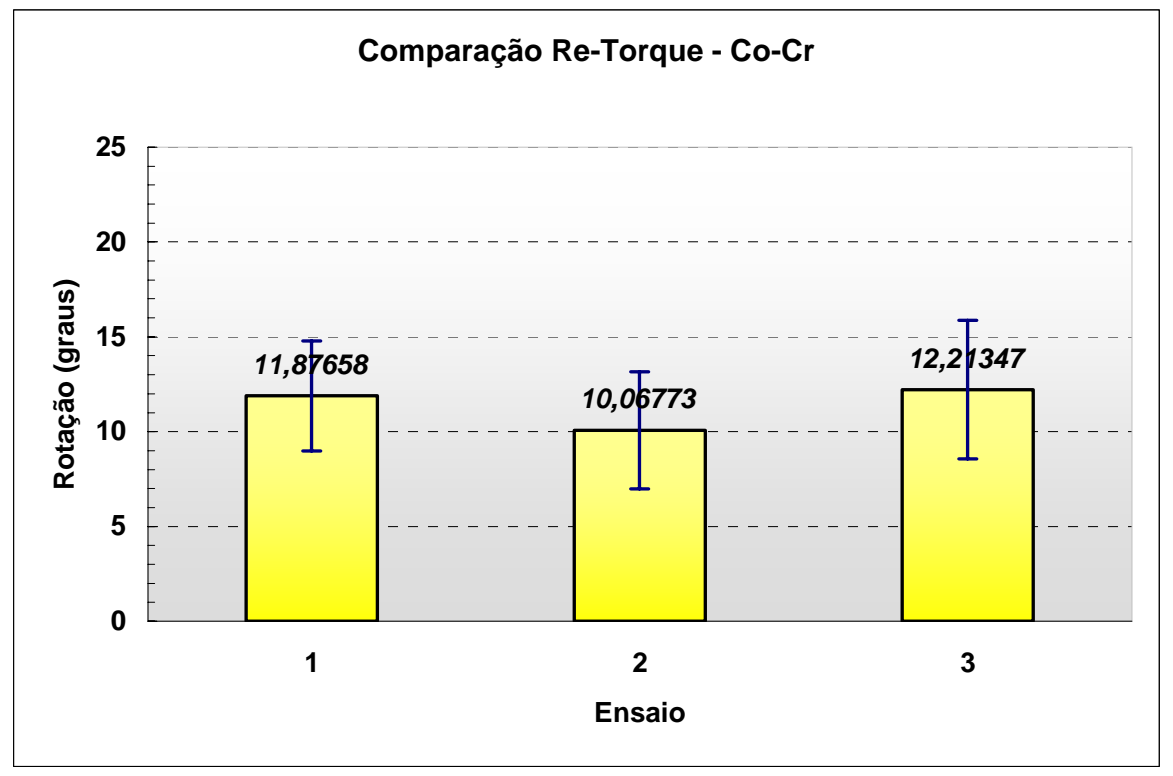

Gráfico 7 - Representação dos valores médios de rotação dos parafusos, durante o momento de re-torque, nos diferentes ensaios realizados para o grupo Co-Cr.

Não há diferença estatisticamente significante entre os ensaios realizados: $P<0,05$. 


\subsection{Comparação entre ensaios - Destorque}

Tabela 18 - Comparação dos valores de Destorque entre ensaios no grupo Acrílico Calcinável.

\begin{tabular}{c|c|c} 
ENSAIO & Média (DP) & $N^{\circ}$ de Parafusos \\
\hline 1 & $27,32500(2,97)$ & 20 \\
\hline 2 & $27,05000(2,82)$ & 20 \\
\hline 3 & $27,02500(2,46)$ & 20 \\
\hline
\end{tabular}

Probabilidade: 0,87443; $p<0,05$.

Diferença não significante na comparação entre os ensaios.

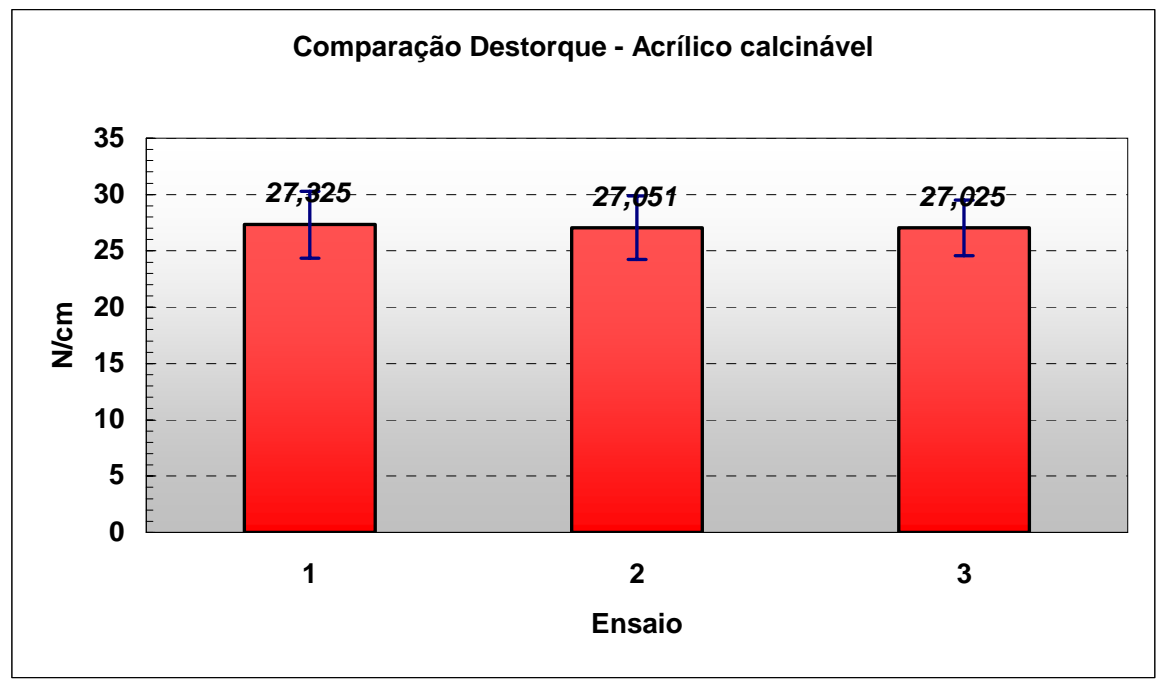

Gráfico 8 - Representação dos valores médios de destorque dos parafusos, durante o afrouxamento dos mesmos, nos diferentes ensaios realizados para o grupo Acrílico calcinável.

Não há diferença estatisticamente significante entre os ensaios realizados: $P<0,05$. 
Tabela 19 - Comparação dos valores de Destorque entre ensaios no grupo Co-Cr.

\begin{tabular}{c|c|c} 
ENSAIO & Média (DP) & $N^{\circ}$ de Parafusos \\
\hline 1 & $26,25000(2,95)$ & 20 \\
\hline 2 & $26,97500(2,98)$ & 20 \\
\hline 3 & $26,40000(1,71)$ & 20 \\
\hline
\end{tabular}

Probabilidade: 0,$55587 ; p<0,05$.

Diferença não significante na comparação entre os ensaios.

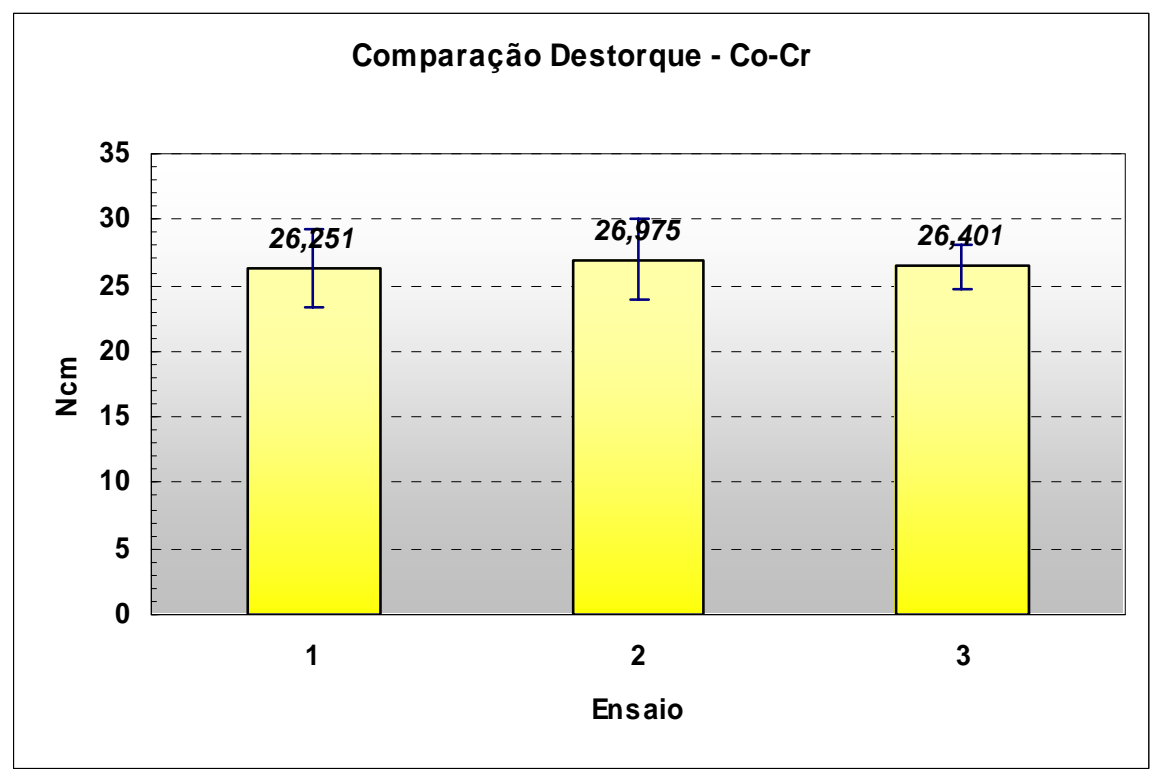

Gráfico 9 - Representação dos valores médios de destorque dos parafusos, durante o afrouxamento dos mesmos, nos diferentes ensaios realizados para o grupo Co-Cr.

Não há diferença estatisticamente significante entre os ensaios realizados: $P<0,05$. 
6 - DISCUSSÃO 


\section{DISCUSSÃO}

No decorrer dos anos da história da prótese dentária, a precisão de adaptação dos elementos protéticos sobre os remanescentes dentais, e atualmente sobre os implantes osseointegrados, vem sendo cada vez mais questionada como um fator significante na transferência de estresse para os retentores e na ocorrência de complicações tanto biomecânicas (SKALAK ${ }^{61}$, 1983) quanto biológicas (COX; ZARB ${ }^{21}$, 1987; JEMT et al. ${ }^{35}, 1991$ ) determinando, dessa forma, uma menor longevidade às próteses.

A adaptação passiva de uma prótese subre implante pode ser definida como uma situação onde a estrutura protética não induz qualquer tensão sobre os implantes e seus componentes, assim como na estrutura óssea ao redor dos mesmos (SAHIN; CEHRELI ${ }^{56}$, 2001). Embora se assuma que a adaptação passiva seja um dos pré-requisitos mais importantes para a manutenção da osseointegração (COX; ZARB ${ }^{21}$, 1987), faltam ainda estudos longitudinais clínicos que suportem essa afirmação, assim como aqueles que mostrem como obtermos uma adaptação totalmente passiva nessas próteses.

Ainda que muito se tenha pesquisado, não há informações precisas de qual seja a quantidade ideal de adaptação entre os implantes e seus componentes, os quais dão origem às próteses sobre implantes. Da mesma maneira, diversos autores tentam esclarecer qual seria o melhor, dentre os diferentes métodos de obtenção das infra-estruturas protéticas, para evitar complicações oriundas de uma infra-estrutura não adaptada (BRUCE ${ }^{13}$, 1964; HULING; CLARK ${ }^{32}$, 1977; SCHIFFLEGER et al. ${ }^{59}$, 1985; ZIEBERT et al. ${ }^{69}$, 1986; RASMUSSEN ${ }^{54}$, 1987; GEGAUFF; ROSENSTIEL ${ }^{25}$, 1989; SARFATI; HARTER ${ }^{58}$, 1992; GOLL ${ }^{26}, 1991 ;$ TAN et al. ${ }^{64}$, 1993; RIEDY; LANG; LANG ${ }^{55}$, 1997). No contexto das próteses sobre implantes, existem muitos fatores que podem contribuir para uma precisão precária de adaptação delas sobre seus retentores, incluindo a variedade de componentes protéticos dos diferentes sistemas presentes no mercado e uma possível compatibilidade entre eles (JAARDA; RAZZOOG; GRATTON ${ }^{34}$, 1995; BINON ${ }^{10}$, 2000), assim como as diversas etapas clínicas e laboratoriais incluídas na confecção das próteses (RASMUSSEN $^{54}$, 1987; GOLL ${ }^{26}$, 1991; APARICIO ${ }^{4}$, 1995). Procedimentos 
como moldagem (transferências), obtenção de modelos em gesso, técnicas de registro e as diferentes maneiras de se obter uma infra-estrutura podem influenciar de forma acumulativa na condição de maior ou menor precisão de adaptação das próteses sobre seus retentores (RIEDY; LANG; LANG ${ }^{55}$, 1997).

A literatura, em alguns momentos, gerou dúvidas a respeito de qual seria a melhor maneira de se obter infra-estruturas para próteses parciais fixas, já que vários estudos compararam a precisão de infra-estruturas obtidas em peça única (monobloco) e pós-soldagem (BRUCE ${ }^{13}$, 1964; HULING; CLARK ${ }^{32}$, 1977; ZIEBERT et al. ${ }^{69}$, 1986; GEGAUFF; ROSENSTIEL ${ }^{25}$, 1989), desde as condições de próteses tradicionais até as atuais próteses sobre implantes. Porém, além das dúvidas, permanecem outros fatores atualmente agregados nessas próteses, os quais demandam maiores estudos e interpretações.

Em função das discussões presentes na literatura, nos vários aspectos já citados, este trabalho teve como objetivo comparar o grau de rotação de apenas um tipo de parafuso (titânio grau 5), durante o momento de torque entre 2 tipos de abutments (Acrílico Calcinável e Co-Cr), ambos obtidos por fundições em monobloco. De acordo com o Gráfico 1, no capítulo RESULTADOS, observamos que em ambos os grupos os parafusos sofreram uma maior rotação durante o $1^{\circ}$ ensaio, sendo que esta, para o grupo Acrílico Calcinável, foi superior e estatisticamente significante em relação ao $2^{\circ}$ e $3^{\circ}$ ensaios deste grupo (Gráfico 4). Já para o grupo Co-Cr, a maior rotação dos parafusos no $1^{\circ}$ ensaio foi superior e estatisticamente significante apenas para o ensaio 2 (Gráfico 5). Além disso, o grupo Acrílico Calcinável manteve uma tendência de maior rotação dos parafusos durante o momento de torque, quando comparado ao grupo Co-Cr, em todos os ensaios (1, 2 e 3), havendo diferença estatisticamente significante entre eles.

Uma provável hipótese para essa ocorrência seria que uma maior ou uma permanente deformação dos parafusos ocorressem nesse primeiro aperto, quando o parafuso giraria mais para se adaptar às condições da união parafusada. Em um segundo momento, o parafuso provavelmente rotacionaria o suficiente para atingir sua posição, sem a necessidade de maiores deformações plásticas. Associada a essa hipótese, uma possível compensação das irregularidades presentes nessas infra-estruturas poderiam estar ocorrendo nesse primeiro aperto, devido à diferença do módulo de elasticidade existente 
na infra-estrutura fundida em relação ao módulo de elasticidade da cabeça do implante em titânio, sendo provavelmente maior no grupo Acrílico Calcinável, visto que maiores irregularidades superficiais se mostraram presentes nas fundições desse grupo, conforme podemos observar em detalhes nas figuras 31 e 32.

Entretanto, se considerarmos a opinião de DIXON et al. ${ }^{22}, 1995$, ao afirmarem que o maior atrito das roscas dos parafusos ocorre em um primeiro aperto em virtude de apresentarem maiores rugosidades superficiais a serem planificadas (embedment relaxation), teoricamente teríamos uma menor rotação dos parafusos num primeiro momento, aumentando conseqüentemente para mais em outros ensaios, referente à diminuição do atrito conseguida pelas superfícies dessas roscas nos parafusos e interior do implante.

Contudo, nossos resultados nos parecem mais concordes com os de MARTIN et al. ${ }^{46}$, 2001, que, ao realizarem 5 ensaios avaliando diferentes tipos e superfícies de parafusos de abutments comercialmente disponíveis, quanto ao ângulo de rotação necessário para o apertamento sob determinados valores de torque e a quantidade de pré-carga gerada nesse procedimento, determinaram uma maior rotação também nos primeiros ensaios, independente de tipos e marcas dos parafusos.

Na obtenção de próteses parciais fixas quer sejam metalocerâmicas ou metaloplásticas, estas invariavelmente necessitam de enceramento, inclusão e fundição (ainda fazendo-se uso da técnica da cera perdida preconizada desde os primórdios por TAGGART $\left.{ }^{62}, 1907\right)$, sendo estas obtidas em monobloco ou previamente já separadas para serem unidas na boca para posterior soldagem. Imperfeições advindas das fundições podem alcançar grande magnitude e, com isso, complicações tornam-se mais propensas a ocorrer. Dessa forma, foi possível observar, nas fundições realizadas sobre abutments totalmente calcináveis, que as mesmas demonstraram maiores irregularidades superficiais presentes (Figura 31 e 32), e de acordo com GOLL $^{26}, 1991$ infra-estruturas obtidas a partir de abutments que não apresentem suas bases de assentamento pré-usinadas antes dos procedimentos de fundição são menos previsíveis quanto à qualidade de seu assentamento e adaptação final. 

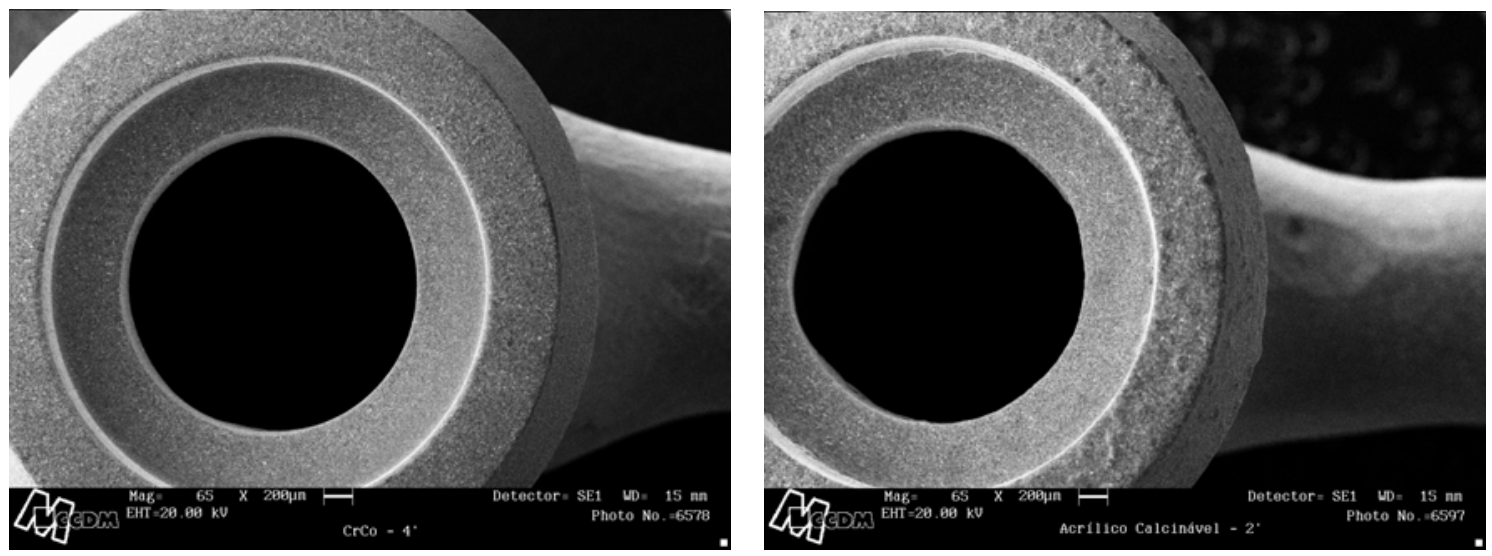

Figura 31 - Base de assentamento de um abutment UCLA do grupo $\mathrm{Co}-\mathrm{Cr}$ (sobrefundido). Notar regularidade superficial. Aumento 65x.

Figura 32 - Base de assentamento de um abutment UCLA do grupo Acrílico Calcinável, (totalmente calcinável). Notar grande quantidade de irregularidades superficiais e "ovalamento" do orifício para o parafuso. Aumento 65x.

Outros fatores inter-relacionados podem interferir de forma mais crítica na estabilidade de uma união parafusada e, de maneira geral, como já referidos anteriormente, podemos citar os efeitos de acomodação das superfícies contactantes (embedment relaxation), a pré-carga e a geometria tanto dos parafusos como dos componentes que se fazem presentes na área de união (JÖRNEUS; JEMT; CARLSSON ${ }^{37}$, 1992; BURGUETE et al. ${ }^{14}$, 1994). Assim, pode-se inferir ainda que a acomodação das superfícies contactantes dependa basicamente da rugosidade superficial dos componentes envolvidos (CARR; BRUNSKI; HURLEY $\left.{ }^{18}, 1996\right)$, e as propriedades dos materiais que os constituem determinem claramente essa condição (JÖRNEUS; JEMT; CARLSSON $^{37}$, 1992; BURGUETE et al. ${ }^{14}$, 1994; KALLUS; BESSING ${ }^{38}$, 1994; MARTIN et al. ${ }^{46}$, 2001; SIAMOS; WINKLER; BOBERICK ${ }^{60}, 2002$; KIM et al. ${ }^{40}$, 2005).

Embora neste estudo os corpos de prova não tenham diferido macroscopicamente ou numa visão a olho nu, entre os diferentes tipos de componentes utilizados, microscopicamente ficou evidente que as fundições dos abutments do grupo Acrílico Calcinável apresentaram maiores irregularidades superficiais quando comparados aos do grupo $\mathrm{Co}-\mathrm{Cr}$ (Figuras 31,32 e 33). 


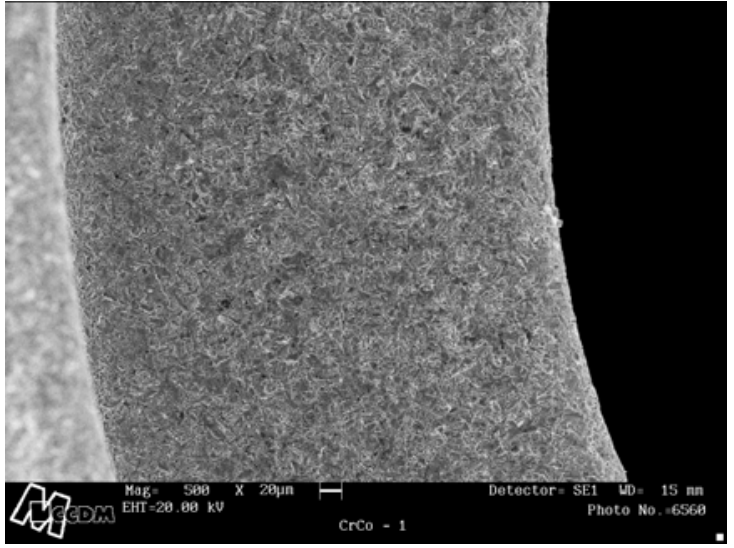

Fig.33 a

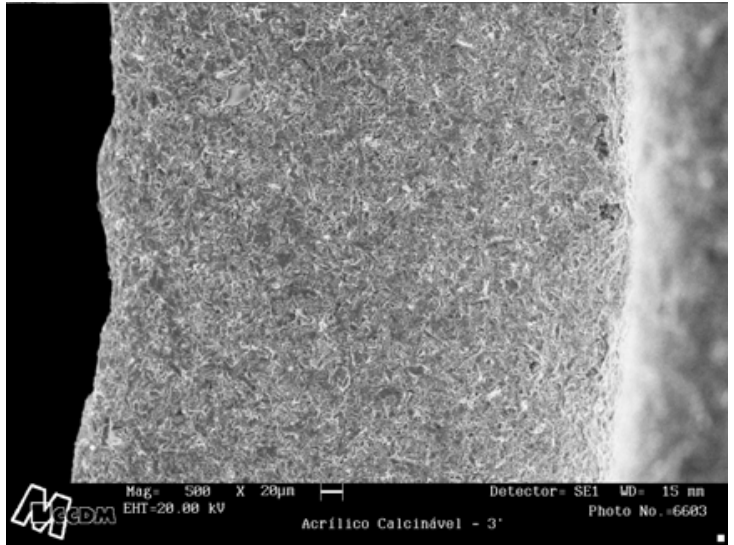

Fig. $33 b$

Figura 33 - Rugosidade superficial da base de assentamento das infra-estruturas as quais se apóiam as plataformas dos implantes, antes da realização dos testes - a: grupo Co-Cr; b: grupo Acrílico Calcinável. Aumento 500x.

O teste EDS caracteriza-se por um bombardeamento de elétrons dispersos, semelhantes aos raios-x, os quais, ao se chocarem com os elementos metálicos, permitem não só sua quantificação em termos percentuais de cada elemento presente, mas também a qualidade dos materiais, diferenciando-os. Esse teste nos permitiu então identificar algumas áreas nas porções internas das infra-estruturas, após a realização dos testes de torque, re-torque e destorque, o que nos despertou bastante curiosidade. Nessas áreas, foram identificadas partículas de titânio aderidas à base de assentamento das infra-estruturas, na sua porção contactante com a plataforma dos implantes. Essa ocorrência provavelmente deve-se às características plásticas do titânio, de que são constituídos os implantes, quando em contato com ligas metálicas de módulos de elasticidade maiores como e o caso da liga de Ni-Cr, empregada nas fundições dos abutments calcináveis e sobrefundidas nos abutments com cinta de Co-Cr (Figuras 34a e 34b). 


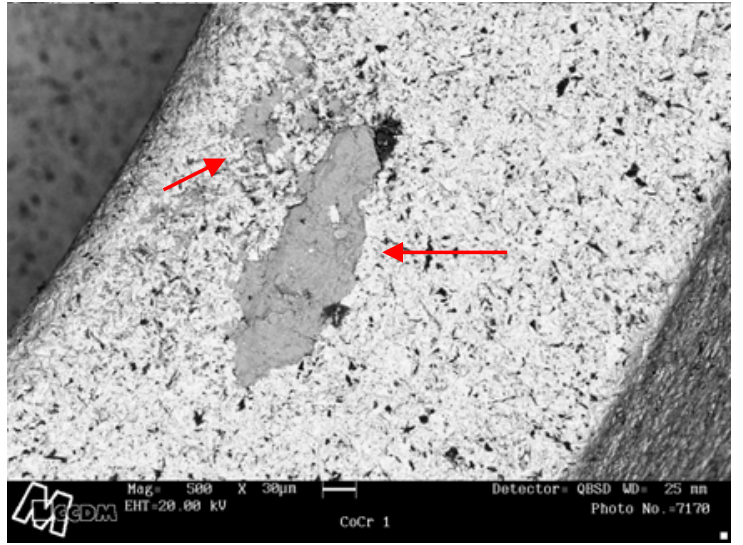

Fig. 34 a

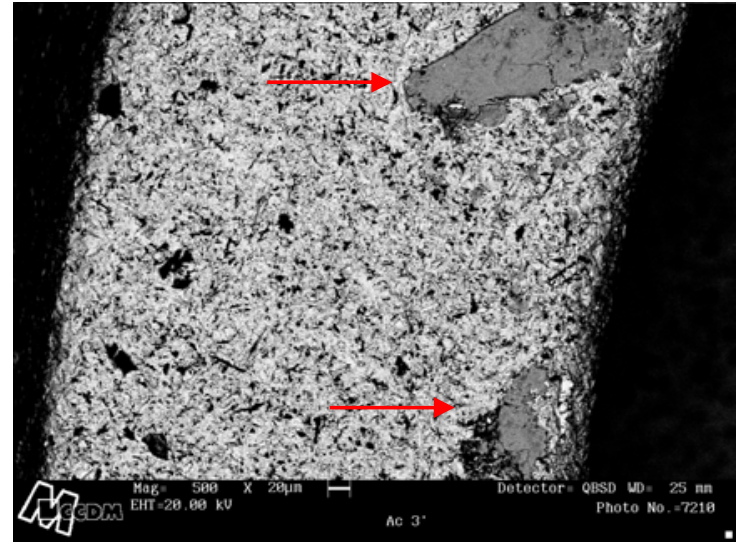

Fig. $34 b$

Figura 34: Rugosidade superficial da base de assentamento das infra-estruturas após realização dos testes - a: grupo Co-Cr; b: grupo Acrílico Calcinável. Notar incorporação de partículas de titânio aderidas às rugosidades superficiais (setas), segundo dados do EDS (ANEXOS). Aumento 500x.

Numa extrapolação clínica, as imperfeições observadas microscopicamente nos corpos de prova podem determinar falhas e/ou vir a provocar fraturas dos componentes da prótese. A falha mais comum seria 0 afrouxamento e/ou a fratura dos parafusos de retenção desses pilares. Entretanto, pode-se ter um grau de comprometimento ainda maior, que seriam alterações na condição da osseointegração, determinando defeitos ósseos identificados radiograficamente, instalação de uma periimplantite e até a possível perda das fixações(implantes) (COX; ZARB ${ }^{21}$, 1987; RANGERT; JEMT; JÖRNEUS ${ }^{53}$, 1989; NAERT et al. ${ }^{50}$, 1992; TAYLOR ${ }^{65}, 1998 ;$ MISCH $^{48}$, 2006; JEMT et al. ${ }^{35}$, 1991; JEMT; LINDEN; LEKHOLM ${ }^{36}$, 1992; EKFELDT; CARLSSON; BORJESSON ${ }^{23}$, 1994; KALLUS; BESSING ${ }^{38}$, 1994; BECKER; BECKER $^{6}, 1995$; GOODACRE et al. ${ }^{27}$, 2003).

$\mathrm{Na}$ interpretação de YOUSEF et al. ${ }^{67}, 2005$, o afrouxamento dos parafusos parecem seguir uma lógica de parâmetros específicos que incluem sentido de rotação anti-horário, alongamento e deformações da união parafusada. Para esses autores, apenas em uniões parafusadas consideradas instáveis e com recorrência de afrouxamento, esses parafusos devem ser substituídos, visto que uma vez que um parafuso novo é introduzido em uma união parafusada, uma nova adaptação à custa de deformações terá que ocorrer entre os componentes para que a estabilidade da nova união seja alcançada. A condição clínica de re-aperto ou re-torque dos parafusos pode gerar no profissional uma falsa impressão de que nos re-apertos se consiga 
uma maior adaptação, podendo muitas vezes exceder a capacidade de deformação plástica desse parafuso, gerando sua fratura e problemas de toda sorte na condição de sua remoção.

Pesquisando também essa condição neste trabalho, foi analisado o momento de re-torque (Gráfico 2). Os resultados referentes à rotação dos parafusos nos permitiu verificar que esta foi maior em todos os ensaios para o grupo Acrílico Calcinável comparado ao Co-Cr, sendo a diferença entre os grupos estatisticamente significante tanto no ensaio 1 quanto no ensaio 2. A observação do ensaio 3 nos faz refletir sobre uma aproximação numérica dos resultados entre as amostras dos grupos Acrílico Calcinável e Co-Cr, demonstrando já uma interação entre os elementos metálicos, visto que manteveram-se critérios rigorosos nos posicionamentos das infra-estruturas (peças fundidas) e na colocação exata dos parafusos nos seus determinados locais de origem. Decorrente disso poderíamos salientar que se as condições de parafusamento não forem rigorosamente obedecidas na clínica, na presença de cargas mastigatórias multidirecionais, poder-se-ia imaginar grandes danos principalmente para cabeça dos implantes e nas suas roscas internas (PATTERSON; JOHNS ${ }^{51}$, 1992; JAARDA; RAZZOOG; GRATTON ${ }^{34}$, 1995; CANTWELL; HOBKIRK ${ }^{16}$, 2004).

Em outra análise, BINON ${ }^{10}, 2000$ definiu como "frouxo" aquele parafuso que necessite de $1 / 4$ de volta para atingir seu aperto ideal, o que numericamente representa um giro de $90^{\circ}$ durante o torque. Neste estudo, embora as infra-estruturas não tenham sido submetidas a qualquer procedimento de fadiga, como proposto como exemplo, carga cíclica, nenhum parafuso, após o aperto padrão de $6 \mathrm{Ncm}$, ponto de partida para análise de quantidade de graus necessária para o aperto dos mesmos, necessitou de tanto giro, para atingir seu aperto considerado "ideal", nem na condição de torque inicial e nem na condição de re-torque.

Para PATTERSON; JOHNS ${ }^{51}$, 1992 em uma análise teórica do tempo de fadiga dos parafusos usados em implantes dentários, demonstrou-se que a concentração de estresses ocorrem em 2 regiões basicamente: uma é a região onde o parafuso se altera em sua secção transversal, entre o pescoço e sua cabeça, porém verificou-se a maior concentração de estresses na superfície da primeira rosca dos parafusos (apical). 
Imagens obtidas por meio de MEV revelaram que os maiores danos dos parafusos realmente ocorrem na $1^{\text {a }}$ rosca (mais apical), na forma de ranhuras e/ou amassamentos (dobramento) (Figuras 35 c, 36, 37, 38 e 39). Foram evidenciados também amassamentos na base de assentamento da cabeça dos parafusos, as quais se alteram, possivelmente, mais em função do contato com o interior do pilar protético, quando na condição de apertado sobre a base do implante (Figuras 35 a, 40 e 41). Da mesma forma, e como relatado no estudo de JAARDA; RAZZOOG; GRATTON ${ }^{34}$, 1995, foram encontrados em nossas análises de MEV amassamentos e ranhuras lateralmente à cabeça dos parafusos, evidenciando um contato efetivo, porém irregular entre estes e as porções internas dos pilares, salientando que esses tipos de contatos podem resultar em diminuição da pré-carga gerada quando realizado o aperto dos parafusos pelo contato friccional e conseqüente geração de calor, energia esta perdida para outras regiões, como a região óssea que ancora os implantes (Figuras 42 e 43).

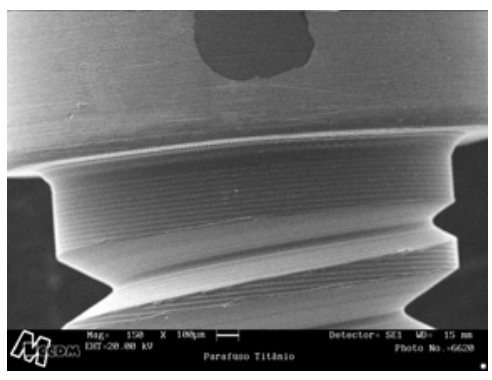

Fig. 35 a

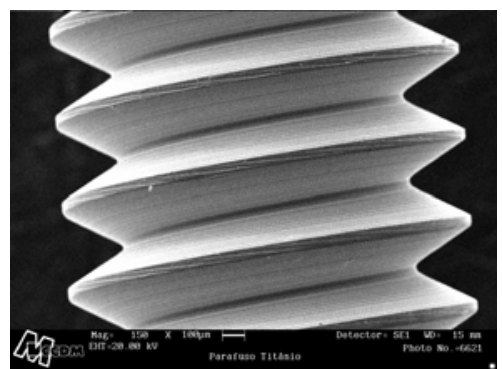

Fig. $35 b$

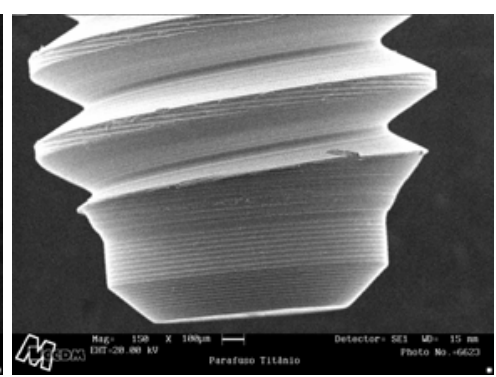

Fig. 35 C

Figura 35: Superfície dos parafusos de titânio, antes da realização dos testes - a: região entre cabeça e pescoço; b: região central das roscas; c: região apical e primeira rosca. Observar na textura de superfície as marcas do processo de usinagem. Aumento 150x. 


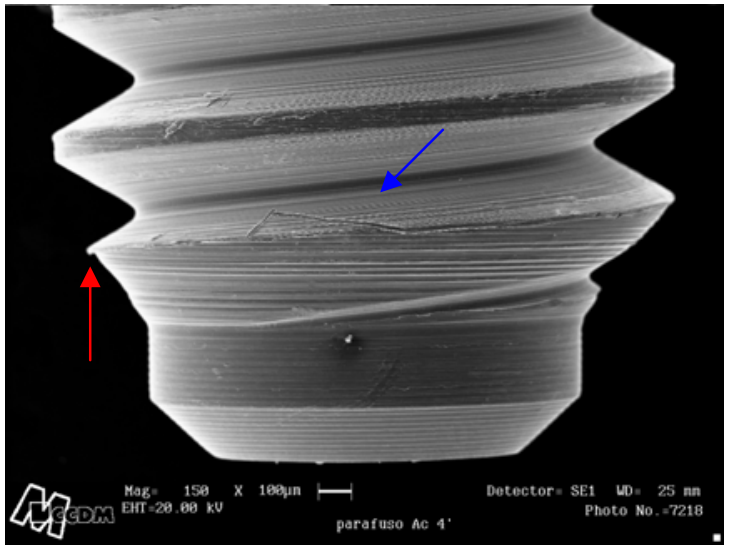

Figura 36: Observar danos ocorridos na $1^{a}$ rosca do parafuso durante os testes, na forma de ranhuras (seta azul) e dobramentos (seta vermelha). Aumento 150x.

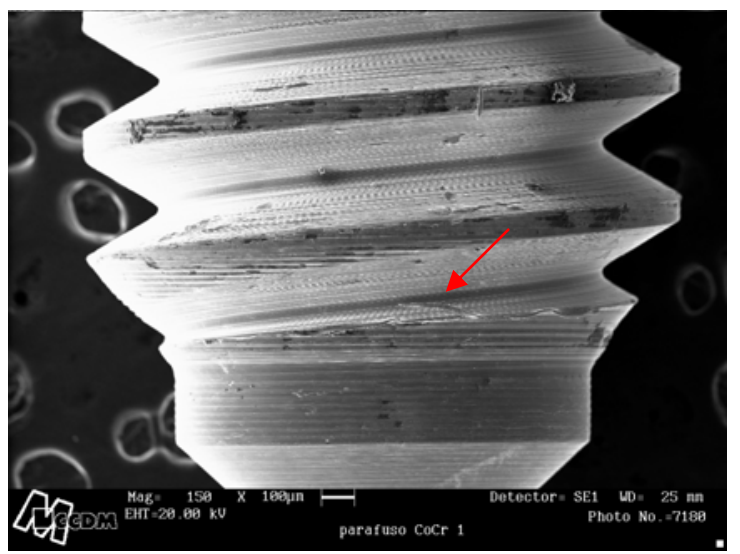

Figura 38: Observar mais ranhuras ocorridas na $1^{a}$ rosca do parafuso durante os testes, na forma de ranhuras (setas). Aumento 150x.

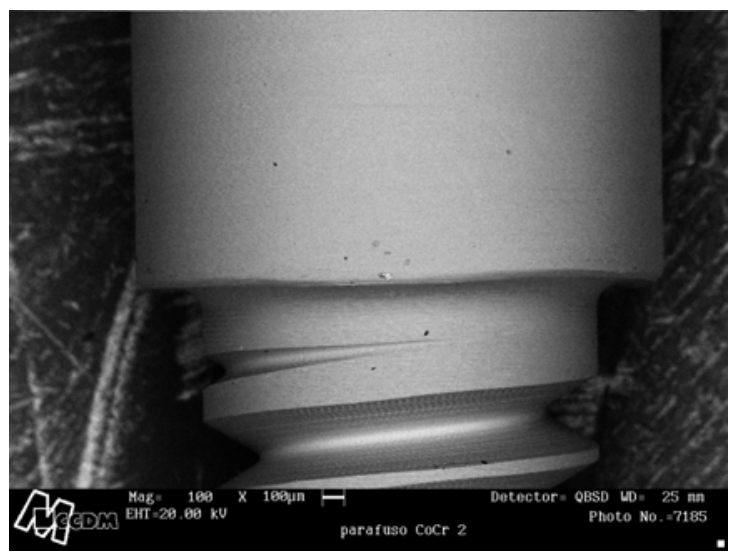

Figura 40: Observar amassamento na região da base de assentamento da cabeça do parafuso sobre o pilar protético após os testes. Aumento 150x.

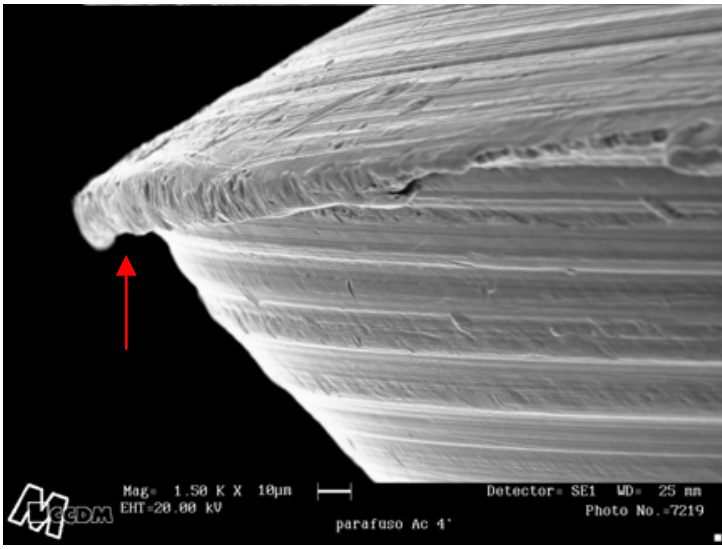

Figura 37: Observar o mesmo dobramento na $1^{a}$ rosca do parafuso (seta vermelha) da imagem anterior durante os testes, agora em maior aumento (1500x).

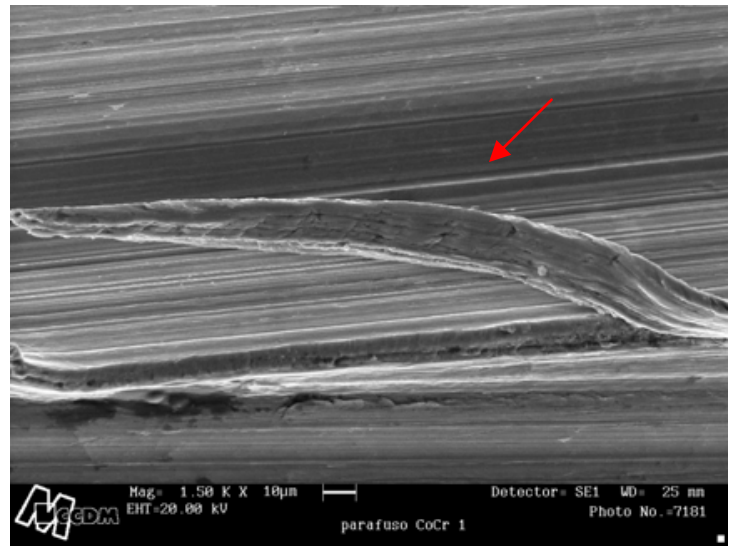

Figura 39: Observar a mesma ranhura da imagem anterior (seta), agora em maior aumento (1500x).

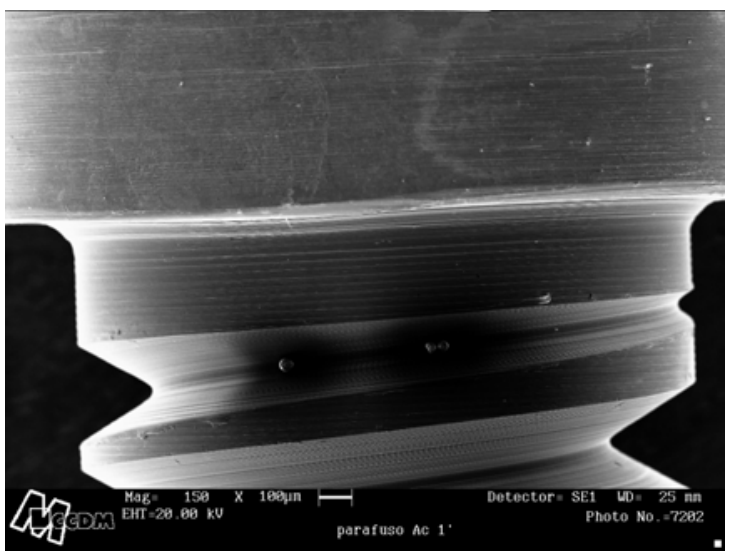

Figura 41: Observar em mais um parafuso o amassamento na região da base de assentamento da sua cabeça sobre o pilar protético após os testes. Aumento 150x. 


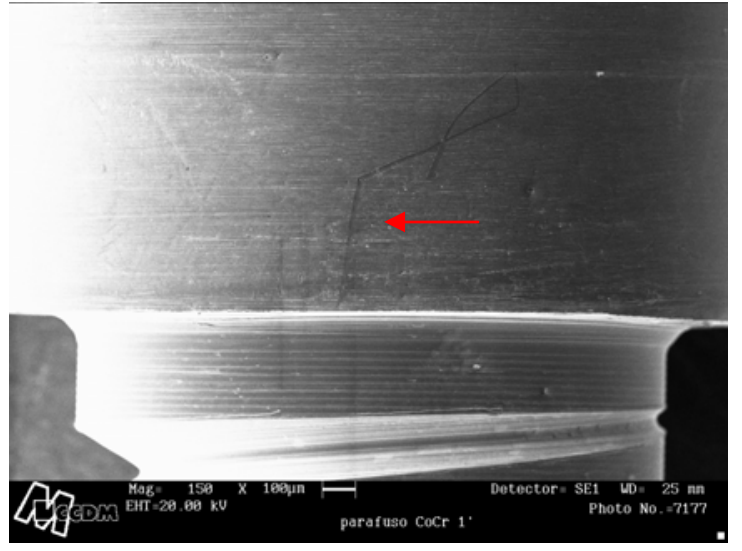

Figura 42: Observar ranhura na porção externa da cabeça do parafuso (seta), provavelmente oriunda de um contato indevido entre esta e a porção interna do pilar sobre o pilar protético durante os testes. Aumento 150x.

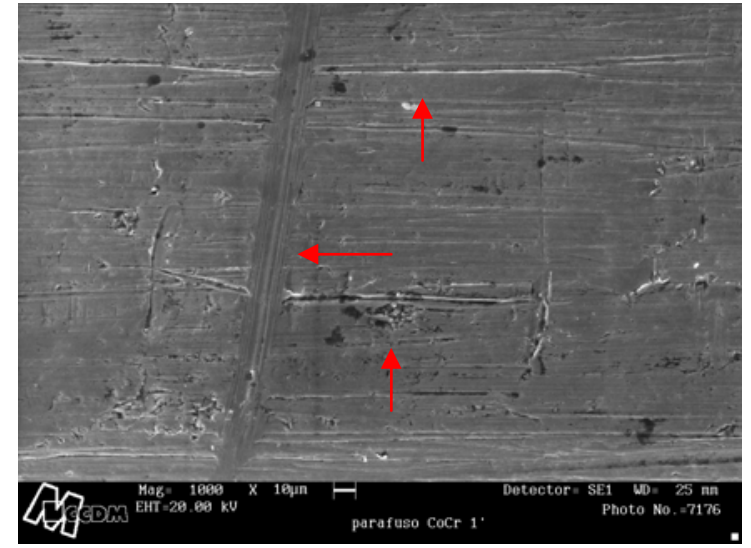

Figura 43: Observar a mesma e outras ranhuras (setas) na porção externa da cabeça do parafuso da imagem anterior, agora em maior aumento (1000x).

Outro aspecto interessante refere-se ao fato de que parafusos com uma maior quantidade de roscas, e conseqüentemente um pescoço mais curto, podem perder maior quantidade de pré-carga em função de ocorrer um maior atrito de suas roscas durante o torque de aperto dos mesmos, além de um mínimo alongamento em virtude da ausência de um "pescoço" que permita tal ocorrência (JAARDA; RAZZOOG; GRATTON ${ }^{34}$, 1995). Embora suas análises tratem de parafusos de retenção de coroas, extrapolações podem aqui ser feitas para outros tipos de parafusos. Atualmente, mais de um tipo de desenho de parafusos de abutments estão disponíveis no comércio, e esta variedade se dá por conta das diferentes marcas existentes. Os sistemas de implantes ditos intercambiáveis utilizam desenhos semelhantes, quando não, iguais. Neste trabalho, optamos pela utilização de um só tipo de parafuso, os quais apresentavam como características uma maior quantidade de roscas em seu corpo e um "pescoço" bastante curto quando comparado a outros modelos. Teoricamente, esses parafusos não proporcionariam uma maior geração de pré-carga quando comparado a parafusos que possuem um menor número de roscas e um "pescoço" mais longo que permite um maior alongamento quando determinado torque de apertamento é gerado. Hoje, nota-se uma tendência das companhias em buscarem a idealização e confecção de parafusos que sejam intercambiáveis. Além disso, cabe aqui ressaltar que algumas dessas 
companhias não produzem os parafusos que vendem, sendo a produção deles terceirizada para, posteriormente, ser vendida por companhias diferentes.

A literatura nos apresenta diversas maneiras para o cálculo da précarga em uniões parafusadas, como fórmulas matemáticas (MARTIN et al. ${ }^{46}$, 2001) e uso de strain-gauges (CARR; BRUNSKI; HURLEY ${ }^{18}$, 1996; BYRNE et al. $\left.{ }^{15}, 2006\right)$. Calculamos, por meio dos valores de destorque dos parafusos dos abutments UCLA, a quantidade de torque retido pela união parafusada após dois apertos de $30 \mathrm{Ncm}$ nesses parafusos, sendo eles realizados em intervalos de 10 minutos para, então, se proceder o destorque dos mesmos, como pode ser melhor visualizado no Gráfico 3. Embora os valores numéricos e percentuais de destorque entre os grupos e entre os ensaios não apresentaram diferenças estatisticamente significantes, uma tendência de maior retenção de torque (maiores valores de destorque) foi obtida pelo grupo Acrílico Calcinável $(90,41 \%)$, em todos os momentos, quando comparado ao grupo Co-Cr $(88,47 \%)$.

Mediante o conhecimento e a interpretação da literatura referente a parafusos de fixação de abutments e infra-estruturas sobre implantes, os quais apresentam variado desenho, e também estruturas metálicas constituintes diferenciadas, optamos pela análise somente de parafusos de titânio, tendo em vista que no momento atual, pelo qual passa o mercado brasileiro, as ligas áureas ou ligas nobres ainda determinam uma condição economicamente desfavorável.

Embora ainda haja diferentes opiniões a respeito do assunto, fundições em monoblocos continuam a ser rotineiramente indicadas por diversos autores (FUSAYAMA; WAKUMOTO; HOSODA ${ }^{24}$, 1964; RASMUSSEN ${ }^{54}, 1987$ ), os quais também sugerem o seccionamento e união intra-oral para posterior soldagem caso se diagnostique imperfeições durante as provas intra-orais. Outros autores reconhecem o potencial de distorções das grandes fundições e, para minimizá-las, sugerem a observação de uma melhor localização dos condutos de alimentação para liga de fundição, adequada seleção e manipulação do revestimento, evitando-se sobremaneira outras variáveis laboratoriais (RASMUSSEN ${ }^{54}, 1987$; GOLL ${ }^{26}, 1991$ ). Para as próteses sobre implantes, GOLL ${ }^{26}, 1991$ sugere que, em se tratando de próteses mais 
complexas, deva-se dar preferência para o uso de componentes pré-usinados, visto que a adaptação desse tipo de componente parece ser mais previsível. Embora a literatura esteja repleta de recomendações, muitas delas são baseadas em evidências empíricas, ou seja, em experiências individuais de protéticos e/ou protesistas. Para TAN et al. ${ }^{64}$, 1993, algumas distorções das infra-estruturas são sempre previsíveis e podem ser oriundas de distorções nos padrões para fundição, alterações decorrentes dos revestimentos, assim como problemas no seu armazenamento, expansões térmicas e de presa, magnitude da contração da liga fundida, ou até mesmo deformações da estrutura fundida após remoção dos condutos de alimentação durante o acabamento.

Diante do exposto neste trabalho, as fundições foram realizadas em monobloco, utilizando-se para isso 2 tipos de componentes: Abutments UCLA de acrílico, totalmente calcináveis e abutments UCLA com cinta usinada em Co-Cr a serem sobrefundidos. O fato de as fundições terem sido realizadas em monobloco se justifica por se tratar de uma rotina protética ainda constatada na clínica diária para peças de pequena extensão. Na interpretação de LEWIS; LLAMAS; AVERA ${ }^{45}$, 1992, sugere-se que as próteses parciais fixas sobre implantes, independente da sua extensão, apresentem-se com suas porções seccionadas e que estas devam ser unidas para posterior soldagem a fim de se evitar um assentamento não passivo, com conseqüente sobrecarga sobre os implantes. Na intenção de se obter um ponto de partida, para determinar as interpretações do grau de rotação de parafusos de titânio sobre sistemas UCLAS calcináveis e sobrefundidos em componentes com cinta previamente usinadas, utilizamos fundições em monobloco e optamos por realizar essas considerações por meio de torque, re-torque e destorque, estando cientes de que novos estudos devam advir das condições agora de solda entre os elementos, para se obter uma informação mais ampla sobre os fenômenos anteriormente discutidos e posteriormente reinterpretados. 
7 - CONCLUSÕES 


\section{CONCLUSÕES}

7.1 Os valores médios equivalentes ao ângulo formado na cabeça dos parafusos, durante o momento de torque, foram sempre maiores para o grupo Acrílico Calcinável, comparado ao grupo $\mathrm{Co}-\mathrm{Cr}$, com diferença estatisticamente significante entre os grupos em todos os ensaios; $P<0,05$.

7.2 Os valores médios equivalentes ao ângulo formado na cabeça dos parafusos, durante o momento de re-torque, foram sempre maiores para 0 grupo Acrílico Calcinável, comparado ao grupo $\mathrm{Co}-\mathrm{Cr}$ em todos os ensaios, porém com diferença estatisticamente significante apenas nos ensaios 1 e 2; $P<0,05$.

7.3 Os valores médios de destorque foram sempre maiores para o grupo Acrílico Calcinável, comparado ao grupo Co-Cr, porém, sem diferença estatisticamente significante entre os grupos; $P<0,05$.

7.4 A análise em MEV das bases de assentamento dos abutments, antes da realização dos testes, demonstraram que os corpos de prova obtidos a partir de padrões totalmente calcináveis apresentaram maiores irregularidades superficiais que aqueles obtidos a partir de padrões com cinta usinada em CoCr.

7.4.1 A análise em MEV das bases de assentamento dos abutments, após a realização dos testes, demonstraram que em ambos os grupos houve incorporação de partículas de titânio oriundas da plataforma do implante.

7.5 As análises em MEV dos parafusos de titânio demonstraram que, após a realização dos testes, os parafusos demonstraram maiores deformações na base de sua cabeça que se assenta no interior dos pilares, assim como ranhuras e dobramentos na região de sua $1^{\mathrm{a}}$ rosca (apical). 
ANEXOS 


\section{ANEXOS}

Dados da análise em Microscopia Eletrônica de Varredura - EDS

Análise da base de assentamento de um abutment do grupo Acrílico Calcinável antes dos testes. Elementos químicos encontrados:
C............. $0.45 \%$
$\mathrm{Na} . . . . . . . .0 .26 \%$
Al..........18.13\%
Si..............3.02\%
Mo...........5.57\%
Fe............ $0.75 \%$
Cr..........24.91\%
$\mathrm{Ni} \ldots \ldots \ldots . . . .46 .91 \%$

Análise da base de assentamento de um abutment do grupo $\mathrm{Co}-\mathrm{Cr}$ antes dos testes. Elementos químicos encontrados:
$\mathrm{Na}$.
$0.58 \%$
Al.
$9.29 \%$
W
$4.58 \%$
$\mathrm{Cr}$ $32.81 \%$
Co. $52.74 \%$

Análise da superfície de um parafuso de titânio antes dos testes. Elementos químicos encontrados:
C.
Al.............8.33\%
Si.............. $0.02 \%$
Ti............90.66\%
Cr............. $0.42 \%$
$\mathrm{Ni}$............. 0.51\% 
Análise de partícula aderida na base de assentamento do abutment 3' do grupo Acrílico Calcinável após realização dos testes (Figura 34b). Elementos químicos encontrados:

C.

Al.......1.67\%

Si...... $0.59 \%$

S. $.1 .31 \%$

Ti...........85.75\%

Cr............3.49\%

Co............ $0.52 \%$

Ni............6.46\%

Análise de partícula aderida na base de assentamento do abutment 1 do grupo Co-Cr após realização dos testes (Figura 34a). Elementos químicos encontrados:
C......
$0.35 \%$
Al.............0.34\%
Si.............1.07\%
Ti...........96.81\%
Cr........... $0.37 \%$
Co........... $0.87 \%$
$\mathrm{Ni} . . . \ldots \ldots . . . .0 .19 \%$ 
REFERÊNCIAS 


\section{REFERÊNCIAS}

1 Adell R, Eriksson B, Lekholm U, Branemark PI, Jemt T. Long-term follow-up study of osseointegrated implants in the treatment of totally edentulous jaws. Int J Oral Maxillofac Implants 1990;5(4):347-59.

2 Albrektsson T. A multicenter report on osseointegrated oral implants. J Prosthet Dent 1988;60(1):75-84.

3 Albrektsson T, Jansson T, Lekholm U. Osseointegrated dental implants. Dent Clin North Am 1986;30(1):151-74.

4 Aparicio C. A new method for achieving passive fit of an interim restoration supported by Branemark implants: a technical note. Int J Oral Maxillofac Implants 1995;10(5):614-8.

5 Artzi Z, Dreiangel A. A screw lock for single-tooth implant superstructures. J Am Dent Assoc 1999;130(5):677-82.

6 Becker W, Becker BE. Replacement of maxillary and mandibular molars with single endosseous implant restorations: a retrospective study. J Prosthet Dent 1995;74(1):51-5.

7 Bickford JH. An introduction to the design and behavior of bolted joints. New York: Marcel Dekker, Inc.; 1981.

8 Binon PP. The effect of implant/abutment hexagonal misfit on screw joint stability. Int J Prosthodont 1996;9(2):149-60.

9 Binon PP. Evaluation of the effectiveness of a technique to prevent screw loosening. J Prosthet Dent 1998;79(4):430-2.

10 Binon PP. Implants and components: entering the new millennium. Int J Oral Maxillofac Implants 2000;15(1):76-94.

11 Binon PP, Sutter F, Beaty K, Brunski JB, Gulbrasen H, Weiner R. The role of screws in implant system. Int J Oral Maxillofac Implants 1994;9(suppl):48-63.

12 Branemark PI, Zarb GA, Albrektsson T. Tissue-integrated protheses. Osseointegration in clinical dentistry. Chicago: Quintessence Books; 1985.

13 Bruce RW. Evaluation of multiple unit casting for fixed partial dentures. J Prosthet Dent 1964;14(5):939 - 43.

14 Burguete RL, Johns RB, King T, Patterson EA. Tightening characteristics for screwed joints in osseointegrated dental implants. J Prosthet Dent 1994;71(6):592-9.

15 Byrne D, Jacobs S, O'Connell B, Houston F, Claffey N. Preloads generated with repeated tightening in three types of screws used in dental implant assemblies. J Prosthodont 2006;15(3):164-71. 
16 Cantwell A, Hobkirk JA. Preload loss in gold prosthesis-retaining screws as a function of time. Int J Oral Maxillofac Implants 2004;19(1):124-32.

17 Carlson B, Carlsson GE. Prosthodontic complications in osseointegrated dental implant treatment. Int J Oral Maxillofac Implants 1994;9(1):90-4.

18 Carr AB, Brunski JB, Hurley E. Effects of fabrication, finishing, and polishing procedures on preload in prostheses using conventional "gold' and plastic cylinders. Int J Oral Maxillofac Implants 1996;11(5):589-98.

19 Cavazos E, Bell FA. Preventing loosening of implant abutment screws. J Prosthet Dent 1996;75(5):566-9.

20 Cho SC, Small PN, Elian N, Tarnow D. Screw loosening for standard and wide diameter implants in partially edentulous cases: 3- to 7-year longitudinal data. Implant Dent 2004;13(3):245-50.

21 Cox JF, Zarb GA. The longitudinal clinical efficacy of osseointegrated dental implants: a 3-year report. Int J Oral Maxillofac Implants 1987;2(2):91-100.

22 Dixon DL, Breeding LC, Sadler JP, McKay ML. Comparison of screw loosening, rotation, and deflection among three implant designs. J Prosthet Dent 1995;74(3):270-8.

23 Ekfeldt A, Carlsson GE, Borjesson G. Clinical evaluation of single-tooth restorations supported by osseointegrated implants: a retrospective study. Int J Oral Maxillofac Implants 1994;9(2):179-83.

24 Fusayama T, Wakumoto S, Hosoda H. Accuracy of fixed partial dentures made by various soldering techniques and one-piece casting. J Prosthet Dent 1964;14(2):334-42.

25 Gegauff AG, Rosenstiel SF. The seating of one-piece and soldered fixed partial dentures. J Prosthet Dent 1989;62(3):292-7.

26 Goll GE. Production of accurately fitting full-arch implant frameworks: Part I-Clinical procedures. J Prosthet Dent 1991;66(3):377-84.

27 Goodacre CJ, Bernal G, Rungcharassaeng K, Kan JY. Clinical complications with implants and implant prostheses. J Prosthet Dent 2003;90(2):121-32.

28 Goodacre CJ, Kan JY, Rungcharassaeng K. Clinical complications of osseointegrated implants. J Prosthet Dent 1999;81(5):537-52.

29 Haack JE, Sakaguchi RL, Sun T, Coffey JP. Elongation and preload stress in dental implant abutment screws. Int J Oral Maxillofac Implants 1995;10(5):52936.

30 Henry PJ, Laney WR, Jemt T, Harris D, Krogh PH, Polizzi G, et al. Osseointegrated implants for single-tooth replacement: a prospective 5-year multicenter study. Int J Oral Maxillofac Implants 1996;11(4):450-5. 
31 Hobo S, Ichida E, Garcia U. Osseointregation and Occlusal Rehabilitation. Chicago: Quintessence; 1990.

32 Huling JS, Clark RE. Compratative distortion in three-unit fixed prostheses joined by laser welding, conventioanl soldering, or casting in one piece. J Dent Res 1977;56(2):128-34.

33 Jaarda MJ, Razzoog ME, Gratton DG. Effect of preload torque on the ultimate tensile strength of implant prosthetic retaining screws. Implant Dent 1994;3(1):17-21.

34 Jaarda MJ, Razzoog ME, Gratton DG. Geometric comparison of five interchangeable implant prosthetic retaining screws. J Prosthet Dent 1995;74(4):373-9.

35 Jemt T, Laney WR, Harris D, Henry PJ, Krogh PH, Jr., Polizzi G, et al. Osseointegrated implants for single tooth replacement: a 1-year report from a multicenter prospective study. Int J Oral Maxillofac Implants 1991;6(1):29-36.

36 Jemt $T$, Linden $B$, Lekholm $U$. Failures and complications in 127 consecutively placed fixed partial prostheses supported by Branemark implants: from prosthetic treatment to first annual checkup. Int J Oral Maxillofac Implants 1992;7(1):40-4.

37 Jorneus L, Jemt T, Carlsson L. Loads and designs of screw joints for single crowns supported by osseointegrated implants. Int J Oral Maxillofac Implants 1992;7(3):353-9.

38 Kallus T, Bessing C. Loose gold screws frequently occur in full-arch fixed prostheses supported by osseointegrated implants after 5 years. Int $\mathrm{J}$ Oral Maxillofac Implants 1994;9(2):169-78.

39 Kano SC, Binon P, Bonfante G, Curtis DA. Effect of casting procedures on screw loosening in UCLA-type abutments. J Prosthodont 2006;15(2):77-81.

40 Kim SK, Lee JB, Koak JY, Heo SJ, Lee KR, Cho LR, et al. An abutment screw loosening study of a Diamond Like Carbon-coated CP titanium implant. J Oral Rehabil 2005;32(5):346-50.

41 Korioth TW, Cardoso AC, Versluis A. Effect of washers on reverse torque displacement of dental implant gold retaining screws. J Prosthet Dent 1999;82(3):312-6.

42 Laney WR, Jemt T, Harris D, Henry PJ, Krogh PH, Polizzi G, et al. Osseointegrated implants for single-tooth replacement: progress report from a multicenter prospective study after 3 years. Int $\mathrm{J}$ Oral Maxillofac Implants 1994;9(1):49-54.

43 Lewis S, Beumer J, 3rd, Hornburg W, Moy P. The "UCLA" abutment. Int J Oral Maxillofac Implants 1988;3(3):183-9. 
44 Lewis SG, Beumer J, 3rd, Perri GR, Hornburg WP. Single tooth implant supported restorations. Int J Oral Maxillofac Implants 1988;3(1):25-30.

45 Lewis SG, Llamas D, Avera S. The UCLA abutment: a four-year review. J Prosthet Dent 1992;67(4):509-15.

46 Martin WC, Woody RD, Miller BH, Miller AW. Implant abutment screw rotations and preloads for four different screw materials and surfaces. J Prosthet Dent 2001;86(1):24-32.

47 McGlumphy EA, Mendel DA, Holloway JA. Implant screw mechanics. Dent Clin North Am 1998;42(1):71-89.

48 Misch CE. Prótese sobre Implantes. São Paulo: Livraria Editora Santos; 2006.

49 Naert I, Quirynen M, van Steenberghe D, Darius P. A study of 589 consecutive implants supporting complete fixed prostheses. Part II: Prosthetic aspects. J Prosthet Dent 1992;68(6):949-56.

50 Naert I, Quirynen M, van Steenberghe D, Darius P. A six-year prosthodontic study of 509 consecutively inserted implants for the treatment of partial edentulism. J Prosthet Dent 1992;67(2):236-45.

51 Patterson EA, Johns RB. Theoretical analysis of the fatigue life of fixture screws in osseointegrated dental implants. Int $\mathrm{J}$ Oral Maxillofac Implants 1992;7(1):26-33.

52 Pesun IJ, Brosky ME, Korioth TW, Hodges J, Devoe BJ. Operator-induced compressive axial forces during implant gold screw fastening. J Prosthet Dent 2001;86(1):15-9.

53 Rangert B, Jemt T, Jorneus L. Forces and moments on Branemark implants. Int J Oral Maxillofac Implants 1989;4(3):241-7.

54 Rasmussen EJ. Alternative prosthodontic technique for tissue-integrated prostheses. J Prosthet Dent 1987;57(2):198-204.

55 Riedy SJ, Lang BR, Lang BE. Fit of implant frameworks fabricated by different techniques. J Prosthet Dent 1997;78(6):596-604.

56 Sahin S, Cehreli MC. The significance of passive framework fit in implant prosthodontics: current status. Implant Dent 2001;10(2):85-92.

57 Sakaguchi RL, Borgersen SE. Nonlinear contact analysis of preload in dental implant screws. Int J Oral Maxillofac Implants 1995;10(3):295-302.

58 Sarfati E, Harter JC. Comparative accuracy of fixed partial dentures made as one-piece castings or joined by solder. Int J Prosthodont 1992;5(4):377-83. 
59 Schiffleger BE, Ziebert GJ, Dhuru VB, Brantley WA, Sigaroudi K. Comparison of accuracy of multiunit one-piece castings. J Prosthet Dent 1985;54(6):770-6.

60 Siamos G, Winkler S, Boberick KG. Relationship between implant preload and screw loosening on implant-supported prostheses. J Oral Implantol 2002;28(2):67-73.

61 Skalak R. Biomechanical considerations in osseointegrated prostheses. J Prosthet Dent 1983;49(6):843-8.

62 Taggart WH. A new and accurated method of making gold inlays. Dent Cosmos 1907;49(11):1117-21.

63 Tan KB, Nicholls JI. Implant-abutment screw joint preload of 7 hex-top abutment systems. Int J Oral Maxillofac Implants 2001;16(3):367-77.

64 Tan KB, Rubenstein JE, Nicholls JI, Yuodelis RA. Three-dimensional analysis of the casting accuracy of one-piece, osseointegrated implant-retained prostheses. Int J Prosthodont 1993;6(4):346-63.

65 Taylor TD. Prosthodontic problems and limitations associated with osseointegration. J Prosthet Dent 1998;79(1):74-8.

66 Tosun T, Karabuda C, Cuhadaroglu C. Evaluation of sleep bruxism by polysomnographic analysis in patients with dental implants. Int J Oral Maxillofac Implants 2003;18(2):286-92.

67 Yousef H, Luke A, Ricci J, Weiner S. Analysis of changes in implant screws subject to occlusal loading: a preliminary analysis. Implant Dent 2005;14(4):378-82.

68 Zarb GA, Schmitt A. The Iongitudinal clinical effectiveness of osseointegrated dental implants: the Toronto study. Part I: Surgical results. J Prosthet Dent 1990;63(4):451-7.

69 Ziebert GJ, Hurtado A, Glapa C, Schiffleger BE. Accuracy of one-piece castings, preceramic and postceramic soldering. $\mathrm{J}$ Prosthet Dent 1986;55(3):312-7. 
ABSTRACT 


\section{Comparative analysis of the rotational angle degree on UCLA} burnout/Cobalt-Chromium machined collar abutment screws for one-piece cast metal frameworks

Problem: The abutment screw loosening is a common drawback which concerns both patients and practitioners.

Purpose: The aim of this study is to compare the rotational angle degree of Grade $\mathrm{V}$ titanium screws during torque, retorque and detorque steps ( $\mathrm{Ncm}$ ) on one-piece cast metal frameworks obtained from UCLA burnout/Co-Cr machined collar abutments.

Material and methods: Two external hexagonal implants with $3.75 \mathrm{~mm}$ in diameter and $13 \mathrm{~mm}$ in length (Revolution, SIN) were secured to a metallic base and the wax patterns directly fabricated over them. The UCLA burnout/ Co-Cr machined collar abutments were screwed to the implants and joined together with an acrylic resin bar. Ten samples for each abutment type were fabricated. Forty Grade V titanium screws were used in the test. The rotation angle degree was measured with the aid of an specially constructed device and a computer software, during torque and retorque procedures, being the retorque made 10 minutes after the initial torque, both under $30 \mathrm{Ncm}$. After the retorque procedures, the detorque values were measured. The overall sequence (torque, retorque, and detorque) was made three times for each sample. SEM analysis at the implant-abutment interfaces were made before and after the tests, as well as on the screw surfaces to detect possible microdamaging. The Student's $t$ test was used for between group analyses and the one-way ANOVA test for within group analyses.

Results: The rotational angle degree was higher for screws used in the UCLA burnout (test 1: $61,664^{\circ}$; test 2: $47,718^{\circ}$; test 3: $47,374^{\circ}$ ) than in the $\mathrm{Co}-\mathrm{Cr}$ machined collar abutments (test 1: $49,038^{\circ}$; test 2: $41,636^{\circ}$; test 3: $43,273^{\circ}$ ) $(P<.05)$. The highest rotational degree values were observed on the first screwing during torque and retorque procedures. During retorque, the angle formed on the screw head was higher for the UCLA burnout (test 1: 14,591; test 2: $12,987^{\circ}$; test $3: 13,095^{\circ}$ ) than the Co-Cr machined collar abutments (test 1: $11,481^{\circ}$; test $2: 10,117^{\circ}$; test $\left.3: 12,213^{\circ}\right)$, being these differences statistically significant between the first and second screwing $(P<.05)$. The mean detorque values were higher in the UCLA burnout (test 1: 27,325 $\mathrm{Ncm}$; test 2: 27,050Ncm; 
test 3: $26,975 \mathrm{Ncm}$ ) than in the Co-Cr machined collar screw abutments (test 1: 26,250 Ncm; test 2: $26,975 \mathrm{Ncm}$; test 3: $26,400 \mathrm{Ncm})$, but not statistically significant. The SEM images demonstrated that the seating surface of the UCLA burnout abutments presented greater irregularities than the $\mathrm{Co}-\mathrm{Cr}$ machined collar surfaces, which present a more smooth and flat pattern. Greater deformations were found at the seating abutment screw undersurfaces and in the first apical thread as well.

Conclusions: The rotational degree was higher in the torque and retorque procedures for UCLA burnout than in the $\mathrm{Co}-\mathrm{Cr}$ machined collar screw abutments. The detorque values were similar in both groups. The SEM images before torque, retorque and detorque procedures revealed more surface irregularities in the UCLA burnout abutments. In both groups, titanium debris were found in the seating abutment platforms after the tests by EDS images. The SEM images revealed that the abutment screws suffer deformation in the abutment head undersurface as well as in their first apical threads.

Keywords: osseointegrated implants, screw loosening, implant biomechanics, screwed implant prostheses 